University of Louisville

ThinkIR: The University of Louisville's Institutional Repository

8-2012

\title{
Ideological tensions, pedagogical gaps : multilingual engineering scholars' response to language variation in academic writing.
}

Ghanashyam Sharma

University of Louisville

Follow this and additional works at: https://ir.library.louisville.edu/etd

\section{Recommended Citation}

Sharma, Ghanashyam, "Ideological tensions, pedagogical gaps : multilingual engineering scholars' response to language variation in academic writing." (2012). Electronic Theses and Dissertations. Paper 1313.

https://doi.org/10.18297/etd/1313

This Doctoral Dissertation is brought to you for free and open access by ThinkIR: The University of Louisville's Institutional Repository. It has been accepted for inclusion in Electronic Theses and Dissertations by an authorized administrator of ThinkIR: The University of Louisville's Institutional Repository. This title appears here courtesy of the author, who has retained all other copyrights. For more information, please contact thinkir@louisville.edu. 
IDEOLOGICAL TENSIONS, PEDAGOGICAL GAPS: MULTILINGUAL ENGINEERING SCHOLARS' RESPONSE TO LANGUAGE VARIATION IN ACADEMIC WRITING

By

Ghanashyam Sharma

B.A. (1997), M.A. (1999), B.Ed. (2004)

Tribhuvan University, Kathmandu, Nepal

M.A., University of Louisville, 2008

\author{
A Dissertation \\ Submitted to the Faculty of \\ the College of Arts and Sciences \\ in Partial Fulfillment of the Requirements \\ for the Degree of
}

Doctor of Philosophy

Department of English

University of Louisville

Louisville, Kentucky

August 2012 
IDEOLOGICAL TENSIONS, PEDAGOGICAL GAPS: MULTILINGUAL ENGINEERING SCHOLARS' RESPONSE TO LANGUAGE VARIATION IN ACADEMIC WRITING

By

Ghanashyam Sharma

B.A., M.A., B.Ed. (1997, 1999, 2004), Tribhuvan University, Nepal M.A. (2008), University of Louisville, Louisville, Kentucky

A Dissertation Approved on

June 25, 2012

By the following Dissertation Committee

Joanna Wolfe

Dissertation Director

Beth Boehm

Tatjana Soldat-Jaffe 


\section{ACKNOWLEDGMENTS}

I would like to take this opportunity to sincerely thank my mentor and dissertation director Dr. Joanna Wolfe. Dr. Wolfe not only provided enormous amounts of time and support during the research, drafting, revising, and the timely completion of this work overall, she also challenged me to improve the quality of it every step of the way. Moreover, the fact that she brought together a dissertation group and organized regular meetings where we could share comments on one another's work has greatly benefited me. I would also like to thank members of the dissertation group: Robert Terry, Kenny Rose, Matt Wiles, and Jason Dietz. The candid and constructive feedback that I got from these colleagues has enriched my thinking and writing over the course of the year.

I am also indebted to another mentor, Dr. Beth Boehm who kindly agreed to be on my dissertation committee. Dr. Boehm's close reading and critical comments on draft material, as well as her advice through informal discussions about my research, have been tremendously helpful. I am also grateful for her constant reminder that my academic development is most important while I worked for her as a graduate assistant in the School of Interdisciplinary and Graduate Studies.

The timely completion of this work was also possible due to the kind support and encouragement from Dr. Bruce Horner, Dr. Min-Zhan Lu, and Dr. Tatjana Soldat-Jaffe, who are other members of the committee. I am grateful to Dr. Horner for providing me the opportunity to develop the groundwork of this study in a graduate seminar that I took with him in 2009 as well as for the subsequent feedback as the study evolved. Dr. Lu's 
intellectually challenging and inspiring comments have similarly enriched my work, besides her teaching in the graduate seminar that I took with her. Dr. Soldat-Jaffe's teaching and advice have added to the perspectives that I have brought to bear on several issues in this study.

Finally, there is someone who has been so instrumental to the success of my entire graduate education as well as the successful completion of this dissertation that I can hardly describe my gratitude towards her in mere words: my loving wife Soni. Soni has not just humbled me by the amount of her support, encouragement, and sacrifice for me but also made me wonder how it is humanly possible for one person to be so fully in the rhythm of another person's months-long research and writing process. Her love and support made this work not only possible but also enjoyable. I owe more than I can ever say to Soni! 


\section{DEDICATION}

I dedicate this dissertation to my parents and to my two beautiful children

Umber and Ava. 


\section{ABSTRACT \\ IDEOLOGICAL TENSIONS, PEDAGOGICAL GAPS: \\ MULTILINGUAL ENGINEERING SCHOLARS' RESPONSE TO \\ LANGUAGE VARIATION IN ACADEMIC WRITING}

Ghanashyam Sharma

June 25,2012

This dissertation examines how nonnative English speaking (NNES) faculty and students in engineering respond to language variation and how that response influences their teaching and learning of academic writing. Using grounded theory approach to analyzing data gathered from multiple rounds of interview, writing samples, informal discussions, and class observation among ten participants, the study draws on and responds to two related bodies of scholarship in composition studies and writing in the disciplines (WID).

Contrary to claims in much of current scholarship on engineering writing, the findings of this study show that in spite of subscribing to views about language and writing that writing scholars consider problematic (as illustrated in chapter two), engineering faculty use a range of effective practices for teaching writing. Some of these practices include letting students use writing for different contexts and purposes, providing feedback, and integrating writing as a means of academic and professional development. Thus, the study argues that WID research and programs should recognize and build on best practices on the ground before confronting the problematic views. 
The findings also clearly show that because NNES engineering faculty and students subscribe to their discipline's discourse about the transparency of language, transience of learning to write, and universality of standard academic English (as demonstrated in chapter three), they typically reject any language variation, through which current scholarship expects that they, as multilingual individuals, resourcefully negotiate meaning. Consequently, in chapter four, the study proposes that in order to promote more complex understanding and practice of language and writing in engineering, writing programs should first understand the dynamics of how multilingual scholars exercise power and agency in their disciplines and professions through prevailing monolingual policies and practices.

The study concludes by using the theoretical framework of chapter four in order to recommend a number of practical strategies toward building effective WID programs (in chapter five). WID literature that has started responding to the monolingual dynamics of the discipline is briefly reviewed, and suggestions are made for further study on how to confront the monolingual myths that affect academic and professional communication in engineering. 


\section{TABLE OF CONTENTS}

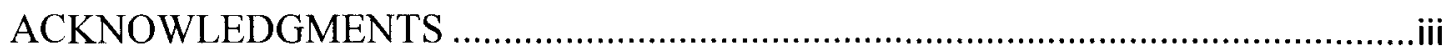

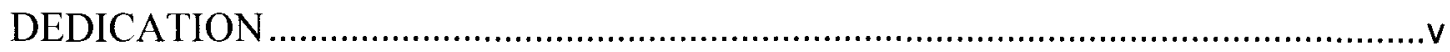

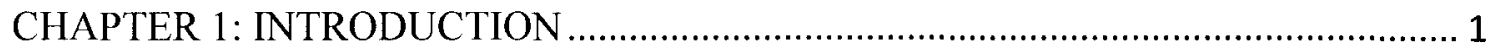

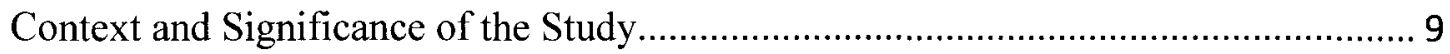

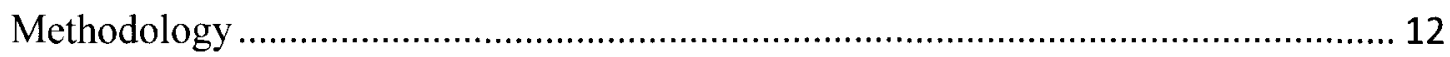

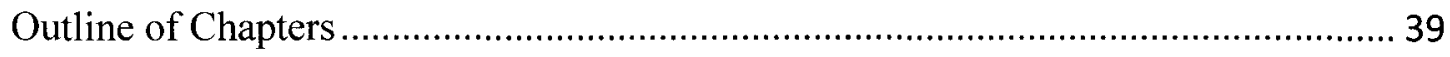

CHAPTER 2: DISCOURSES ABOUT LANGUAGE AND WRITING IN

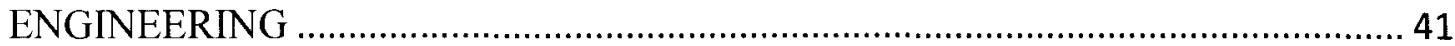

The myth of Transparency: Engineering Writing is clear Writing .............................. 43

The Monolingual Myth: Standard English as Universal in Technical Writing ............ 48

The Myth of Transience: Writing "Happens"............................................................. 53

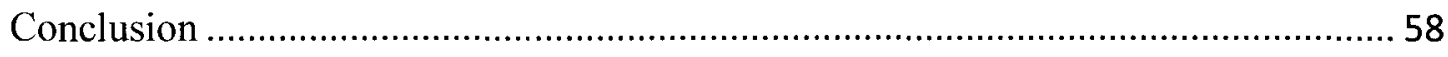

CHAPTER 3: MULTILINGUAL SCHOLARS, MONOLINGUAL PRACTICES ........ 61

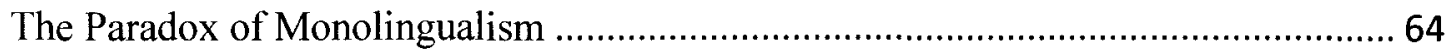

Quality, Standard and Passing the Buck of Gatekeeping ........................................... 75

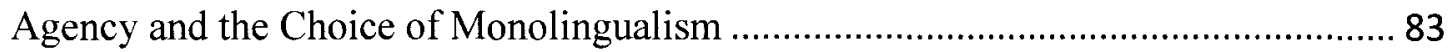

Being in the same boat: Multilingualism and Affective Domain ................................. 92

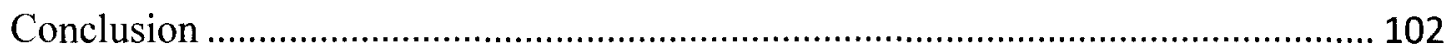

CHAPTER 4: A PRAGMATIC APPROACH TO PROMOTING WRITING IN

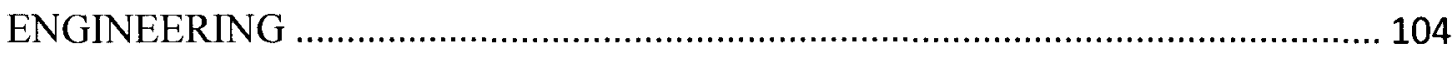

Best Practices of Teaching Writing among the Faculty Participants........................... 106

Integrating Writing into Engineering Education................................................... 107

Treating Writing as Part of the Big Picture of Professional Development............. 109

Letting Students Write for Practical Purposes Beyond Academic Requirements .. 111

Giving Writing its Due Place Alongside Oral and Object-Oriented Communication

Providing Feedback on Students' Writing.......................................................... 116

A Pragmatic Framework for Promoting Writing in Engineering ………..................... 119

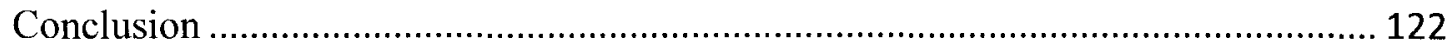

CHAPTER 5: SPECIFIC RECOMMENDATIONS AND CONCLUSION .................. 127

Recommendations for Writing Programs …………………………………….... 127

Focus on the NNES Majority and Graduate Students ......................................... 128 
Point out the Limitations of Oral Communication .......................................... 129

Draw Engineering Faculty's Attention to the Complexity of their Writing ........... 130

Provide Support for Professional Writing......................................................... 131

Incorporate Engineering Faculty's Approach to Writing Consultation ................. 133

Make Best Practices Visible by Using Web Technologies................................... 136

Foster a More Critical Conversation about Writing ........................................ 136

Promote Writing as a Means of Transnational Professional Communication........ 138

Recommendations for engineering faculty and departments.................................. 139

Make the Language and Discourse of the Discipline Explicit............................ 139

Help NNES Students with Academic Orientation During Transition ................... 141

Engage Students in Low Stakes Writing for Practical Communication ................. 144

Let Students Read, Analyze, and Respond to Engineering Scholarship............... 146

Provide Feedback and Let Students Revise/Improve their Writing..................... 147

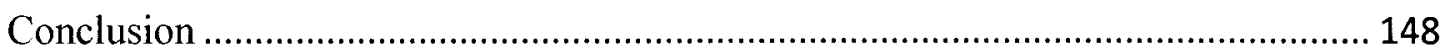

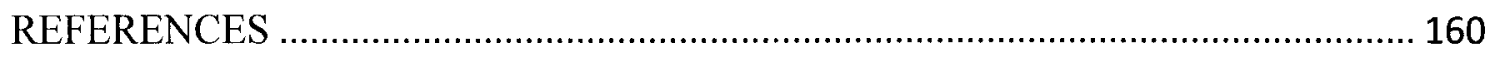

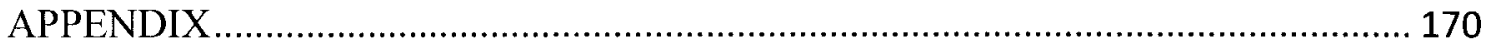

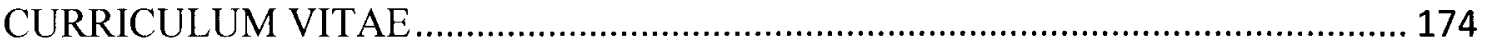




\section{CHAPTER 1}

\section{INTRODUCTION}

According to the Institute of International Education, international graduate students comprise about ten percent of total graduate students in US universities (IIE, 2010). A recent Congressional Research Service Report (CRSR, 2010) further showed that foreign students earn more than sixty percent of doctorates awarded in engineering. Because most of these students are nonnative English speaking (NNES) students ${ }^{1}$ who come from countries where academic writing is not integral to college and university education, they need much more support than just help with their language proficiency, as it has historically been the focus of university writing programs and curricula historically. Many of these students need support with the discourse and conventions of advanced disciplinary writing. The fact that disciplines like engineering give low priority to explicitly teaching academic writing skills makes the challenge of the NNES students in such disciplines even more critical.

Furthermore, the CRS Report also states that more than half of the foreign doctorate degree earners remain in the United States upon completion of their degrees, adding that more than a quarter of full time faculty in engineering are foreign-born (1). Consequently, the increasingly higher concentration of NNES faculty in the American university adds yet another layer to the problem: if the majority of the NNES faculty have gone through college and university experience without much training in academic

\footnotetext{
${ }^{1}$ For instance, $71.8 \%$ of international doctoral students are from Asia.
} 
writing, their ability to teach or otherwise support their graduate students with academic writing may also be limited even when they are willing to do so. Thus, from the data about the status of academic writing in NNES-majority disciplines like engineering, a problematic picture emerges on both sides of the teaching and learning processes.

There is a rich body of scholarship that deals with issues of language and writing among NNES ${ }^{2}$ students in the academy. For more than four decades, this scholarship has established that NNES students lag considerably behind their "native" English speaking (NES) counterparts in performing the wide variety of rhetorical functions that they need to perform in academic writing. For example, in a TESOL article published in 1983, Pearson focused on the particular discipline of engineering and pointed out that NNES engineering scholars need to explicitly learn how to perform complex and nuanced rhetorical functions such as "a veiled criticism, an urgent request, a recommendation that is expected to meet resistance, a pro forma trip report, a projected outcome of incomplete action, a hypothesis ... a tentative conclusion based on preliminary data" (Pearson, 1983). As Pearson suggested, while NES students may manage to perform rhetorical functions such as these more easily, NNES students cannot do so without deliberately learning those skills; their teachers need to explicitly help them with how to perform complex rhetorical skills like the above. This first body of scholarship has continued to focus on how to address the challenges that NNES students face with learning and writing as they enter US colleges and universities.

\footnotetext{
${ }^{2}$ This population has been referred to with a whole host of terms and acronyms in the literature. Some of the terms include ESL/English as second language, EFL/English as a foreign language, EIL/English as an international language, ELL/English language learner; other terms are used in combination with "users" or "speakers" of ELF/English lingua franca, ESP/English for specific purpose, EAP/English for academic purpose, EAL/English as additional language, ESOL/English (for) speakers of other languages; other terms more directly describe the individuals using terms such as LEP/limited English proficiency, CLD/culturally and linguistically diverse, bilingual, multilingual, and plurilingual. This plethora of terms attempts to describe users of English a language that is not, although debatably, "native" to them.
} 
More recently, the scholarship on NNES writing, both within composition studies and in related fields, ${ }^{3}$ has pointed out problems with conventional scholarship's focus on language proficiency of NNES students in terms of how competence was defined, how normal sociolinguistic variations were viewed as a deficit by native English speaking (NES) "gatekeepers" in the academy and the professions, and how the policies and politics of language in the academy shaped expectations and attitudes about language and language variation in academic writing (Belcher \& Braine, 1994; Flowerdew, 1999, 2001; Horner, 2001; Horner \& Trimbur, 2002;Canagarajah, 2006a, 2009; Horner, NeCamp \& Donahue, 2011). Some of the scholars who write about the ideological nature of language policies and practices in the academy (e.g., Canagarajah, 2009) argue that NNES, multilingual individuals can in fact be more proficient at navigating and negotiating meaning through and in spite of language variation than their "native" English speaking (NES) counterparts - instead of being language learners who indefinitely need help with language, as they were too often represented in traditional scholarship.

It must be noted here that the scholarship on multilingualism has usually dealt with the more theoretical issue of how individuals negotiate meaning through language variations. While the research has included participants from the discipline of science and engineering, the particular issue of how academic and professional writing in disciplines like engineering bears on language standard differently than it does on the writing of disciplines like social sciences needs to be borne in mind while identifying any gap in the

\footnotetext{
${ }^{3}$ especially research on writing in the discipline (WID) and English as a second language (ESL) on the one hand, and on the other theoretical scholarship about the policies and politics of language (POL) in the academia

${ }^{4}$ especially by those who are in positions of authority as teachers, reviewers, editors and so on
} 
scholarship. In other words, I am aware that engineering faculty and students are less concerned with academic writing or literacy as such and the importance of being able to negotiate meaning across language varieties, and it would be unfair to argue that they should be; for them, language and writing proficiencies are a means toward achieving academic and professional goals (for instance, writing and getting an article published, rather than learning how to write as a goal on its own). Nonetheless, neither the conventional scholarship on "second language writing" nor the more current scholarship on policies and practices about language in the academy as it affects NNES writers has examined the views about language and writing among NNES scholars themselves and how their views might affect the teaching, learning, and practice of academic writing/communication. ${ }^{5}$ It has generally concentrated on how NES scholars perceive language and language "standard" in academic writing, and it finds fault with how they view the same (Flowerdew, 2001; Horner, 2001; Horner \& Trimbur, 2002; Spack, 2004; Morita, 2004; Belcher, 2007; Horner \& Lu, 2007; Roberts \& Cimasco, 2008; Lillis \& Curry, 2006; 2010). Even the more current scholarship generally assumes that NNES members of the academy are on the receiving end of often unfair policies, politics, and standards of language and writing which reject different styles and varieties of English used by NNES students and scholars as defective and inappropriate for academic and professional writing. In response to the focus on the deficit view of language variation in earlier scholars on NNES writing, the current scholarship has highlighted the linguistic strengths that NNES writers could bring into language including academic writing, but

\footnotetext{
${ }^{5}$ Incidental mentions in this direction can be found in studies about NNES writing all the way back to the 1980s (e.g., Santos, 1988; Kobayashi, 1992; Flowerdew, 2001; Roberts \& Cimasco, 2008), but no dedicated studies have been conducted in the context of NNES majority disciplines like engineering in the US.
} 
the latter scholarship has not yet asked whether NNES writers may actually put their multilingual abilities and resources into practice in academic writing within predominantly monolingual institutional and professional settings.

There is also another body of scholarship on academic writing in the disciplines (WID) that has addressed the problematic perceptions and treatment of language and writing in academic disciplines like the natural sciences, technology, and engineering (Herrington, 1985; Jenkins et al., 1993; Winsor, 1996; Haas \& Witte, 2001; Reave, 2004; Zhu, 2004; Wolfe, 2005; Jordan \& Kedrowicz, 2011). In spirit, this body of work follows the tradition of scholarship by Rose (1985) and Russell (1989, 1991, 2007), who have historicized and demonstrated what they call the "myth of transparency" of language ${ }^{6}$ and the "myth of transience" of writing in the academic disciplines. This critique is a general commentary on the academic disciplines as highly specialized fields that, as Winsor $(1996,2000,2003)$ has most comprehensively discussed, do not see language and writing as mediating the content of their discipline. When this scholarship has focused on engineering, it has paid some attention to how prevailing views about language and writing impact NNES students as learners of language and academic writing skills (Zamel, 1995; Angelova \& Riazantseva, 1999; Dennett, 2000; Morita, 2004; Cox, 2011). With regard to NNES students, WID scholarship largely continues to focus on the language needs of these students. While it has addressed problematic views about language and writing in the academic disciplines at large, WID research has not yet

\footnotetext{
${ }^{6}$ The myth of transparency of language, which I discuss in more detail in Chapter Three, refers to the idea (prevailing especially in academic disciplines outside of the humanities) that language is a transparent means for encoding thought; the myth of transience of writing, as a corollary to the first assumption, refers to the belief that writing is learned once (ideally before) or "automatically" while learning the content of particular disciplines, or the belief that learning to write "happens" while learners are focusing on the content that they need to communicate.
} 
directly addressed how those views play out when NNES scholars are in the majority and, additionally, in positions of authority like teachers, advisers, and administrators. In light of the fact that the majority of graduate students in engineering have been nonnative speakers of English since the 1980s (Barber \& Morgan, 1987) and by now even the NNES faculty are in the majority as well (CRSR, 2010), it seems increasing necessary for WID scholarship to focus on how prevailing views about language and writing in the discipline of engineering shape and influence NNES engineering scholars' and students' views and practices of academic writing.

By situating NNES writing in a particular disciplinary setting and at the graduate level, this study simultaneously builds upon and complicates the two bodies of scholarship described above. In response to the expectation in the more recent scholarship on multilingualism that multilingual writers are likely to draw on their sociolinguistic experiences and abilities toward negotiating meaning across variation and complexity of language in use, I discuss how the prevailing monolingual standards and policies in the current institutional and professional settings may trump NNES faculty's multilingual attitudes and also NNES students multilingual abilities toward maintaining the monolingual status quo. That is, NNES scholars may not cultivate complex views about language when they are in positions of institutional and professional authority, responsibility, and privilege. Since engineering scholars--whether they are NNES or NES - do not have any significant incentives for challenging the prevailing beliefs and practices about linguistic norms and standards in their discipline, most of them are likely to instead adopt and enforce the same beliefs and practices. Some of the NNES faculty supported their NNES students with learning academic writing, but they did so in spite of 
their strong monolingual beliefs rather than because they believed in the need to teach their students complex rhetorical skills, not to mention that they did not value multilingual resources that the students writing may manifest as a positive phenomenon.

On the contrary, in response to current WID scholarship's claim that engineering faculty generally shun the teaching of writing, I highlight some of the best practices that seem to deserve serious consideration. As I suggested above, engineering facultywhether they are NES or NNES - may not value or teach writing as an educational goal unto itself, like writing scholars tend to do; but at least some of them seem to value and teach writing as a practical tool for fulfilling immediate academic needs and as a means for professional development. In other words, while the findings of this study corroborated that engineering faculty generally adopt reductive views about language and writing, some of the faculty provided their students a number of significant opportunities and support with writing. These faculty taught their students how to write because they valued language and writing skills as defined in monolingualist ways. The support that they provided to their students constitutes considerable good practices that WID scholarship tends to overlook because of being predominantly critical as well as largely theoretical; these practices deserve to be taken more seriously.

Thus, in this dissertation, I first examine how NNES scholars' perception and treatment of language and writing are influenced by the discourses and ideologies about language in their discipline, and how that influence shapes their teaching and learning of language proficiency and writing skills as engineering scholars and students. To that end, I describe the problem by demonstrating the impact of prevailing discourses upon the teaching and learning of writing in the engineering discipline in general. I then present a 
framework along with a few specific strategies using which it seems possible to establish among engineering scholars the importance of the variability, complexity, and rhetoricity of language in engineering writing. I argue that in order to promote writing in the disciplines, universities, writing programs, and writing teachers need to counter the prevailing notion in disciplines like engineering that the language of academic, especially scientific, writing is a simple, transparent, and universal means for encoding thought in a straightforward manner.

This study is driven by two interrelated interests. One is an interest in examining the extent to which NNES scholars' views about language and writing may be shaped not just by their sociolinguistic identities and life experiences but also, and perhaps more strongly, by disciplinary discourses about language and writing, as well as specific institutional and professional structures and incentives. The second is an interest in investigating how prevailing discourses about language and writing in the discipline shape or influence how NNES faculty members and their students approach the teaching and learning of engineering writing. Considered together, these interests prompt me to study the connections between beliefs/discourses about language in engineering and the practices of teaching/learning to write. What kinds of views about language and writing lead to what kinds of teaching practices — or lack thereof — among engineering faculty? What views and practices facilitate the process of learning and using writing as a means for learning, disciplinary socialization, and professional development of engineering students in general and NNES engineering students in particular?

Thus, on the one hand, I describe how the prevalence of views about language and writing generally undermine the teaching and learning of academic writing; on the other, 
I dedicate a chapter to discuss the dynamics of monolingualism among the NNES faculty and students as multilingual individuals. These analyses allow me to develop a framework for addressing the problem of pedagogical/educational gap with regard to academic writing in engineering, focusing on NNES students' need for acquiring the knowledge and skills for advanced academic writing. In other words, the relatively richer teaching and learning practices and the underlying views about writing among the participants form the basis of the major argument of this study: in order to promote academic writing in engineering, writing scholars/researchers, teachers/tutors, and program administrators should start by recognizing the engineering faculty and students' own views and best practices before they try to challenge them or offer to provide support and resources from the outside.

\section{Context and Significance of the Study}

Having introduced the subject and focus of the study, let me briefly pause to highlight the significance of it as one that is situated in the intersection of how engineering faculty and students in general approach writing and how NNES faculty and students may further complicate the teaching and learning of that writing vis-à-vis their response to prevailing monolingualism in engineering. Broadly, the significance of this study has to do with realities like the following:

(1) Ideologies of the Discipline: Engineering as a discipline tends to demand a simple, clear and universal code in the name of standard or "technical" English and considers this demand as nothing but pragmatic and as essential for effectively communicating scientific/technical knowledge; but this demand is inherently political and ideological because it is based on the how engineering defines itself as 
a discipline of "objective" knowledge, as well as how it defines language and communication (Russell, 1989, 1991, 2007; Winsor, 1996, 2000, 2003). This ideological position contributes most to the pedagogical gap that I discuss and recommend solutions for.

(2) Engineering Education versus the Profession: Engineering faculty and even their students deem writing as important to their profession, especially when students complete their degrees and join the workforce, but they consider explicit teaching or learning of the language, skills, and conventions of writing a low priority during graduate education (Jenkins et al., 1993; Reave, 2004; Jordan \& Kedrowicz, 2011). Because engineering scholars essentially believe that "writing happens," a kind of "do nothing" culture prevails among the faculty in terms of helping students learn how to write. Effective practices of teaching writing are an exception rather than a norm and therefore deserve promotion.

(3) NNES Demographics: As mentioned at the beginning of this chapter, NNES faculty and students have long been in the majority in engineering, and their numbers are on the rise. Because of the high concentrations of NNES students at the graduate level, the need for support with their advanced disciplinary writing is most dire at this level; however, university writing programs and curricula are seldom geared toward the graduate student population. ${ }^{7}$ Moreover, even when NNES students' needs are addressed, writing programs too often focus on their language proficiency as such, rather than on helping them learn the language, discourse, genres, and conventions of advanced disciplinary writing.

\footnotetext{
${ }^{7}$ The need for NNES graduate students is only addressed by a minority of universities.
} 
(4) Social versus Academic Contexts: While NNES scholars, as multilingual individuals, may be highly capable of negotiating meaning in spite of variation in language and the attendant complexity and rhetoricity in their social lives (e.g., Canagarajah, 2009) outside the academic and professional domains, the discourses and dynamics of their disciplines, institutions, and professions at large require or encourage them to enforce restrictive, monolingualist policies and practices, obscuring the need to attend to the complexity of writing and the need to teach and learn it deliberately.

(5) Diversity versus Assimilation: Since language variation is inevitable in the writing of NNES students and scholars, the fact that they are in the majority in disciplines like engineering warrants closer study of how they may practically negotiate meaning through the diversity of language use in spite of the monolingual rhetoric that they subscribe to. If, for instance, the increasing numbers and diversity of NNES scholars and students practice, accept, and establish variation from standard academic English as a normal and positive aspect of writing in their disciplines, that would enhance the understanding, teaching, and learning of academic writing in those disciplines. But if the positive findings about how NNES individuals view and use language variation in day to day communication do not apply to the context of the academy, especially in the geopolitical centers, the process of teaching and learning language by and to NNES scholars and students respectively could be adversely impacted.

The following chapters illustrate the impact of the gaps, tensions, and paradoxes like the above upon students' learning and performance in writing, and they go on to recommend 
strategies for overcoming the roadblocks toward promoting academic writing in engineering.

\section{Methodology}

The research question guiding this study evolved from a pilot study that I had conducted about a year before I started the current study; that study met a kind of dead end but helped plan and focus this study more effectively from the outset. Conducted among nine international graduate teaching assistants (IGTAs) from six different departments at the same university with the intention of studying how IGTAs assessed student writing, that study showed that the IGTAs avoided assigning writing-intensive work by giving objective tests, mathematical calculations, or problem-solving; the participants were also strikingly unwilling to talk about writing, not to mention how they assessed it in their classrooms, so after conducting interviews, transcribing them, and attempting to analyze the data, I essentially gave up that study. In order to address the roadblocks that I encountered with the pilot study, and also to focus more closely on the discourse and practices about writing in a specific discipline, I eventually designed the dissertation study by shifting my focus to the writing practices of NNES faculty and their NNES graduate students in a particular discipline, engineering.

Let me pause at this point to briefly describe my own identity and position as a researcher as it might have shaped or influenced my perspectives on the subject of this research. I am an international student from Nepal where I used to be a university lecturer of British literature, linguistics, and critical theory; I was and still am actively engaged in the professional development of Nepalese English language teachers, and the issue of monolingualism and multilingualism interest me because I grew up speaking different 
standard Englishes (first in grade school in India, then in college and university in Nepal, and finally in the United States) so from my personal experience, the idea of trying to impose a monolithic variety upon the learner and even members of any professional community strikes me as both impossible and unnecessary. As an English teacher who has taught the language for a long time-directly as a teacher of language and linguistics in Nepal for twelve years and indirectly as a writing teacher in the US for another six years - I certainly don't hold an "anything goes" view toward language variations. But as a scholar of Rhetoric and Composition, I am in favor of the discipline and profession's adoption of students' right to their own language (varieties). I started this study by trying my best to not express my views about monolingual policies and practices that the participants seemed to generally adopt; but after the first two rounds of interview, I shared my views on the subject, letting the participants respond candidly also. I believe that the data of the study was considerably enriched as a result, also allowing me to make productive comparison between their earlier and latter responses.

In the early interviews with all of the faculty and students, there were considerable amounts of resistance, gaps, and tensions in their stated beliefs. They often told me that their view of writing is different from "you English people" (in the words of one of the faculty members). I had become aware of the defensiveness among students from the pilot study, but this time I encountered a new challenge: how can I see past the apparently deliberate attempt to define language and writing in contrast to how the participants believed I defined them as one of the "English people"? One of the strategies that I adopted with the initial interviews was to not ask any questions that might encourage the participants to make inter-disciplinary distinctions. I also let participants 
respond to an anonymous writing sample provided by one of the students. I started the second round of interviews by asking the participants to describe (and where possible show me materials about) how they taught or learned writing and the language/discourse of engineering. This helped me shift the focus from belief to experience, from perspective to practice. I was cautious that when I asked the participants to describe their practices, they might describe what they considered good practices instead of their actual practices of teaching or learning to write. So, I tried to establish rapport by meeting with the participants informally outside of the formal interview settings, by conducting multiple rounds of interviews, offering to help with their writing or assessment of student work, and communicating via email and phone before and after the in-person meetings.

I conducted three rounds of formal, in-person interviews with the faculty members and two rounds with students over the course of about eight months; I had to conduct two of the student interviews during the second round via email because the students graduated and left town. In order to elicit more specific responses, I also used charts, figures, and examples of problems and best practices during the interviews. After establishing the rapport, during the later interviews, I explicitly brought up the "cultural gap" that I had been trying to avoid or reduce early on, this time asking the participants to "help me understand" some of the tensions that I had found in the earlier interviews. I also asked them to "tell me what [they] would recommend" as solutions to problems and issues that they considered as feasible within the context, priorities, and limitations of their discipline. The more open and candid discussions in later interviews helped me address rather than intensify some of the disciplinary differences that the participants had been using to frame their responses during the initial interviews. Assuming a participant- 
observer role rather than taking a detached observer's approach was useful in making the data from the interviews and informal discussions richer and more reliable.

The careful and gradual attempts that I made for alleviating the cultural gap between my own discipline and the discipline of engineering vis-à-vis language and writing and the teaching and learning of them greatly helped me understand the problems as well as formulate my theoretical perspectives and practical recommendations in this study. This approach aligns with the central argument of the study that the best way to start promoting academic writing in the disciplines is by drawing upon the perspectives and practices among the members of that discipline, however limited or problematic the underlying views may seem to writing scholars. Accordingly, I structure the dissertation to reflect a three-step pragmatic approach to promoting writing in the disciplines: understanding stakeholders' perspectives on a problem, building on existing best practices, and promoting a more critical understanding and enhanced practices of teaching/learning academic writing/discourse.

\section{Participants}

Five faculty members from four different departments in a school of engineering at a large public university participated in this study. With the help of one of my professors, I had invited almost two dozen engineering faculty members to participate; six of them responded. ${ }^{8}$ Among the six faculty members, a civil engineering instructor did not have a student to suggest, so I excluded the one interview that I had conducted with him. All of the five faculty were highly accomplished scholars; they had published extensively and some of them were in administrative positions. All of them were very willing to talk about writing. The students were at various stages of their doctoral

\footnotetext{
${ }^{8}$ This was the approximate number of participants that I desired.
} 
programs, ${ }^{9}$ and some of them were more willing to talk about their writing than others, mainly because they had different amounts of experiences with writing. All of the participants were NNES. For the sake of anonymity, I call the faculty members Dr. A, Dr. B and so on — and also call students Student A, Student B and so on.

\section{Student participants.}

Once the faculty members volunteered to participated, I requested them to recommend one NNES graduate student each whom they were advising and who may be involved in considerable amounts of writing at the time; all of the recommended students volunteered to participate. In this section, as I introduce the student participants, I tentatively put them into two groups with the purpose of identifying different views and practices regarding writing among them. I identify the relative difference in the views and practices on the basis of the analysis of interview data, notes from one-on-one advising of students by their instructors as well as informal discussions with all participants, writing samples including emails. I call two of the students "writing-confident" and the other three "writing-anxious." In Chapter Four, I will refer back to the relative confidence and competence versus anxiety and resistance regarding writing among the students in order to illustrate how these phenomena seemed correlated to the views and approaches that their teachers took with teaching or facilitating writing - or the relative lack thereof.

\footnotetext{
${ }^{9}$ The student participants were research assistants and none of them had considerable experiences of teaching or assisting their professors in classroom teaching; hence, I refer to them as students rather than "teaching assistants" even though that might be their official status. I do not refer to them as "research assistants" because I do not focus on their identities/performance as researchers. The focus of this research is to see how beliefs about language affect their learning/performance of writing, so I consider them as students and writers.
} 


\section{Writing-confident students and their views about writing.}

The writing-confident students placed a high value on writing, were willing to invest time in it, and expressed relatively nuanced and complex views about the role of writing in engineering education. They viewed writing as a means for academic and professional success rather than a transparent tool that needs no teaching or learning. By contrast, the writing-anxious students were resistant to writing and minimized its importance. They not only avoided writing as much as possible but also believed that it is not necessary to invest time or efforts trying to deliberately learn writing skills. They defined writing as a much less complex phenomenon than the confident students did, and they did not view writing as a means for academic and professional communication with their peers and faculty members. They considered writing as primarily the last stage of completing the thesis or dissertation as a degree requirement, an activity about which they did not think seriously. Their struggle with writing and resistance toward investing time and improving their writing skills seemed to be shaped by the reductive ways in which their teachers perceived, defined, and treated writing. Because they adopted the problematic notions about language and writing that are prevalent in their discipline, the writing-anxious students obscured their own challenges with writing and downplayed the need to deliberately learn it.

\section{Student A.}

Student A was a fourth year Chinese doctoral student of chemical engineering, working with Dr. A, whom she greatly respected, especially for Dr. A's one-on-one support with her writing. She had written extensively and took great pride in her achievements as a student writer. She demonstrated this confidence, for instance, when I 
asked for writing samples for the first round of interview: she sent me a total of six documents including a rough draft and revised version of the results and discussion section of a paper that she had written during her first year in 2007; a rough draft and revised version of the background and significance section of an article written in 2008; and the study design and abstract sections of two different versions of an article she had coauthored with her adviser. Later on, when asked for samples of emails she had written, she sent me five threads of email exchanges that she had had with her adviser, another faculty member, and a salesperson of a lab equipment business between 2006 and 2011. All the samples showed that Student A was highly proficient in her language and communication.

Unlike the writing-anxious students who saw writing as something that they only attended to when necessary, Student A described a deliberate approach that she took to her development as a writer, emphasizing that she was conscious about the role that writing proficiency played in her success as an engineering scholar.

Student A: Well, in the first few years, I did feel that [language] was the difficult part. Sometimes you have kind of complicated thoughts, and it's very difficult to write it down. So I tend[ed] to just use some vague sentence or something just to get it down. ... It's not only the content, it is also the language, because I just [didn't] know how to, uhm, those sentence [didn't] come to my mind. But now when I write it comes to my mind whatever I want to say, I have those sentences right away.

As the above quotation indicates, she saw her progress as a writer as involving learning language, content, and disciplinary conventions for writing. When asked what qualities of 
writing she considered essential in her discipline, she mentioned not just clarity and correctness but also effective organization and the ability to adapt writing to particular audiences.

\section{Student B.}

Student B was also a fourth year doctoral student from China who had found an internship opportunity at the time of the interviews and would be leaving in a few months. Working with Dr. B, a very highly regarded professor in the industrial engineering department, she seemed greatly motivated as well as deeply influenced by his view of writing as a means of professional development. She was proud of her proficiency and accomplishments as a writer, for which she gave much credit to Dr. B. She was also appreciative of other teachers in the department who had helped her grow as a writer: "In our department, our professors [are] always very encouraging. No matter what you submit to them, they will say, 'Good job. Okay here is the problem."' Most importantly, she took the initiative to learn how to write better, which she said came from her personal interest in language and communication as well as her understanding that good writing skills would help her become a more successful engineering scholar.

Like Student A, Student B said that her adviser gave her many writing opportunities, adding that she has been asked to revise an article up to ten times. When I asked her to send me examples of emails she had written, she sent me over a dozen emails, which she had written to a wide variety of audiences in and outside her department. The draft and revised versions of an abstract that she sent me as writing samples for the first interview showed impressive improvements in syntax, grammar, transition, and preciseness of wording. 
When I asked her how her writing had changed over the four years of her graduate studies, she said that she found it easier to write as a result of her increased knowledge of her field as well as improved language proficiency: "Generally, it feels easier for me to write a draft based on what I have done." She added that because of an excessive focus on research and other projects in recent months, she was anxious about being unable to write as regularly and substantively as she wanted. However, she was happy that because she had written extensively during her time in the graduate program, she was now able to draw on that writing for new projects or publication.

Compared to the writing-anxious students, Student B also expressed quite complex and nuanced views about language and writing. For instance, when asked whether she believed that there must be one universal standard of English for technical writing, she said:

Student B: Uh, I shouldn't say one standard, because it depends on what kind of paper, right? Like probably you propose a new method, or you present some comparison among different methods, so--but the basic structure should be the same.

Student B was aware of how context and genre can influence her use of language; as she suggested in the quotation above, she said that while engineering writers will vary their writing styles, they need to always follow certain overall conventions for structuring and organizing their writing. She said that she wanted to write as much as possible and her conversations about writing suggested that she was conscious and deliberate as a writer. 


\section{Writing-anxious students and their views about writing.}

The writing-anxious students were not only significantly less proficient and less confident writers but their views about language and writing were also less nuanced. In comparison to the two students above, these students said that they did writing only as and when required by their advisers. They did not consider writing as integral to engineering education and professional success. And they believed that learning to write just happens over time if they focused on understanding the content of their discipline.

\section{Student X.}

Student X, a third year Chinese doctoral student in the department of mechanical engineering who was working with Dr. X, seemed to be the hardest working student. Describing himself as "almost living in the lab," he added: "I do not write too much. Most of time I read the paper [articles] and stay in the lab and do experiments." Unfortunately, despite the time and energy that he invested in the lab, he was evidently the least competent and confident writer among the student participants. When I requested writing samples for the interview, he only provided three pages from two different reports, adding in the email that the only other significant writing he had done until then was his master's thesis. When asked for email samples, he sent me six emails which contained only one or two short sentences.

Student $\mathrm{X}$ was anxious and defensive about discussing his writing. For instance, when I mentioned that I wanted to understand his and his adviser's views and approaches to teaching and learning writing, he said, "What? Why do you want to talk about my writing with my adviser?" and almost cancelled the planned interview. He said that he wrote as little as possible, adding: "I cannot write very fluently, so I just want to write the 
very important sentences." His ideas about writing were starkly less complex and nuanced than that of the writing-confident students. When asked what he considered the most important quality of engineering writing, he said

Student Z: In my opinion, I just want to use images to show what I am saying. I don't want to use words. ... I do lots of pictures in my computer, and put good ones here. ... The second one, I try my best to use very standard form to write a sentence.

When I followed up with what else he considered as good qualities of engineering writing, he said, "very short sentences."

Student X was also evidently a meticulous researcher, but he seemed to neither see the importance of nor had the ability for representing his findings in writing: he not only paid most of his attention to producing and presenting images and figures, but he also considered verbal language, especially complex language, as unimportant and worth avoiding in engineering writing.

\section{Student Y.}

Student Y was a second year Chinese doctoral student working with Dr. Y, a chemical engineering professor (who was a prolific writer). When I asked her to share writing samples, she said that she had not yet written anything worth sharing. In order to make the interviews consistent, I used someone else's writing sample, but she largely refused to comment on the writing not only because it was someone else's writing but also because she said that she did not have the ability to do so. Later on, when I solicited sample emails, she again responded by saying that she had not yet written emails as a research student or member of research projects. Furthermore, when I asked what kinds 
of programs, courses, and resources might help her develop as a writer, she said "I haven't thought about that."

Student $\mathrm{Y}$ expressed the same view as her adviser that students learn to write by regularly doing oral presentations. Her adviser told me during his interview that he only let his students write substantively starting their third year when it was time for them to work on their dissertations. Student $Y$ accepted this delay in beginning to learn writing skills. She did not think that writing facilitates or mediates the process of learning and communicating new knowledge. She said that the most important quality of engineering writing is clarity, adding that "finding the right word" was also a challenge for her:

Student Y: I think the most difficult thing is to find the right word to describe, although I learn English for so long, for many words I can recognize it if I see it but if I want to use it, I just can't get it.

Like other writing-anxious students, she also considered "simplicity" and the need to avoid complexity as other important qualities of engineering writing.

\section{Student Z.}

Student $Z$ was a second year doctoral student in chemical engineering who was from the Middle East. He had been Dr. Z's student during his master's degree in civil engineering. He said that he had not yet written much other than his master's thesis (so his interview was also conducted using an anonymous sample of engineering writing); similarly, when he was requested to provide email samples, the one email that he sent me was very brief and it contained few rhetorical moves that would engage the audience. When describing his experience with writing in college in his home country, he said:

"The challenge was that there was no standard like here. They didn't pay attention to the 
English. They only thing they would care was the technical content." He also highlighted the challenge that he faced when he first came to the US: "When I came here, I was thinking in Farsi, you know. So it changed the way that I think when I had to think in English." After four years of being in a US university, he still did not view writing as a discipline-specific set of skills, a complex repertoire of linguistic and rhetorical skills, or a means of professional development.

Student $Z$ defined language and writing in terms of grammar, correctness and clarity; when asked what he considered the most important quality of engineering writing, he said, "It should be clear. The second thing is that there shouldn't be any grammatical mistakes. Or you should gradually eliminate them." Although he talked about "honesty" as a quality of good engineering writing, this seemingly complex point turned out to be a matter of ethical responsibility rather than an issue about writing skills. Student Z's overall view of writing was quite arhetorical:

Student Z: in engineering you don't pay attention to writing. But there is a standard for writing the article and that's very simple. ... in engineering, you just have to follow simple instructions to write your paper, and that's very easy. When asked what he needed to improve as a writer, he said that the ability to use clear and simple language is all that matters to him as an engineering scholar

\section{Faculty Participants.}

\section{Dr. A.}

Dr. A was the graduate program director of one of the engineering departments in her university. She said she came to the US about thirty years ago as a graduate student; she added that she had not had academic writing experience in college in her home 
country in East Asia. ${ }^{10}$ As a program director, she was concerned not only about the engineering students in her classroom (and those whom she advised) but about all students and the quality of their education in her department. She also added that it was her personality to be critical about the lack of motivation among students and in some cases the lack of dedication among the faculty. Dr. A expressed very strongly monolingual opinions about non-standard English in academic writing, but as a teacher, she was the most rigorous in helping her students learn to write. Sharing a few samples of her students' writing, she told me that she normally marked language issues in red ink and writing suggestions for revising for content in blue ink; she had also circled welldeveloped paragraphs in green highlighter. Dr. A was very eloquent during the interviews, but she also generally continued her own train of thought while loosely connecting to new questions that I asked.

\section{Dr. B.}

Dr. B was an extremely busy professor because he was involved in many projects in and beyond the university. He too said that he did not have much experience in academic writing in his home country, in South Asia, before he came to the US more than two decades ago. Dr. B responded to my questions relatively concisely and to the point. His ideas about language and writing were so nuanced that he often sounded like an English professor. He did strongly support the idea that there should be a universal standard variety of English in academic writing; but his stated beliefs and teaching

\footnotetext{
${ }^{10}$ I have not specified the national backgrounds of the faculty members to ensure anonymity; whereas the students were mostly from the same country, China, the teachers were from separate countries. More importantly, while prior educational and professional backgrounds might have influenced the participants' views about language and writing and therefore those factors could be considered relevant in the introduction of the participants, the implications of those factors are outside of the primary focus as well as scope of this study.
} 
practices did not jibe well because he was also significantly tolerant of varieties and variations in language use. In fact, when I followed up some of his responses in later interviews, he essentially shared views such as engineering writing being rhetorical writing. So, Dr. B was the least monolingualist in his views about language and writing.

\section{Dr. X.}

Dr. X was a younger professor who had joined the current university about six years ago. He expressed quite idiosyncratic opinions about language and writing, and he emphasized that he was a "non-conformist professor" whose ideas about writing do not align very well with those of his colleagues. Dr. X also said that he did not have any significant experience of academic writing in his home country in South Asia before he came to the US about ten years ago. He provided extensive support to his students on a daily basis, but that support did not involve helping them learn how to write very often. He said he mainly put pressure so that his students would write often enough and thereby improve their writing. For instance, he said that students can learn to write if they are required to present good writing in order to ensure their funding for graduate studies, adding, "It's like Pavlov's dog, you know." He said that successful writers in his discipline are "like creative writers" but also stated that basic language and writing skills are sufficient for the rest of engineering faculty and students.

\section{Dr. Y.}

Dr. Y was from South America and had received his graduate degrees from the US; he had been teaching at his current university for almost a decade. He also provided close attention and regular support to his students, but this support did not include helping the students to write. He emphasized on oral presentation and believed that 
students learn to write if they keep presenting their ideas orally (that is understand the concept clearly) and keep reading relevant scholarship. He required writing of his students only toward the end of their degrees when it was time for them to start working on their theses or dissertations. Dr. Y's responses about writing were also characterized by the same striking monolingual beliefs with regard to a universal, simple and clear English; but he greatly empathized with the NNES students, considering himself "in the same boat."

\section{Dr. Z.}

Dr. $Z$ was the most experienced scholar among the participants. Having been in the US since the mid-1970s when he came for undergraduate studies from the Middle East, he spoke with almost no trace of an accent from the English from his national background. But interestingly, he also supported monolingual standards most explicitly and strongly. Similarly, he defined language with a great emphasis on grammar and writing with a similar emphasis on correct and standard English. Accordingly, his key suggestion for improving the current state of writing among engineering students was for the faculty to assess their writing more often, which he said takes a great deal of time. Showing a shelf full of master's theses written by his students over the years, he asserted that engineering students do write and also get their work corrected before they submitted for the record. But Dr. $Z$ did not seem to invest his time teaching or otherwise helping his students how to write; it seemed that for him, this was the responsibility of the writing center or writing courses. 


\section{Data Analysis}

The approach that I took for analyzing the data is a combination of strategies drawn from grounded theory and general strategies of rhetorical analysis. The grounded theory approach is one that allows the researcher to build theory out of the data rather than using an opposite process. In their book Basics of qualitative study: Techniques and procedures for developing grounded theory, Strauss and Corbin (1990) state that a grounded theorist must be able to "step back and critically analyze situations" (7). In a demonstration of this approach as applied in his dissertation study about the challenges he faced while conducting a WID research of NNES graduate students' writing practices, Hu (2009) describes the benefits and challenges of the grounded theory approach. Hu's study gradually evolved - because participants graduated, research tools did not fit the changing population, the researcher was a learner so his data collection methods were also recursively developed, and the researcher benefited from using an "elastic" research design. Another illustration of this approach is a dissertation study that is elaborately described by Sokladiris (2009) in an article titled "The process of conducting qualitative grounded theory research for a doctoral thesis: Experiences and reflections." This article provides philosophical and theoretical bases as well as how the researcher faced and solved problems in the process of the study. Emulating the adaptation of the grounded theory approach by $\mathrm{Hu}$ and Sokladiris, I analyzed data by consciously remaining open to the possibility of the data reshaping the course of the research, helping me pursue multiple hypotheses, and letting the theorizing evolve with a sound basis on the findings. This approach helped me to recognize the disciplinary difference in how the participants view and practice the teaching and learning of writing; it also made me self-critical about 
my own beliefs and knowledge about academic writing as a composition scholar, as well as willing to explore the validity of different views and approaches to writing. It also allowed me to draw insights from relevant literature.

I supplemented rhetorical analysis to the strategy of comparing/contrasting that grounded theory encourages because the use of rhetorical analysis helped me even better explore the patterns in the data. As a student of rhetoric and composition, and as someone with a background in stylistics, I found rhetorical analysis a rich additional tool that helped me explain the meaning and implication of language in context, with an awareness of the audience, purpose, ethos, and so on.

\section{Comparison}

The discussions and demonstrations in the rest of this work are based on relative distinctions in the writing proficiencies of the students and the views and approaches to teaching writing among the faculty. The distinctions constitute a methodological device for highlighting views and approaches that are more or less effective; they are also the basis for the framework for promoting writing in engineering that I propose in the penultimate chapter and the specific recommendations that I offer in the final chapter. In light of the importance of the distinctions in the analyses of data throughout the rest of this work, let me illustrate the device with a few writing samples.

The first set of samples was collected as prompts for the first round of interviews, but these samples also highlighted the difference in language and writing proficiencies of the students and the discussions based on the samples helped me gather what approaches the students (and their advisers) took to writing. The writing-confident students not only provided more polished writing but also multiple drafts of the same writing (including 
suggestions using track change from their advisers). In contrast, the samples of the writing-anxious students were unclear because they did not contain clear rhetorical moves and effective organization. In the case of the writing-confident students, their writing contained non-standard features at the levels of grammar and syntax; these samples were characterized by seemingly deliberate steps such as establishing the context, identifying the focus, and then proposing a solution. Here is, for instance, the first paragraph of the "background" section of an unrevised draft provided by Student A: Fluorophore is an important tool in many areas of biotechnology and medical application, such as diagnostic imaging, biosensing, and etc. However, some of the limits of these applications are: (1) for in vivo bioimaging, only a few ... (2) in some cases of sensing, the target molecule is at extremely low .... Therefore, artificial fluorescence enhancement is highly desired.

As the underlined phrases indicate, Student A first "acknowledges" an existing technology for achieving a certain goal, then shows some limits of it (identifying a gap), and then proposes an alternative to the current approach. In the paragraphs that follow, she reviews relevant literature (citing them properly) and then elaborates on her own proposition. Her revised writing samples were even more polished and effective.

Student B also provided both rough drafts and revised versions, including a draft with track change suggestions by her adviser; the track changes demonstrate the kinds of support that her adviser said that he provides to his students with their writing. Underlined words were added and those that were struck through were deleted in the original. 
This thesis compares the key performance measurements in manufacturing measures of DRS and MRP-based scheduling systems. We start from begin with a single-machine problem and develop simulation models for varying levels of uncertainty in forecast demand (i.e. base demand scenario, under-estimated scenario and over-estimated scenario) and levels of variability in the system (i.e. moderate variability and without no variability).

The suggested changes indicate that Student B's adviser was helping her at the level of editing the draft for publication; but other samples showed that Student B was a careful and expert writer who focused not just on content but in effectively conveying it to the readers.

In contrast, the writing-anxious students' writing samples showed lower proficiency in language and also a seeming lack of attention to the organization and presentation of detail. Here is, for instance, an excerpt from the introduction section of the sample that Student X provided:

Different actuation kinds of nano-gripper and nano-tweezer are stated first and be explained, it includes electrostatic actuation, electro-thermal actuation.... Then talk about advantages and disadvantages of each. ...

Following, different kinds of nano grippers' and nano-tweezers' materials and the fabrication method are stated. For example, some groups use $\ldots$ to do inplane move; Some groups use two ... multi-wall CNT; Also some MEMS nanogripper/tweezer and applications are reported. There detailed work and some 
results will be shown. This report will also show some advantages and disadvantages of these different kind devices.

How many works it can be done by using nano-gripper/tweezer? Show some work before.

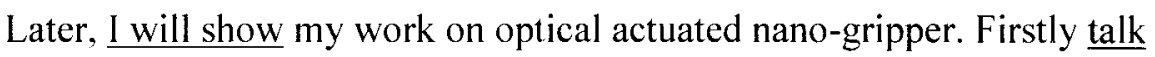
about the photo-actuation and the fabrication process, and then show package process and characterizing. Some electrochemical and electrical measurement will be discussed. Compared with other types of nano-gripper/tweezer, it will show advantages of optically actuated nano-gripper. Finally also talk about future work. (emphasis indicates shift in active/passive or related syntax)

During the interview that followed, I asked Student $\mathrm{X}$ why he used passive voice in the first paragraph, instruction-like syntax in the second, and then a combination of active/passive as well as tense and even it-cleft syntax in the rest of the section. To my surprise, he said that he makes such variations in style in order to make his writing "beautiful." He added that his English teachers in school and college in China had taught him to use such variations in order to make writing more interesting to read. When asked if he had received any feedback from his adviser or anyone else about this issue in his writing, he said that that had not yet happened. The samples that Student $\mathrm{Y}$ and $\mathrm{Z}$ provided also showed better language proficiencies but a similar lack of focus on organizing and presenting the content effectively.

As already indicated in the introduction of the student participants above, the students' language proficiency and writing skills are even more distinct in the sample emails that they provided. The emails of the writing-confident students showed much 
greater range of rhetorical skills besides just the ability (and possibly a desire) to simply represent the content in simple English. Using language to communicate with an immediate audience seemed to boost these students' competence and confidence, consequently helping them to write better academically. For example, in an email that Student A wrote to an equipment company named "BIC" in 2008 , she uses elaborate details, explaining the problem, clarifying what she understands and what she doesn't about it, and then asking specific and clear questions of the salesperson. Here is part of that email:

I am using the particle size analyzer 90 Plus from your company, and it is working very well with my gold nano particle samples. However, I got some new samples recently. It is gold particles linked with fluorophore (with Ex 780 $\mathrm{nm}$, Em $830 \mathrm{~nm}$ ). The analyzer seems not giving [sic] correct result for these samples with fluorophore in it. I know that the analyzer measures the light scattering information, so when there is fluorophore in the sample, it might disturb the size analysis. I don't know very well about the principle that [sic] the analyzer works, so I would like to have some suggestions from you. Do you think the particle analyzer can work with the sample that has fluorohpore? or is there anything I can do to remove this disturbance caused by the fluorophore? Thank you very much!

[Student A]

PhD Student, [...] Engineering University of $[\ldots]$ 
In a more recent email (written on May 22, 2011), she begins with the salutation, "Hi" and first name of the recipient, organizes the information very effectively, and writes in a confident voice. The body of the email starts with the problem, goes on to describe the experiments that she had conducted and highlights its success so far, and concludes with a call to action: "Would you please let us know whether you think this plan is reasonable/practical or not, and what your thoughts are on this?" Student A told me that she learned the discourse of her discipline not just by reading and writing academic literature but by engaging in practical communication during meetings, when writing and responding to emails, and so on:

... by writing emails, or communicating with people, you feel that they are understanding you, and that's encouraging. And a lot of the emails, when you communicate with your professors, you know that you are making a point and they understand what you are saying. (Student A)

The emails written by Student B, another competent and confident writer, showed similar engagement with writing for professional purposes that went beyond her academic work. Her emails were elaborate, she used a strong personal voice in her emails, and her writing demonstrated the desire that she expressed for using language within a broader scope encompassing personal, social, academic, and professional contexts. Student B also emphasized the support and opportunity to take responsibility that her professor gave. When asked if she had anything else to add about her experience as a student in her program, she emphasized that she was grateful for the amount of time given by her professor, who she said was an extremely prestigious and extremely busy professor in engineering. "I like it's very fortunate to be in this department." She said that Dr. B was 
always sure to give her the feedback and support that she needed whenever she had a writing-intensive project: "Yeah, support [is good], because when you want, when you finish writing something, definitely you want some good feedback. You feel like okay your work is valuable."

In contrast to Student $\mathrm{A}$ and Student B, the emails provided by the three other students did not show that they were engaged in professional communication more broadly. Here is, for instance, an email that represents the writing of Student X.

Dear Dr. [X],

I redo a sample with $0.5 \mathrm{wt} \% \mathrm{MWNT}$ with light treated and update the figure.

In Figure 3, I have a note there which may be interesting.

Thanks,

[Student X]

As Student $X$ had told me in his interview, he has used images (evidently attached to the email) as the primary means for conveying his point. The email itself is not only vague in its language, it is severely lacks detail, considering the nature of the subject. While the writer refers to a note in the figure, there is no detail or explanation, nor a clear sense of context and next step. It is possible that the brevity of his emails represent his personality more than they do his resistance to write substantively, but these emails do confirm what Student $\mathrm{X}$ said about writing during the interview. Student $\mathrm{Y}$ sent me a sample writing from a course in lieu of email and Student Z's email samples showed a lack of detail, effective rhetorical moves, and engagement with the audience, as did Student X's emails.

Generally, these writing samples indicate that when students are engaged in writing and communication in practical contexts like conducting the business of their lab 
by using email, they are more likely to develop their language and the confidence to use it in all kinds of contexts including academic writing in the future. Observing these samples largely confirmed what they said about language learning and writing as well as their emotional and intellectual responses towards language and writing during the interviews.

\section{Language Variation}

At the heart of this study is the research question as to how NNES engineering faculty and students in US universities as multilingual individuals in a monolingual discipline respond to language variation as a specific function of how they define language and writing as members of their discipline and profession. So, it seems worth briefly defining and illustrating what that variation is and what significance the participants' attitude toward it has in the larger context of teaching, learning, and engaging in academic communication.

As an example, let me use the first sentence from Student X's writing sample that I quoted extensively above. I had a long discussion about the use of "be" in that sentence: "Different actuation kinds of nano-gripper and nano-tweezer are stated first and be explained, it includes electrostatic actuation, electro-thermal actuation." Student X said that he was taught to use "be" as an acceptable variation of other "be" verbs in passive constructions like this. This variant use of "be" could be seen from a number of different perspectives. Let me use the four types of attitudes toward language variation that Horner and $\mathrm{Lu}$ (2007) present in their article. From an "eradicationist" perspective, this is simply an error and must be removed/replaced with a grammatically correct, standard English version. From the perspective of language acquisition, this is a manifestation of a 
misapplication of a grammatical rule - whether it is done by an individual or by a whole community (Student $\mathrm{X}$ suggested that this was acceptable in the school and college that he went to in China). From the third, accommodationist perspective that Horner and Lu have identified, this difference is a matter of "discourse clash" between a dominant standard English discourse and the discourse that is acceptable to a different variety of English that a community outside of the mainstream uses; Student X's usage doesn't have the privilege to be considered "standard" or else it would be acceptable as a synonymous or variant usage. Finally, from a multilingual perspective, Student $\mathrm{X}$ is meshing two kinds of codes (whether or not he is fully conscious about them) and so this could be considered the basis or manifestation of a new kind of usage or variety. So, how we look at variant forms is not just a black and white issue of correct and incorrect language use. Furthermore, in the context of this study, language variation like this are significant from educational/pedagogical and policy/political perspectives. From an educational perspective, it is not enough to simply call this an error, tell the student to correct it, and/or reject his/her writing based on such variations. Even as an observation of this relatively simple variation shows, the writing of every individual (even NES) will include very complex and subtle variations that cannot be assessed with just the first lens of "error" but must be seen from the second, third, and fourth perspectives. Within the brief passage from Student X's writing that was quoted above, there is a kind of spectrum of variations ranging from what is clearly an error that the writer himself would correct when pointed out to stylistic differences for which he had very convincing rhetorical explanations. In fact, some of the more subtle interferences of different varieties of English also inevitably characterize the writing style of even the most seasoned writers in 
engineering. Here is, for example, how one of the faculty participants corrected the title of his student's work; the correction seems more precise in its wording but it seems less "standardized" in its grammar and syntax.

Original: "Quantifying the Cost and Benefits of ...: A Simulation Case Study" Updated by the faculty: "A Simulation Case Study to Quantify the Impact of ..." The updated version either has a missing verb ("done") or it has replaced a more "correct" present participle "quantifying" with a to-infinite form. It is not easy to tell why the revision was made in this way, but what is worth considering is whether the slight variation in the syntax is acceptable to the writer and his/her audience in that particular discipline or discourse community.

As I will argue in later chapters, when scholars and teachers of language and writing are faced with the spectrum of variations ranging from obvious errors to established/acceptable differences, they need to look at those variations from multiple perspectives (for an illustration of how language variation can be a great teaching moment, see Lu, 1994). For this reason, when the participants of this study "stated" that they only accept a simple, clear, and universally consistent standard English in academic writing, they were not describing the reality of their own writing but restating their belief about the subject. Being conscious of this paradox would not only help them correct their students' writing where correction is deserved but it would also enhance their understanding and appreciation of the variability of language use and its potential for richer expressions. At the very least, if the engineering faculty had a more nuanced view of language variation than just the black and white distinction of error versus correctness, they would not discourage their students by calling them "horrible writers" (as three of 
the five faculty participants thought that Chinese international students generally tend to be) as the NNES students transition from the variant usage of their past to the more standard usage that they are learning.

\section{Outline of Chapters}

As an introduction to the study, this chapter has situated the subject of this study in relevant scholarship, discussed the significance of the specific topic, and described the methodology of data collection and analysis. In Chapter Two, I pause to review the relevant scholarship and also further elaborate some of the prevalent beliefs and ideologies regarding language and writing that are prevalent in engineering. I analyze data from the study to demonstrate the prevalent monolingualism in engineering.

Chapter Three is a discussion of the ideology and politics of monolingualism in engineering with a focus on multilingual faculty and students. In this chapter, I use the perspectives of agency and authority vis-à-vis disciplinary and professional incentives in an attempt to discuss why NNES, multilingual engineering faculty and students subscribe to the prevailing monolingual discourses in the discipline. Drawing primarily on the works of scholars like Horner and Lu (2007), this chapter explains the monolingualism among multilingual scholars as a matter of disciplinary and professional dynamics.

In Chapter Four, I develop a framework for addressing the problems described in Chapter Three and Chapter Four. I propose that in order to promote the explicit teaching and learning of writing in engineering, it is first all necessary to understand the perspectives of engineering scholars and students as the stakeholders, as well as their context and constraints. I argue that it is not enough for WID research to provide analysis and discussion of the problem; it needs to develop solutions and find ways to build upon 
best practices in the academic disciplines. Solutions to the prevailing monolingualism and undervaluing of writing in engineering need to begin by bridging the "cultural" gap between members of the engineering and writing disciplines. Recognizing perceptions and practices on the ground makes it easier to promote more critical views about language as well as more realistic practices for promoting writing in the discipline.

The conclusion, Chapter Five focuses on solutions and recommendations. I highlight some of the best practices that I found among the faculty members who participated in this study, point out key obstacles and how they can be overcome, and offer a number of practical strategies that writing programs and also engineering faculty can adopt for promoting academic writing, as well as for cultivating more realistic, accurate, and nuanced views about language and writing in this discipline. 


\section{CHAPTER 2}

\section{DISCOURSES ABOUT LANGUAGE AND WRITING IN ENGINEERING}

"It's not about, you know, Jane Austen's writing, it is about what the fact is and how much accurate it is. " - Dr. A, in response to what she considered the most important quality of writing in her discipline

As briefly mentioned in the first chapter, scholarship on engineering writing has demonstrated that engineering faculty and students generally subscribe to what Rose (1985) and Russell $(1991,2007)$ have called the "myth of transparency" " about language and the "myth of transience" 12 about writing. Following the lead of Rose and Russell as two of the most prominent scholars of Writing in the Disciplines (WID), current literature on engineering writing continues to show that as a consequence of these beliefs, engineering faculty and students consider it unnecessary to explicitly teach or learn language and writing skills (Winsor, 2000, 2003; Zhu, 2004; Leydens, 2008; Jordan \& Kedrowicz, 2011; Carter et al., 2011). This scholarship highlights that engineering graduate students are a subject of complaints among employers due to low levels of proficiency in writing and communication skills (Conrad et al., 2009); most engineering faculty do not give much priority to the teaching and learning of writing because they do not typically consider it integral to engineering education or necessary to teach it because students can learn it on their own (Krase, 2007; Kranov, 2009). As Winsor (2003) pointed out, engineering scholars do not consider the language and writing used in their

\footnotetext{
"the belief that language is a transparent medium for encoding thought

${ }^{12}$ the belief that academic writing is a discrete skill that students either learn before or do so automatically while learning the content of a discipline
} 
discipline to be complex and rhetorical; they do not think that their writing involves interpretation of facts, use of arguments to persuade others, or use of language to represent reality in ways that are shaped by context-specific discourses and perspectives. Based on the "epistemologies and ideologies of their disciplinary community" (7), they view writing as a rather straightforward recording of thought.

But the fact that successful writing in engineering programs especially at the graduate level does require high levels of rhetorical skills, complex language, and a variety of genre conventions means that engineering students are ill-equipped to meet those requirements. Unfortunately, because they too subscribe to the same reductive views about language, many students face failure and frustration when required to write. Describing a dysfunctional project team of engineering students, Burnett (1996) showed how the students did not consider writing as necessary or useful in helping them explore, consolidate, and represent their learning until there was a crisis in the collaboration and project completion. Burnett suggested that the lack of appreciation for the role of writing in producing and communicating knowledge is characteristic of engineering as a discipline.

In this chapter, I discuss a few significant discourses about language and writing that seem to serve as roadblocks against cultivating more accurate and complex views about language and writing among the participants. This chapter is meant to develop the first of the two important arguments about the prevalence of monolingualism among multilingual faculty and students in engineering ${ }^{13}$ : it describes and illustrates three specific ideologies that influence how engineering scholars, seemingly regardless of

\footnotetext{
${ }^{13}$ The next chapter will focus on how the monolingual ideologies play themselves out in the context of NNES faculty being in positions of authority and how they also influence the NNES students' views about and approaches to writing.
} 
whether they are multilingual or not, view and approach writing. In doing this, I argue that the beliefs about language and writing may be problematic but they are also at the heart of engineering scholars' and their students' sense of professional identity and epistemological worldview as engineers; for this reason, I address the need to recognize this reality in Chapter Four and Five.

\section{The myth of Transparency: Engineering Writing is clear Writing}

The participants of this study generally believed and demanded that engineering writing needs to use clear and universally consistent norms of "technical" and standard academic English. Their expectation of transparent language and simple writing comes from their subscription to the prevailing worldview about language and writing in their discipline. According to Russell $(1991,2007)$ this worldview historically emanated from how higher education has been structured and has developed since the establishment of universities within the industrial model of departments and specialization. The modern "mass-education system in America created to train [the] cadre of professionals [has historically] failed to adjust its concept of writing to account for the fact that both writing and education [have] been transformed" (5), In reality, writing has changed from what was supposed to be a "single, generalizable skill learned once and for all" to a "complex and continuously developing response to specialized text-based discourse communities" (ibid.) However,

Despite [the] profound changes [in the real world], the mass education system [has] tenaciously clung to the outmoded conception of writing as transcribed speech and to the vanishing ideal of a single academic community, united by common values, goals, and standards of discourse. . . One important result [of 
the clinging to outmoded concepts about what constitutes academic writing and other activities is] a conceptual split between 'content' and expression,' learning and writing. If writing was an elementary, mechanical skill, then it had no direct relation to the goals of instruction and could be relegated to the margins of a course...."(5)

Similarly, in Writing like an engineer: A rhetorical education, Winsor (1996) showed how engineering students do not think that their written communications constitute arguments which their readers would interpret based on their prior knowledge and perceptions about the subject; the engineering students in Winsor's study believed that they were simply conveying the data or describing the reality because that is how the epistemologies and ideologies of their disciplinary communities have shaped their understanding of the function of writing. Thus, the demand for clarity is based on the belief about reality as independent of language and discourse.

We [scholars in the humanities] accept the idea that our knowledge is shaped by our language. But this view of language and writing is not necessarily accepted in other parts of our campuses, as those of us who teach engineers, for example, can attest. ... engineers tend not only to see their own knowledge as coming directly from physical reality without textual mediation, but also to devalue the texts engineers themselves produce, seeing them as simple write-ups of information found elsewhere. (Winsor, 2000; p. 58)

This view of language and writing vis-à-vis communicating any idea in engineering undergirds the belief that the same simple and clear language can serve the purpose of expressing any levels of complexity in that content. 
When conducting the first round of interviews, just to get started, I asked the participants what they considered the most important quality of writing, a quality that they valued most highly or advised others to follow while writing in their discipline. Most of the participants used to the word "clear" or a synonym of it to characterize good writing in response to this question. From Student X, a student who had limited experience writing in English, to Dr. Z, who came to the US at the age of seventeen almost forty years ago, these engineering students and scholars considered "clarity" a prime quality of good writing. For example, Student X said: "Uh, there are two parts. The first part is how to have good image[s]. The second part is explain very clearly the experiment stages. These two is what I focus on." I will discuss the subject of using pictures as part of the emphasis on object-oriented communication later on; but what Student X called the need to "explain very clearly the experiment stages" aligns with the idea that engineering writing is made effective by avoiding complex language at all costs. In another striking response, Student A more explicitly separated language from content and deprioritized language against content/logic.

Student A: I would say, like, language is not the most difficult part. The difficult part is probably the logic and how to explain a complicated system very concisely and very clearly.

Student A started by suggesting that language is not the most difficult aspect of writing to her-a move that somewhat separates the content of writing from the language that conveys that content - she essentially argued that understanding the content automatically leads to good writing. For most participants, both faculty and students, clarity and conciseness of language came not from a writer's ability to handle both 
complex logic/content and complex language but from the ability to express one without the other. That seems to be why language is "not the most difficult part," for if a writer just focuses on the logic, the language takes care of itself. The inevitable increase in the demand for complex language for expressing increasingly complex thought seemed to elide most of the participants. Thus, as members of a discourse community that views language as transparent and as something that must be kept from escaping into the realm of complexity, both Student $\mathrm{X}$ and Student A first separate language from the visual or logical contents of their work and then demand that language to remain simple and unencumbered of anything like rhetoric.

The faculty members shared more complex responses to many other issues during the interviews, but when it came to this question about the quality of good writing, their responses, too, boiled down to the fundamental notion of clarity. Dr. B, for instance, used a variety of terms related to "clarity" in response to the question about the best quality of engineering writing:

Dr. B: Yeah, I tell them to keep their writing very, uh, simple, because they need to be able to convey their ideas in a very succinct manner, but also keep it simple, just say it like what it is. Start out with what the problem is, how they approach it, how they solve it, what the results are. Just keep discussion at a simple level, that's what I tend to--[tell them].

All of the underlined words in the response above have "simplicity" and the notion of transparency as their connotative common denominator. On top of words like "simple" and "succinct," the expression "say it like what it is" points to the "what" of the logical core that the screen of language is expected to not block. 
As Rude (1992) pointed out, this ideology of clarity is generally used for defending science against the muddy rhetorical language of the humanities. This defense of the objectivity of science against the vagaries of language was manifest in response to a variety of questions and instances when the participants directly or indirectly defined language used in engineering writing. Barnard (2010) has discussed the prevalence of a similar ideology of clarity in the humanities as a defense against the tendency of critical theory to be overly complex; the same kind of ideology is prevalent in engineering in defense of "scientific" writing against the language of the social sciences. The problem with this view is that it creates a discourse that denies the reality about the complexity of language in engineering writing. The tendency to define language and writing defensively was more prominent in earlier interviews, when, for instance, Dr. A described engineering writing in juxtaposition to how she believed members of other disciplines like English defined writing. Hence, Dr. A's response to my request to describe effective writing in engineering: she said, "it's not about, you know, Jane Austen's writing." In a certain sense, and in the engineers' point of view, clarity in scientific writing is a laudable aim in itself. For instance,

Dr. Z: I would tell my students that the way they should write, and that's the way I try to write, is: make it as clear as possible, as concise as possible, and I always tell my students, for example, when they are writing a thesis, they're describing their experiment or something that they did, I say just put yourself in the place of someone who's reading this, and your description for someone who has not done this before, not as experienced in this field as you are, should be as clear to that person. I think that's what I tell them. I think good writing in my discipline would 
be, in my opinion, written very clearly, short sentence, simple way, simple writing, and concise. (emphasis added)

What such a view of language leaves out is the basic fact that clarity does not come just from using a simple language: clarity comes from a writer's proficiency at handling the level of complexity in the content of writing relative to his or her mastery of the language that is needed to express that complex content. As Barnard (2010) urges, the insistence on clarity raises the question as to " $[\mathrm{w}]$ hat travels under the sign of 'clarity' ...? What is foreclosed by the insistence on parochial standards of transparency as requisite for all communication? What does 'transparency' keep obscure?" (441). The belief about clarity is inherently ideological because it favors the language of certain groups, help maintain a certain sociolinguistic structure within the profession, and can potentially regulate access and privilege to the profession. But for engineering scholars, this view of language is a necessary one: simple and clear English is necessary for precise and objective representation of scientific knowledge.

As scientists and engineers would argue, the demand for clarity is nothing but a practical and logical necessity. But the demand becomes problematic because it shapes the teaching and learning of academic writing.

\section{The Monolingual Myth: Standard English as Universal in Technical Writing}

The ideology of clarity shapes how engineering scholars define writing, apparently regardless of their language identity and sociolinguistic experiences and abilities. Thus the beliefs that a simplified standard English is a necessity for effective scientific communication trumps even multilingual scholars' rich experiences with variability and complexity of languages. As a result, NNES scholars and students also 
subscribe to the idea that clear language of technical writing is one and the same in all contexts, purposes, genres of writing in their discipline. As Turner (1999) pointed out in "Academic literacy and the discourse of transparency," the assumption that clarity of understanding and transparency of language converge leads to this paradoxical belief that a simple and standardized universal English is a sufficient and desirable means for communicating highly advanced scientific research done in any material, social, and cultural settings.

During the final round of interviews, I explicitly asked the faculty members why even as multilingual scholars they believed in and demanded a universal monolingual English standard. Their explanations were quite simple: English is a universal language of science and only standard English is appropriate for academic writing because it is most clear and precise.

Dr. X: So, yeah, you want to gravitate towards one linguistic style, because it is simple and everybody can understand that, whoever reads your work. And English is a universal language, I mean everybody understands and everybody is forced to gravitate towards English. Yes, of course, you can have someone from Thailand, or from South America, have their own linguistic practices. But if their work is not going to be accepted because of the fact that they have not actually presented their ideas in English. ...

The acceptance of English as a "global" language of scientific communication was almost absolute among all the participants. This finding seemed quite surprising at first because the participants were scholars and students who used recognized varieties of world Englishes. 
The participants were not unaware about the different varieties of world Englishes and some of them even acknowledged that NNES writers bring in different writing styles as well as different varieties of English. But they still insisted that there is one universal standard of language and style in scientific writing.

Dr. A: Well, because we are in the science field, or applied science, one needs to know about technical writing aspects of writing. It's basically technical writing, [so] it has to be concise, accurate, straightforward. So, writing is not about, to me, it's not about English.... It's more about the thought process.

By shifting the focus from language to "thought process," Dr. A not only denied language variation a place in engineering writing but also downplayed the importance of language and relation to the content/logic of that writing.

The relatively hardline explanation of this monolingualism is that it is a byproduct of a political mechanism designed to impose the language of the socio-economically powerful groups upon other groups in an attempt to prevent their languages, cultures, and epistemologies from gaining equal status in society and the professions. Viewed from this perspective, the NNES scholars' enforcement of monolingual standard of academic English is a perfect example of social hegemony where marginalized groups seek to exert power by accepting the same dominant mechanism of hierarchy of power. This kind of ideological explanation would seem to be irrelevant in the case of NNES scholars; but since the findings of this study clearly showed that NNES scholars who have the privilege of joining the elite community of global academic and professional communities in countries like the United States adopt and enforce the monolithic linguistic worldview upon their disciplines and professions. Here is another response 
from Dr. B who seemed to confirm that a hegemonic structure is inevitable and also desirable.

Dr. B: So, it's this argument between melting pot and a mosaic, right, about culture. So, you can't have a mosaic in writing. You just wouldn't-- maybe there is instead a melting pot, [even though] the pot changes ever so slowly.

Shyam: So, [are you saying that] the mosaic didn't work, or can't function in writing?

Dr. B: Not in writing, I don't think.

An experienced professor, Dr. B asserted that the idea that the society is a "mosaic" of different cultures and linguistic varieties does not work in the case of writing, especially "technical writing" as a globally standardized practice. His point is that while the idea of a social and cultural mosaic may be relevant to other spheres of life, academic and professional communities must function as melting pots where the content changes very slowly, if at all; hence, academic writing rarely changes or deviates from the standard.

From a different, less critical perspective, it could be argued that this discourse about the failure of the mosaic and persistence of the melting pot has less to do with the pragmatics of engineering as a discipline that needs to represent knowledge as objectively as possible and more to do with the power dynamism in its discourse community. Referring to Giroux's article, McLure writes in her article "Clarity bordering on stupidity: Where is the quality in systematic review," that calls for clarity are "never innocent" $(2005 ; 395)$. Critiquing the British scientific community's launching of what is called the "systematic review," an attempt to implement a universal and discipline-neutral scientific review mechanism, McLure argues that the calls for clarity are "usually issued 
by powerful discourse communities acting as if their worldview is 'transcendental': that is, existing 'outside history, language [and] context', while everyone else's is partial and limited" (ibid). Critiques like McLure's expose the power dynamism behind the discourse of clarity from the perspective of how disciplinary and professional communities maintain structures of power and privilege. This view considers power as an unavoidable component of how any community works.

In a discussion about language difference, Canagarajah (2006b, 2009) has optimistically suggested the possibility of different varieties of world Englishes becoming increasingly accepted. In his article "Pluralization continued: The place of world Englishes in composition," he considers that possibility from a demographic perspective: "At its most shocking, this [rise in the number of multilingual English users in the world] gives the audacity for the multilingual speakers of English to challenge the traditional language norms and standards of the 'native speaker' communities" (589). Canagarajah does consider the issue of NNES users' act of opting for standard English as an "ideologically favored action," but the argument that the increase in English speaking population will naturally lead to the challenging of monolingual norms seems to be inadequate in accounting for the political forces that shape language choices. The fact that English is a "plural language that embodies multiple norms and standards" (589) in the world outside seems insufficient to project that a similar situation may come about within academic and professional communities. Indeed, even in the context of teaching writing within the humanities, Canagarajah was not sure "how to practice what I preach" (613). 
NNES scholars may accept language diversity in certain types of contexts like day to day conversations among, and they may indeed appreciate English as a "plural" language outside the academia; but the myths about monolingual standard seems to be fully justified and even appealing to them within the academic domain. In fact, because engineering scholars generally consider language variations as either "error" or insignificant differences between varieties of English, demographic diversification is unlikely to cause linguistic diversification on its own or any time soon.

\section{The Myth of Transience: Writing “Happens"}

The myths about clarity and universality of standard academic English lead to a third myth that is equally prevalent in engineering: the myth of "transience" or the belief that academic writing is a discrete skill that new members of a discipline should learn either before entering higher education or can do so on their own while learning the content of the discipline (Rose, 1985; Russell, 1991, 2007). This view defines writing as a generalized skill that can be acquired once and for all.

The myth of transience manifested in the following ways in the NNES scholars' response to my question about how NNES students learn to write: (i) if students focus on the "logic" and content of the discipline, the challenges with writing gradually but automatically disappear, and (ii) NNES students can overcome their challenges with writing in their disciplines by learning standard English, and (iii) NNES students become successful writers by eliminating any variations in their language. Here is, for example, Dr. A's suggestion that learning how to write well in engineering is a matter of just being in an English speaking academic community or society for a certain period of time: 
Shyam: Yeah, you were talking about the--.... students from far eastern Asia have different kinds of patterns.

Dr. A: Yes. But I think those can be overcome probably within five years, assuming that five years is their $\mathrm{PhD}$ training. We don't use--I mean I am from [...], so, we don't use articles as much as, [or] accurately as, Americans do, and then sometimes I would ask Americans okay when do I use "the" and "a" and no plural. They wouldn't be able to answer, usually. It's just by, you know, by staying in America... using this language forever, you just automatically know about it. I kind of got the idea [about the articles] but sometimes it's not really clear.

Dr. A suggested that standard English is learned through the elimination of language variations, which she seemed to identify with "errors." She also suggested that this gradual learning of the standard automatically happens by "staying in America" or continued exposure to standard English.

The larger context of the above exchange with Dr. A was about how she responded to language variations, or different world Englishes, that students from different backgrounds may use in their writing. Her response was basically that other than minor issues like articles, other differences, which seem to be synonymous with error, must and will be gradually eliminated. The same seemed to be true of writing as well: the correct way to write is learned "automatically" in the process of learning the content in the new environment. In the opinion of another faculty member, writing is learned through reading the works of established authors in the discipline: 
Dr. Z: Yes. And you can improve your writing by reading more. But specifically you are questioning about non-native writers. Well, one thing I would tell them is to go to the Writing Center to get help, and I tell them to basically listen to the advice that they receive. And if their work has improved, I want them to pay attention to what happened, what happened, what caused the improvement, so they can learn themselves.

Dr. $Z$ also suggested that students also learn to write by reflecting on their writing, as from the advice that they get from writing tutors. Bu the fact that Dr. Z saw the writing center support as intended for fixing language issues situates his view of writing and the writing center squarely within the myths of transparency and of transience.

The latter two of the above views are of particular relevance to this study because they are connected to the other myth about language (that of "transparency") in that the challenges and complexities of writing, too, are issues to be overcome and left behind, rather than engaged. The first two views seem to influence engineering scholars, whether NNES or NES, in the ways that Rose and Russell have described; the latter two views are more significant in the case of NNES scholars because their belief that scientific writing has little or nothing to do with learning the conventions of the specific academic culture of US universities (because the conventions of scientific writing, like technical English, are universal) has the consequence of obscuring the need to teach NNES students those conventions. In fact, by believing that conventions of scientific writing are universal, the students themselves simply desired to eliminate any features of their previous writing conventions as deficiencies or errors in favor of learning the correct and universal conventions of scientific writing. The monolingual myth prevents both NNES students 
and faculty from recognizing potentially positive resources that writers from different academic, linguistic, and cultural backgrounds could add to their writing in the discipline. The idea that students can pick up language and writing skills necessary for pursuing advanced degrees in intuitive and automatic manners, and furthermore the idea (among some of the participants) that this picking up can happen "very quickly" and without any explicit instruction can aggravate the challenges faced by students who enter graduate programs in an academe that demands very high levels of linguistic and discipline-specific writing skills from the students. All the faculty members who participated in this study did agree that it is necessary to provide the NNES students more opportunities and resources to help them develop their writing skills. However, those who provided support to their students did so not because they acknowledged that learning to write takes a challenging and gradual process but because doing so benefited the students immediately and in the long run.

Some of the faculty were actually concerned about the lack of interest in writing among their fellow engineering teachers as well as among the students. For instance, Dr. $\mathrm{X}$ said that there is a serious lack of interest or efforts to improve student writing in engineering:

Shyam: So if they don't care, they don't do it or teach it, and there's not much discourse about teaching writing, how is good writing defined? Is that definition explicit?

Dr. X: No there is no definition of good writing in our technical disciplines. You either say this is a good paper or you say it is a bad paper. And journal papers that are published, they have some basic standards for writing. As long as you need 
those basic standards, as long as it looks good, you basically think that it is publishable. Mainly the content is the most important. .... quality depends on individual basis. In the engineering disciplines there is no standard.

But the majority of the faculty seem to consider the lack of attention to writing in engineering as a matter of the discipline's priorities.

Thus, whereas limited support that students seem to receive in these contingent ways is certainly better than nothing, it is also necessary to address how prevailing views about language and writing among the majority of engineering scholars undermine the necessity for more explicit, systematic, and deliberate teaching of writing in this discipline. The view that learning to write is a transient process, engineering faculty will continue to expect students to become able to meet the profession's standards of language and writing within a certain time window, mainly on their own. NNES students also enjoyed a certain amount of sympathy (an issue that I discuss in the next chapter) and seemingly more support, but even these students are expected to have learned to use the one and universal standard English, like everyone else:

Shyam: So, more generally speaking ... in your discipline, do you think other NNES scholars also kind of demand that high level of standard from NNES writing or could this be your [personal] approach?

Dr. Z: No, in my opinion, I think they are even tougher than others [NES scholars], because of two reasons: One is that they say, "well, we've learned this, we've mastered this, so others should." But also I think we always want our international students and NNES students to master English.... I have a difficulty understanding and accepting it because they're getting a degree, a high level 
education, from an English speaking institution. For that reason, I don't think we should provide a lot of allowance, that we should not provide excuses for the students....

Dr. Z said it all when he stated that NNES scholars who have academically and professionally succeeded, possibly after struggles, themselves are likely to have this kind of "bootstrap mentality" that asks others to buckle up and achieve what their predecessors have proved is possible.

\section{Conclusion}

The faculty members' own writing was strikingly complex, rhetorical, and even showed features of non-native varieties of English, but that reality did not undermine their belief that engineering writing must follow a universal standard English at all costs. This means that the major tenets of a community's belief system shape the worldviews of its members in spite of their own experiences and in spite of the reality. Academic disciplines/communities value the discourses and norms of their discipline as something that new members should embrace as quickly and fully as possible; most of the times, insiders are not even aware of unfair pressures and adverse conditions for newcomers. For this reason, even serious scholarship on academic writing and education at large view learning itself as a process of "socialization" which is in effect assimilation. According to Lave and Wenger (1991) and Wenger (1998), new members gradually become insiders through increasingly legitimate participation. Traditionally, there has been a great deal of research and scholarship on NNES students' struggle toward understanding and embracing the monolingual discourses of the academic community than there is attention and scholarship on how the adoption of problematic discourses can adversely affect these 
students' educational experience. Thus, Morita (2004) examined how NNES students learned to become members in the academy, showing "major challenge[s] in negotiating competence, identities, and power relations, which was necessary for [the students] to participate and be recognized as legitimate and competent members of their classroom communities" (573). Accordingly, WID programs have also aimed at helping NNES writers move toward "legitimate" participation in the monolingual norms as soon as possible. My study showed that unfortunately, even the NNES faculty members seem to unquestioningly enforce the norms of their discipline uncritically. In fact, some of the faculty even seemed to be over-performing their membership in the monolingual discourse community by enforcing prevalent language policies in apparently stricter manner than their NES counterparts might.

Also, it is not that these faculty members do not "teach" writing, but for most of them that teaching generally means demanding students to follow the norms and requiring them to focus on the content of the writing and correctness of the language rather than helping them learn the language and conventions of writing for various genres and contexts of writing. For most engineering faculty, the expectation that students will automatically learn to write seems to obscure the need to teach writing; a minority of them who do help their students with their writing do so in spite of rather than because of their beliefs about the slow and challenging process in which students can meet the expectations of advanced writing in their discipline.

The nature and demands for writing are rapidly changing in the face of technological advancements and the transformation of the field, but the ideology of simple and clear standard English prevails even among multilingual scholars. I focus on 
this apparent paradox of the prevalence of this monolingualism among multilinguals in the next chapter, focusing on institutional, disciplinary, and professional dynamics behind the monolingualism. 


\section{CHAPTER 3}

\section{MULTILINGUAL SCHOLARS, MONOLINGUAL PRACTICES}

"No, in my opinion, I think [NNES scholars] are even tougher than others [NES scholars], because of two reasons: One is that they say, 'well, we 've learned this, we 've mastered this, so others should.' But also I think we always want our international students to master English . . they're getting a degree, a high level education, from an English speaking institution." - Dr. Z

A long line of empirical and theoretical scholarships in composition studies (especially second language writing) and some WID scholarship that focuses on NNES students' writing has considered NES members of the academy and the professions faculty, administrators and policy makers, editors, reviewers, and so on - have played gatekeeping roles against NNES writers. In essence, the critique is that "native speaker and monolingualist orientations impute deficiency to the unique strategies that multilinguals employ to work English" (Canagarajah, 2009: 17). Critiquing such a "deficit" view of NNES writers, some of the scholarship argues that multilingual individuals are actually savvier at communicating across language barriers (e.g., Canagarajah, 2009; Weiner, 2004) as well as more tolerant of language variations. Canagarajah argued that multilingual individuals are more able to "co-construct intersubjective norms for communication" based on the needs of a situation, are able to "communicate through hybrid codes," tend to be more "consensus-oriented and supportive" of one another, "exploit ecology for meaning making" in specific contexts 
and based on who the audience is, and for them "language use and language learning are interconnected" (2009; p. 18-20).

It must be noted that Canagarajah highlighted these strengths in the context of interactive, social communication, and he concluded the article by saying that the status of multilingual negotiation in writing is "unclear." However, Canagarajah or other scholars who have critiqued individuals', institutions', or disciplines' monolingual dispositions and policies have not yet addressed how multilingual individuals and multilingual-majority institutions or disciplines may also adopt and enforce the same monolingualism--in spite of their identity, experience, ability, or demographics.

As I will discuss in detail in one of the sections of this chapter, more recently, Horner and $\mathrm{Lu}(2011)^{14}$ have forwarded a theoretical framework that can be used to explain monolingual or multilingual dispositions on the basis of individuals' expression of agency through those dispositions, regardless of the individuals' language identity and experience. ${ }^{15}$ Horner and Lu's theory of agency, along with the dynamic of power in the academy (Burbules, 1986), forms the basis for the discussion and illustration of the monolingual dynamics among multilingual engineers in the rest of this chapter.

As I illustrated in Chapter Two, the participants of this study generally adopted the myths of transparency, transience, and universality of standard academic English in scientific and technical writing. In this one, I focus exclusively on the institutional, disciplinary, and professional dynamics whereby multilingual scholars enforce monolingualism. By using the concept of agency and power, I ask: How does

\footnotetext{
${ }^{14}$ The authors provided a draft copy of this keynote speech that they gave at the $22^{\text {nd }}$ Pennsylvania State University Conference on Rhetoric and Composition, July 2011.

${ }^{15}$ Canagarajah had also mentioned the notion of agency earlier but did not apply the concept to explain the possibility of monolingual disposition among multilingual individuals.
} 
monolingualism function "through" multilingual faculty and students? What complexities, if any, arise out of the conflict of linguistic awareness of multilinguals in positions that reward monolingualism? How much does language identity matter, if at all?

The theories of agency and power can largely account for the major paradox of multilingual scholars enforcing monolingualism. But the data of this study also shows that there is more than a simple and straightforward enforcement of monolingualism when multilingual scholars and students are in the majority, including in positions of professional responsibility as well as authority. Here are some of the complexities that I will discuss in this chapter. (1) some of the participants readily acknowledged that in social contexts or oral communication, language variation in the form of accent is natural and both impossible and unnecessary to eliminate; they also agreed that different Englishes exist outside of academic writing, especially technical writing; (2) some participants were willing to allow different English varieties for certain contexts and purposes within academic writing; for instance, they were tolerant of variations in students' writing; (3) participants who supported a strict and universal monolingual standard generally did so because they believed that that is the only way to succeed academically and professionally in their discipline (which is what Dr. Z meant to say in the quote used as epigraph for this chapter); they either accepted monolingualism as a strategic tool for success or passed the buck to the system/discipline; and (4) empathy with NNES students, especially new students, significantly softened the intolerance toward non-standard English in engineering writing among most participants; more 
importantly, when their own identity and experiences as NNES individuals were brought up, their responses were the softest toward NNES writing.

Thus, in this chapter, besides mainly using the theoretical framework of agency and power in order to explain the monolingual dynamic among multilingual scholars, I also account for the variations and complexities that seem relevant toward developing programs and strategies for countering the monolingualism and promoting more complex views about language and writing that NNES engineering students need to cultivate.

\section{The Paradox of Monolingualism}

The demand for standard English as a clear and simple code for scientific communication gives rise to paradoxes in different ways. For instance, the faculty participants defined engineering writing as essentially rhetorical in function: all of them acknowledged that engineering is a discipline situated between pure science and the industry and business, and therefore their writing involves communicating in a variety of contexts, with different audiences, and often for persuasive purposes. However, they still insisted that all engineering writing uses a simplified, universal code. This insistence did not seem to prevent the faculty from using complex and rhetorical language in their own writing, but it affected their teaching —or lack thereof—of language and writing skills to their students. So, the faculty who did invest time and energy for helping their students with their writing did so in spite of their beliefs rather than because of it.

In scientific and technical writing, the rejection of any variation from standard English is quite universal. In fact, there are legitimate reasons for such writing to demand simplicity, clarity, and objectivity in its language. However, the ideology on which this demand is based is problematic for many reasons: (i) it obscures the fact that standard 
English is a complex repertoire of linguistic resources and that clarity and simplicity are contingent upon the nature of the content to be communicated as well as the genres and contexts of writing, (ii) it prevents the possibility of glosso-diversity-or the enriching of meaning brought about by diversified language standards - in NNES scholars' writing, (iii) as discussed in Chapter Two, it discourages the explicit teaching of language and writing skills in engineering particularly affecting the NNES students who are in large majority in this discipline in the American university, and (iv) because it perpetuates a false idea that clarity is gained by "avoiding" rather than mastering complexity, NNES students seem to exacerbate frustration and failure in the process of their learning the language and writing skills by internalizing that idea.

For more than three decades, research and scholarship on NNES writing has focused on the challenges faced by NNES students (and even professionals) in the academic disciplines including engineering. Perhaps because of this predominant focus on the prevalence of language ideology among NES faculty, editors/reviewers, and academic administrators and policy makers, and others in positions of authority, the field has largely overlooked the possibility of monolingualism functioning through multilinguals.

In some of the incidental mentions about how NNES faculty perceive language variations in NNES students' writing, scholars have hinted at this paradox. In a survey that assessed university instructors' reactions toward NNES student writing, Santos (1988) noted the "lower ratings to the acceptability of the language" differences in NNES students' writing by NNES faculty members. He implied that this relative intolerance to language errors among NNES faculty members was the result of their own "extremely 
high level of proficiency in English" which they had gained through significant "investment of effort in the language" (p. 85). He hinted at what I call the "bootstrap mentality" among NNES scholars, who want their students to master the "standard English" as they did it in their times as students.

In a study done in 1992, Kobayashi investigated the question of variability of error correction in sample NNES composition by native and nonnative editors. Due to the mixed nature of the population ${ }^{16}$ this study did not show any clear patterns. Among the findings of this study which counter the conventional assumption that NES and NNES individuals are monolingual and multilingual in attitude respectively here is one: educated NES participants were more tolerant of grammatical errors than their NNES counterparts. In a study of professor's response to ESL writing which was designed to focus on differential response to L2 writing based on cultural identities, Roberts and Cimasco's (2008) mention a similar incidental finding that "professors in engineering and math sciences [were] slightly more exacting in their expectations of ESL writing" (138). Even though English teachers are traditionally known for their high demands for correct language, research on language difference in academic writing like this have sometimes shown that scholars in the natural sciences and engineering can be even less tolerant towards language difference in NNES writing. As one of the NES editor of a journalwho would be generally "accused" as a monolingual gatekeeper by much of the discourse on language and writing - notes during an interview with Flowerdew (2001), multilingual scholars can be more monolingualist in their views and practices than their NES counterparts:

\footnotetext{
${ }^{16}$ NES and NNES students and scholars from the University of Hawaii at Manoa and several universities in Japan
} 
Interviewer: Do you find that [NNS reviewers] are particularly sensitive perhaps to issues concerning NNS [writers]?

Editor 6: ... I don't think so, honestly. In a way, actually, one of the paradoxes of ELT in general it seems to me [is that] the NSs [reviewers] are much more tolerant of language problems out of NNSs [writing] than other NNSs are. You know, I think it seems to me generally true, in my experience, a NNS teacher will pick up mistakes and errors made by students far more actively than NS teachers will do. And I haven't noticed any difference on the panel in terms of willingness to accept or be tolerant of deviations on the part of NNS - no, I wouldn't differentiate it in that sense. (132)

The fact that multilinguals can enforce monolingualism is not surprising; the question is how and why they may do so, as I will discuss in detail in a later section of this chapter.

While the possibilities of monolingualism among multilinguals has been indicated in some past research, there are as yet no studies primarily designed to address this dynamic in the academic setting. This question continues to elide most researchers perhaps because it seems obvious that NNES scholars will be more tolerant of language difference due to their being multilingual in identity and experience. Even the more recent scholarship on multilingualism has largely assumed what seems intuitive and not paid attention to research data like the above (however meager they are); the marginal findings in studies like the few that I mentioned above seem to describe the reality of monolingual dynamics in the academy quite well and therefore seems worth drawing on. The works of scholars like Flowerdew (1999), Lillis and Curry $(2006,2010)$ and others have for quite some time consistently shown that NNES scholars outside the 
global geopolitical, academic, and professional centers suffer the brunt of monolingual policies. But the participants of this study favored the discourse of their discipline to the point of overlooking the fact that there is in reality no such thing as a universal variety of English that everyone across social, cultural, national, and disciplinary borders will use the same standard for all scientific and technical communication. Exchanges like the following suggest that NNES scholars at the global centers are on the enforcing rather than receiving end of the monolingual gatekeeping mechanisms.

Shyam: If you insist that there should be only one standard for global communication among engineering [communities in the world], then it becomes a kind of cultural and political issue of some members saying that their variety is right and everyone else's is wrong. ...

Dr. A: I don't know if that actually happens in engineering. Shyam: No?

Dr. A: The reason is (pause) we don't really, really value the journal that is published in India, whether it is printed in English or not. We don't. Dr. A added that "we" don't value those journals because of their lack of a rigorous review process, but the claim that there are no journals worthy of her consideration in India—or any country for that matter-is an extreme example of Dr. A's being an insider of the global center. Thus, it is not surprising that the NNES scholars working in the American academy do not perceive the challenges that they may face in the same way that current literature describes the NNES writers as doing in the literature.

It must be emphasized that the faculty members who participated in this study were highly committed to their students' academic and professional development. Some 
of them were directors of graduate studies, took part or led initiatives for enhancing graduate education, and they were distinguished faculty members in their departments. My observation of their classroom teaching, one-on-one advising sessions with their students, samples of their students writing which they had marked for revision and improvement, and the informal discussions that I had with them all clearly showed that these scholars systematically groom their NNES students towards becoming professionals in their discipline. However, when it came to teaching language and writing skills, the laudable teaching and support mechanisms were undermined by the persistent language ideologies that the scholars nonetheless bought into. In fact, even the NNES graduate students who participated in this study rejected the value of learning and using the complexity, variability, and rhetoricity of linguistic form in academic and professional writing.

In order to provide the participants with a point of reference, instead of asking abstract questions about their beliefs and attitudes towards language difference, I showed them a handout with a table that named and described four different types of attitudes towards language difference that Horner and Lu (2007) identified among writing instructors: eradicationist, second language acquisition, accommodationist, and multilingual.

\begin{tabular}{|l|l|l|l|l|}
\hline Approach & $\begin{array}{l}\text { Status Given } \\
\text { to Difference }\end{array}$ & $\begin{array}{l}\text { Explanation of } \\
\text { Difference }\end{array}$ & $\begin{array}{l}\text { Pedagogy Aims } \\
\text { and Means }\end{array}$ & $\begin{array}{l}\text { Value } \\
\text { Assigned EAE }\end{array}$ \\
\hline Eradicationist & Error & Ignorance & $\begin{array}{l}\text { Eradicate error } \\
\text { Eradicate error } \\
\text { maker }\end{array}$ & - Correct \\
writing \\
\hline Second-language & $\bullet$ Interlanguage & $\begin{array}{c}\text { Mediation of } \\
\text { writing }\end{array}$ & $\begin{array}{c}\text { Diagnose and } \\
\text { treat }\end{array}$ & - Correct \\
& & "Target" \\
\hline
\end{tabular}




\begin{tabular}{|c|c|c|c|c|}
\hline & & $\begin{array}{l}\text { Idiosyncratic rules } \\
\text { Proofreading } \\
\text { habits }\end{array}$ & $\begin{array}{l}\text { idiosyncrasies } \\
\text { - Teach editing }\end{array}$ & language \\
\hline Accommodationist & $\begin{array}{l}\text { Discourse } \\
\text { clash }\end{array}$ & $\begin{array}{l}\text { Ambivalence to } \\
\text { dominant } \\
\text { Discourse } \\
\text { Discourse } \\
\text { interference }\end{array}$ & $\begin{array}{l}\text { Translation from } \\
\text { unprivileged to } \\
\text { privileged } \\
\text { Discourse }\end{array}$ & $\begin{array}{l}\text { Dominant } \\
\text { "Power" } \\
\text { Discourse }\end{array}$ \\
\hline Multilingual & $\begin{array}{l}\text { "Code- } \\
\text { meshing" } \\
\text { Discourse- } \\
\text { blending }\end{array}$ & $\begin{array}{l}\text { Strategic design to } \\
\text { create new } \\
\text { discourses }\end{array}$ & $\begin{array}{l}\text { Development of } \\
\text { language and } \\
\text { languages }\end{array}$ & $\begin{array}{l}\text { - False ideal } \\
\text { - Contingent }\end{array}$ \\
\hline
\end{tabular}

Adapted from Horner \& Lu (2007), "Resisting Monolingualism ... Politics of Language."

Briefly, those who hold the eradicationist view equate variations from the standard as error, consider the cause to be ignorance of the norm, use teaching to eradicate the error/variation, and only value what they consider "correct" and standardized academic English when it comes academic writing. A second group of writing teachers considers variation an inevitable part of second language acquisition, so they are more tolerant of the variations as interlingual phenomena; this group also believes in diagnosing and treating the idiosyncrasies of language learners, because their goal is "correct" writing as well. The accommodationist writing teachers, a third group, view variation as a matter of discourse clash between the language varieties involved and they are ambivalent to the idea that the dominant discourses must be favored; as a result, the accommodationists suggest that students learn how to translate unprivileged discourse represented by their home language into the privileged discourse of the language they are learning. Finally, writing teachers who subscribe to the multilingual view are open to the possibility of 
"code-meshing" and "discourse-blending" that people who use multiple languages can perform in their writing; they believe that students can strategically use different codes of the languages or varieties in order to create new discourses, so they are critical of edited academic English as a "false ideal" that academic institutions attempt to change from a contingent to an enforced norm.

Most of the faculty and students in this study chose the eradicationist or second language acquisition view as best describing their position on the issue of language difference in academic writing, especially writing in engineering. Six out of ten participants considered themselves "eradicationist," two of whom were graduate students who were, interestingly enough, anxious about their own English language proficiency. The students' desire to eradicate any variations in their own writing was understandably based on their desire to learn better English, but they also strongly believed that there must be a fixed and consistent standard for engineering writing that engineering scholars around the world can use. One of the students who chose the eradicationist view justified it this: if he had a choice, he would learn "American" English rather than Chinese English because learning standard English would be a more productive investment of his time and energy anyway.

After I described the four kinds of attitudes towards language difference and asked him whether the demographic diversification of engineering might make different varieties of English become more acceptable in engineering writing, Dr. Z said:

Dr. Z: Well, it's possible, but I have not seen evidence of that shift. Again because, [as] you said, there are gatekeepers where a published paper has to meet certain standards, and I think that how it is and how it "should" be. 
Dr. Z not only doubted that NNES writers could be making an impact on what he firmly believed to be a universal English standard, he also saw no problem with the gatekeeping mechanism. He considered it not just "how it is" but how "it should be."

In a less critical way, Dr. B also justified a universal monolingual standard, which he did on a practical basis:

Dr. B: Yeah, I'd like them to follow [the standard] — I mean many of them are students here, and many of them are going to make their careers here. So, it would be better for them to stick to this standard. ... if [their writing] is going to get published, you might as well clean it now and meet the standards that the journals expect. So I am probably in this first category than any other.

While Dr. B clearly appreciated the idea of tolerance and accommodation for language variation in the writing of NNES students, he had clear reasons on the contrary for wanting them to learn and use the proper standard. In his response above, "here" is an important word to notice: if students want to succeed here in the US, both as students now and if they want to pursue their professional careers, "it would be better for them to stick to this [meaning "American"] standard. He further suggested that he spends a lot of time helping students eradicate non-standard variations, which his student, Student B confirmed with gratitude towards him. But even Dr. B considered linguistic variations either as errors to be eliminated or as insignificant spelling differences between varieties of English.

Dr. B: . . in our field I don't think there's that much of a difference between a European journal's writing [style]--something like "optimizing," they use "z"-stuff that editors will take care of at the end. 
When I reminded him that those small differences occur in two standard varieties of English, Dr. B added that they still don't matter very much because they don't really constitute significant language differences: “... other than that, the text is pretty standard, and the writing style is pretty standard in our field, whether you pick a European journal or an American journal." This refusal to recognize language varieties beyond spelling variations is a manifestation of an ideology that shapes their view of language and writing; this ideology is more powerful than the inevitable lessons that engineering scholars learn from their actual experiences of the wide variety of language that they do use for academic and professional communication.

Four of the participants, two faculty members and two students, said that they identified with the second language acquisition camp. One faculty member stated that he would like to see diversity of language and ideas promoted. None of the participants supported the multilingual view; in fact, no one supported the accommodationist view either. Interestingly, those who supported the eradicationist view had similar justifications for their beliefs as those who agreed with the second language acquisition view, because, in the end, everyone believed that it is ultimately necessary for engineering students and scholars to use the correct and universal standard. Except for the complications and contradictions elicited by my direct question about their monolingualism at the end of the second interview--and more significantly their responses to my last question in the third and last round of interviews - the participants rejected language variation as well as complexity and rhetoricity as unfit for engineering. 
In later interviews, I shared my own perspectives on language with the faculty members, challenging them to explain the apparent of monolingualism among multilingual scholars like them.

Shyam: ... If you insist that there should be only one standard for global communication among engineering, then it becomes a kind of cultural and political issue of some members [the global professional community of engineering] saying that their variety is right and everyone else's is wrong. What those other people are using is not "wrong English"; what they're using is variant forms of standard English.

Dr. A: I don't know if that actually happens in engineering.

This blunt response not only represents what scholars like Dr. A, who are situated in the geopolitical and intellectual centers of their discipline's global community, believe about language; it also shows how NNES scholars in this setting are positioned to enforce rather than undermine monolingualism in their discipline. Both the spoken and written English that these scholars use may continue to have features of the English that they learned in different parts of the world, but their theoretical rejection is a mode of operation that authenticates their membership at the center.

Russell (1989) stated that "the engineer is much more likely to face complex rhetorical problems in translating information from one community to another. Thus, [in reality] writing cannot as easily remain transparent" as it does in their claims (39). But that reality does not seem to affect some of the hardcore ideologies about language that are nonetheless sustained by the discourse about language and communication in their discipline. The views about language variation in academic writing that are prevalent in 
the discourse of their discipline undermine the multilingual scholars' personal and social awareness about as well as tolerance to language variation when it comes to academic, especially engineering writing. Their professional roles as engineering scholars and teachers (or even students) preceded their multilingual social identities in shaping their views about the subject-barring certain other factors that complicate their monolingual dispositions.

\section{Quality, Standard and Passing the Buck of Gatekeeping}

In the first round of interviews, I showed the participants a writing sample which I told them was written by an NNES student; I had underlined a number of problems including grammatical errors, correct but awkward wording, and an unusual shifting of voice forms from one paragraph to another. My objective was to assess what kinds of language issues the participants considered acceptable in academic writing in their discipline. As I discussed in the previous section, the participants generally rejected the NNES features of the writing sample as something to be eliminated from scientific and technical writing; however, when asked if they were "bothered" by the deviation from standard English, their professed monolingualism gave way to quite complex responses. Some of them "blamed" the system for rejecting language variations, while others were tolerant about NNES students as opposed to more experienced writers, and yet others justified monolingual standards as a logically desirable means and end of success for NNES students. Let me focus on one of those complex dynamics, that of "passing the buck" to the system in this section. I dedicate a separate section to this issue because it seems to me that in order to build successful writing programs for disciplines like engineering with their NNES majority, it is essential to understand the seemingly 
intractable issue of "blaming" the system or any other justifications for embracing the rejection of the natural linguistic phenomenon of variety/variation.

When I asked why they considered NNES features in academic writing a problem, some of the participants said that "they" (meaning NES readers and reviewers, or perhaps the academy and profession at large) will not accept NNES students' writing without eliminating the features of non-standard English. For instance, when asked if she was bothered by an awkward phrasing in the writing sample, Dr. A said the following:

Shyam: So, are you saying that this word "averagely" would bother you if it affects the clarity and logic or the audiences' understanding of this content? Dr. A: In the regular scientific journal, they're not going to accept it. (emphasis added)

She went on to suggest that as a teacher she is responsible to make sure that her students are professionally successful by following the standard. Another faculty, Dr. B, first said that he was bothered by non-standard language, because he was worried that students' writing will be rejected in academic publication due to the variations, but he also conformed to the monolingual system by equating standard English as a language that "reads well":

Shyam: ... would you be bothered if a student has a really good project, really well laid out idea, logically acceptable, and yet the writing style sort of keeps you from--I mean that kind of awkwardness--

Dr. B: Yeah, I think that's sort of distracting, and that's one problem. And that's a problem that's central. You know having grammatical errors or otherwise [i.e., variation in style and usage coming from different varieties of English]. It can 
distract you from the main point, right? But the second more important thing is that, if it is important work that I'd like to get it published, and you send it to referees, you know, they'd be distracted as well. [They'd say] Okay it's really not a great paper, and they'd tend to turn it down. Not so much because they looked at the content fully but they're distracted so they really didn't pay as much attention as you'd like them to. So, it's important to have papers that read well, that flow well. So that makes an impression on the referees in the process.

So, in this case, there is a combination of "passing the buck" and also essentially agreeing with why those who reject language variation reject it. Moreover, Dr. B did not want to be distracted by the variations himself; and then he also accepted the rejection of writing based on any variation that someone might turn down as distracting as well.

As we just saw in part of Dr. B's response, not all of the participants, however, "blamed" someone or something else for the gatekeeping that happens against language variation. Some of them considered the pressure for rejecting language variation coming from a simple need for quality and standard: they defended linguistic gatekeeping on the basis of what they called a straightforward need to represent scientific knowledge in an objective and accurate manner. That allowed them to pass the buck to a self-sustaining mechanism of quality and standard. Here is, for instance, the response of Student B, who said that she can "tolerate" language variations in "everyday language" but not in "academic writing":

Shyam: ... like in academic English, you are sort of more demanding?

Student B: Why I said that is because when I review papers for conference or journals, I have certain standards. I don't want some written, to make the paper--I 
mean they should try to be error-free. . . . in terms of academic writing, it's different.

The fact that Student B continued to use the word "error" even after I clarified what I meant by "language difference" or "language variation" (specifying them as different from grammatical errors) suggests that she defines "standard" in binary terms of correct and incorrect rather than "variation" as I tried to convey to her.

WID scholars have studied the prevalence of beliefs about the presence of common core standards of disciplines in general; NNES scholars seem to be no exception in buying into the beliefs. In their article "Questioning alternative discourses," Thaiss and Zawicki (2002) investigated how conscious scholars across the disciplines were about the conventions that they assumed guided writing in their disciplines. They started by hypothesizing that (i) "writing practices by scholars within disciplines will show that the boundaries around disciplinary discourses are far more permeable than we indicate to students when we teach them to conform to the discourse conventions of their majors" and also that (ii) "academic working outside of rhetoric and composition are not likely to be aware of the usefulness of certain kinds of rhetorical performances to disrupt dominant discourses, either as protests against hegemony or as assertions of identities typically invisible in the academy" $(81)$. The first hypothesis was confirmed from the interviews: "each of our informants easily noted a formal center of the discipline or a clear range of acceptable styles in terms of ways of thinking, standards of evidence, and format. None of them doubted that there were identifiable standards, and could easily tick of a few features" (ibid.). The results regarding the second hypothesis was more mixed, but even when scholars in the disciplines do not know what exactly constitutes the "standards" of 
their discipline, they still subscribe to the idea of "standard" English, "academic" discourse, and so on. When asked more explicitly why engineering scholars were so supportive of the idea of a universal standard, Dr. B suggested that there is no better alternative to standardized English, going on to add that the journals will reject anything else:

Shyam: So, my question is like why, what are the reasons that everybody tends to gravitate towards one standard?

Dr. B: Because otherwise it is problematic--I mean it is easier to get something published if you follow the standard.... Because I think that there are many journals that will primarily reject papers in which there are writing differences and errors and things like that. So that may be the motivating factor, I think, for everyone gravitating towards the standard.

As we see in Dr. B's response, members of academic disciplines in the natural sciences and engineering tend to be more confident in their belief about formal centers, language standards, and qualities or writing than scholars in other disciplines. In "Global scientific communication," Ammon (2007) argues that the English language is certainly the current default of global scientific communication: "What are the basic facts of the present situation, i.e. what is reasonably safe knowledge that cannot seriously be called in question, and what parts of it are particularly relevant to desirable and possible improvements in the present situation or for the development of a policy plan?" Ammon's answers, obviously, include points like the following:

(i) "English is the predominantly preferred language of science especially for international communication," (ii) "The preference of English is much stronger in 
the pure or theoretical sciences," (iii) "English can be called the 'dominant' language of science because scientists--and to a lesser extent scholars in the humanities - are forced to use it if they want to follow new developments in their disciplines (passive use) ...." (iv) "The existence of a global lingua franca has advantages for everyone, including the non-Anglophones and their countries" (124).

NNES scholars and students in the sciences and engineering seem to see no value or benefit in challenging the norm.

Dr. B: But then the difference [between world Englishes] is not that significant. ... [and] there's always that adherence to being academic. There is adherence to some core principles, some basic guidelines. Outside of that, yeah, because of shifting of demographics and all, there may be some minor changes--

The "adherence to being academic" seems to be a motivation that NNES scholars have for becoming a more accepted and respected member of their disciplines. In fact, as Morita (2004) stated, even for NNES students, the primary or immediate objective is to become legitimate members of their discipline by adopting the tenets and perspectives of their discipline: "a major challenge for the [NNES] students was negotiating discourses, competence, identities, and power relations so that they could participate and be recognized as a legitimate and competent members of a given classroom community" (583). The idea of membership through participation and conformity means that while no academic or disciplinary community will explicitly reject persons marked by different linguistic or cultural identities/backgrounds, their failure to conform to the norms and 
expectations of the community will make it difficult for them to fully participate or be equally recognized and respected. In Morita's study,

the individual student's participation had a reciprocal relationship with her sense of competence produced in the classroom. For instance, in some cases, the students struggled to participate actively in discussion and therefore developed an identity as a less competent member, which in turn made participating even more difficult for them. (596)

The identity was not only constructed by how other, insider, members of the community perceived the outsider but also by how the outsider themselves constructed and perceived their own identity.

Based on the beliefs that their disciplines have common core of standards and that legitimacy is only gained through conformity — and not by challenging or updating the norms - most of the NNES scholars who participated in this study seemed to justify gatekeeping as "review process," as an unproblematic means for maintaining quality and so on. In response to the same explicit question as to why NNES scholars seem to subscribe to monolingual demands of a strictly universal and standard English, Dr. X justified the need for a standard in the context of his discipline:

Shyam: ... Why do engineering scholars gravitate towards that one universal standard, even when they know that in the real world writing and language are naturally varied? ...

Dr. X: Because there has to be some standard...

In light of the fact that Dr. $X$ argued that advanced writing skills in engineering can be creative and different from the basic norms, this response seems to suggest that perhaps 
NNES scholars who are socially and academically established in the US no longer even align themselves with what language scholars like to call "nonnative." Indeed, the very distinction between native and nonnative has been complicated from the perspective of proficiency, attitude, and so on (e.g., Leung \& Rampton, 1997); the NNES professors in this study practically aligned themselves with native users of the language on the basis of their acceptance of the discourse about language in their discipline.

I will discuss the acceptance and/or reinforcement of gatekeeping against language variation from the perspective of authority and agency in the next section; suffice it to say here that the acceptance and reinforcement of standard and quality seems to be largely "automatic." The ideologies about language and writing seem to perpetuate themselves because in all the justifications of gatekeeping, there seems to be a certain amount of denial of individual agency. From the perspective of engineering scholars, the rules and standards are parts of keeping scientific communication clear and simple. Let me also emphasize here that it is essential to understand this dynamics of "blaming" the system for its rigid monolingual standards because writing programs and teachers cannot simply confront such deeply entrenched monolingual policies in engineering by proving the "correct" perspective on language as a complex and variable phenomenon may only serve to intensify interdisciplinary misunderstanding. It seems necessary to understand and address the dynamics of the discipline before trying to promote more critical views about language and writing and thereby promote higher competency in language and writing among engineering students. 


\section{Agency and the Choice of Monolingualism}

As I indicated at the beginning of the Chapter One, research and scholarship on NNES writing - both on students' writing at the undergraduate and graduate levels in the US (e.g., Jenkins et al., 1993; Zamel, 1995; Angelova \& Riazantseva, 1999; Trice, 2001; Horner \& Trimbur, 2002; Lax, 2002; Wiener, 2004; Canagarajah, 2007, 2009; Vickers, 2007; Brandt, 2009; Hall, 2009; Cox, 2010, 2011; Jordan \& Kedrowicz, 2011) and the writing of NNES professionals in transnational contexts (e.g., Canagarajah, 1999, 2002; Braine, 2002; Flowerdew, 2000, 2001, 2008; Lillis \& Curry, 2006, 2010)--have generally considered NES individuals to be in position of assessing NNES writing. The situation of NNES scholars being in positions of authority - as faculty, editors, reviewers and so on - has not yet been addressed in the literature. Because the results of this study showed that NNES individuals in position of authority generally accepted the monolingual standards of their discipline, the question arises: why do individuals who might be able to challenge the status quo decide not to do so? Why do NNES faculty and even their students believe that the right monolingual standard of engineering "should be" what it is? This question is a crucial one as a part of developing and implementing WID programs and initiatives in NNES-majority disciplines like engineering not only because NNES students evidently need more support for developing more complex and nuanced understanding in order to acquire sufficient linguistic/rhetorical abilities, but also because the rampant monolingualism in engineering cannot be confronted without understanding why multilinguals prefer monolingual beliefs and dispositions?

The participants apparently embraced and enforced monolingualism unconsciously. Their choices are shaped by the structure of their institution, the social 
dynamics in the discipline, and the resulting motivations for institutional and professional progress. That is, they exercise their agency through monolingual practices; the monolingualism that they adopt is less of a function of their language identity, life experiences, and personal views about language difference and more of a function of how they belong and succeed in their discipline and profession. Even though the adoption of monolingualism performs an ideological function in essence, at least from their own perspective, that adoption is the result of "practical" choices that they make as part of their regular academic and professional roles. Their exercise of agency is almost invisible.

The dynamics of how individuals can exercise agency through monolingualism as well as multilingualism is addressed quite comprehensively in recent literature on the policies and politics of language (especially Canagarajah, 2006b; Horner \& Lu, 2011; Horner, NeCamp and Donahue, 2011). In their article "Language difference in writing: Toward a translingual approach," Horner, Lu, Royster, and Trimbur point out that individuals who are

identified by conventional standards as monolinguals might take a translingual approach to language difference, as demonstrated by their response to unfamiliar ways of using language, while individuals identifiable by conventional standards as multilingual with regard to their own linguistic resources might well approach language differences in ways at odds with a translingual approach. (31112)

The authors suggest that both multilingual and monolingual choices--whether made within or across these linguistic identity positions or dispositions-can be ways of 
exercising agency. Furthermore, Horner and $\mathrm{Lu}(2011)$ argue that using a translingual approach that foregrounds the dynamic of agency can help us understand the language choices that individuals make within specific historical social contexts: they state that a translingual approach asks how, when, where, and why specific language strategies are deployed. They add that treating all choices as being temporally as well as spatially located can help us pay attention to the production of semio-diversity even in utterances that appear simply to reiterate "the same." Drawing on Gidden's (1979) argument that social and institutional structures and individual agency are mutually dependent and coconstitutive, they go on to suggest that every instance of the use of language, including what is recognized as repetition, represents an exercise of agency, and a choice, whatever the level of consciousness in the making of that choice. That is, agency does not only manifest in deviations from the norm but rather in all language acts that the user makes deliberately; thus, they point out that the production of conventional language does not mean a lack of agency, nor the subordination of an individual's will to institutional demands as an unwitting, un-agentive reproduction of dominant language norms. Similarly, Canagarajah (2009) argued that the legitimacy of a language user's decision to choose a "standard" grammatical structure is always involves an act of exercising his or her agency. As Canagarajah states, the decision of the participants of this study to adopt monolingual standards is inherently "an ideologically favored option" (610) in their particular context and status in the discipline and the institution.

The dynamics of why multilinguals adopt and enforce monolingualism can also be accounted for in terms of how power operates in the academe and professions. In "A theory of power in education," Burbules (1986) states that 
power is a relation that is not simply chosen (or avoided) but made more or less necessary by the circumstances under which persons come together. These circumstances include ... a presumption or expectation of certain roles that constrain the alternatives the [persons as] agents see as possible; or psychological traits-sometimes unconscious - that predispose persons to carrying out dominant or submissive positions in the relationship. (97)

Seen from this perspective, whether they consciously and deliberately enforce the norm or comply with it out of sheer necessity, power and agency in the enforcement or compliance are relational. From the perspective of the power dynamics, monolingualism works through multilinguals, as hegemony works through "dominated" groups adopting and appropriating the power structure often for their own benefit. According to Burbule, There is a natural tendency for [the ideologically shaped discourses in a community] not simply because any group actively promotes and maintains them but because most persons take most of their beliefs and values for granted, and because they tend to accept the first minimally plausible account of affairs that comes along, if it fits their more salient experiences. (106)

Thus, when Dr. A said "it's not me tolerating" (in the quote below), her response essentially showed how the discourse of her community functions through her agency. Dr. A: Well, they're not going to be able to publish--as bad as it can be. . . I mean it's not me tolerating. The person has to be functional in whatever they're going to be or they are in. I don't think it's possible for the person to survive. The idea that a student has to be "functional" and what it means to be functional is shaped by and also shapes the discourse where Dr. A belongs. In response to how she 
would respond to occasional awkward wording," she said: "No, it's not going to go out. There's no way that I would send it out. They're not going to review." Between the two seemingly complementary reasons - "they're not going to review" and "there's no way that I would send it out"-her own agency is inevitably tangled in the power structure of her discourse community, a community that both requires and legitimizes her disposition toward language difference as legitimate and part of the profession.

The participants also justified the rigid linguistic standards on the basis of apparently straightforward need to maintain the "professionalism" and professional standards of their discipline. Indeed, it is hard to get anything published in the field of engineering if the author doesn't first of all eliminate all traces of language variation. However, when they said, for instance, that "[i]n the regular scientific journal, they're not going to accept [any writing with NNES features]," the participants were aware that the majority of "they" are multilingual scholars. In fact, all of the participants acknowledged the current situation of multilingual majority ${ }^{17}$ in engineering, while continuing to insist that a monolithic variety of English is an absolute necessity for the discipline. Thus, it is not possible to separate the NNES teacher as an agent from the mechanism of enforcement, because the teacher is part of the hegemony that makes the system function in the first place.

The participants' expression/exercising of their agency as students and professionals often had a strong personal element. As more or less established professionals and as aspiring scholars of a discipline that rewards monolingualism and rejects multilingualism, the participants' actually liked (rather than find problem with) the

\footnotetext{
${ }^{17} \mathrm{I}$ use this phrase in the sense that there is a large majority of multilingual faculty and a clear majority of multilingual students in the discipline.
} 
system. This sense of belongingness is not surprising when we take into account the fact that the faculty members have great admiration for the US academy in general and their profession in particular which they clearly aspired to be part of. They suggested this sense of attachment in comparison to the quality of education and/or the society at large in this country. For instance, Dr. A stated that "Americans are much more accepting of international people compared to like Japan or Germany, but still if you are not good in even expressing things, you're not going to hold a job." So, if we consider what the participants said about the fact that NNES students and scholars have become a large majority in engineering, the complexity about the NNES scholars' agency becomes even more complex and prominent.

Current literature on NNES writing has extensively documented the struggles that NNES scholars who are situated in the global periphery but increasingly need to publish in English (e.g., Flowerdew, 2001, 2008; Lillis \& Curry, 2006, 2010): in this literature, NNES writers' works are regularly rejected on the basis of the non-standard varieties of English that they use, and typically it is NES scholars in the geopolitical center like the US who serve as gatekeepers in the system. But the response of participants in my study sharply contradicted the findings of that literature. When asked if any of their writing had been rejected or assessed unfairly due to language issues, the faculty generally indicated that that had never happened to them and in fact went on to add that language issues are never significant in engineering writing.

Shyam: And, can you remember any incident when the response came back and you saw--maybe the feedback was based on the perception that your writing was not typical, "native" kind of writing? 
Dr. X: Uh, no. I don't have that. I don't think that has happened. Most of the people in the technical world, the people who review it, there are also maybe nonnative speakers themselves! ....

One of the explanations for the real or perceived lack of monolingual bias toward their writing is that, as Dr. X's response above indicates, the majority of the reviewers are NNES individuals themselves. But this explanation is not compatible with the striking monolingualism among the NNES faculty themselves; there must be more to the perceived lack of monolingual bias in the discipline. So, I cited the literature and asked each faculty what they thought about the prevalence of bias in that literature.

Shyam: There's actually a huge body of research in my discipline about the perception of non-native scholars, writers like you, by native speakers.... literature that basically criticizes the [NNES] gate-keepers who do not understand that there are different Englishes, the different ways people write. So, you are saying that in ten years, your experience disproves that research?

Dr. X: Right.

Shyam: That's kind of interesting, because I would have expected that at least once or twice somebody would have told you something like "this paper needs to be seen by a native English speaking writer."

Dr. X: No, that doesn't happen in science and engineering. It doesn't happenDr. X's blunt statement "that doesn't happen in science and engineering," which other faculty also suggested, arguably represents more of his perception than the reality.

It is possible that Dr. X and the other faculty members are exceptional writers and so they have not had the kinds of response that researchers like Lillis and Curry (2006, 
2010), Flowerdew $(2001,2008)$, and others have consistently found in the case of NNES writers writing for mainstream publications. But as their own responses suggested, it is more likely that that the faculty are squarely positioned to enforce the monolingual standards.

Shyam: Yeah, how would language play a role in that process [of students attaining high quality in their education]?

Dr. A: The first thing, when you go for an interview, that's the time. I can see somebody, I can tell somebody is not prepared, or somebody is prepared. If the person doesn't know his language is good or bad, he will be assumed that he is not prepared. And he will be assumed that he is rude.

This response contains a clear example of how agency is generally dynamic, dispersed and multidirectional rather than functioning in a unidirectional manner. After naming a setting, the interview, Dr. A starts with an explicitly agentive expression "I can see," but then she returns to the passive structure "he will be assumed..." as if to attribute the assumption and judgment about the connection between language and preparedness to the discipline rather than to herself alone.

Moreover, it is not just the faculty members who are generally well established in their disciplines as well as the institution whose responses about language difference demonstrated the complexity of agency, power dynamism, and functioning of hegemony in their discourse and professional communities. Most of the times, even the students' agency seemed to function through their adoption of, or compliance to, monolingualism. The authority that the students know will come along with being able to conform to the standard, as well as the responsibility to uphold the norms and conventions that comes 
with holding positions of authority, shape the students' view of language as well. For instance, Student B told me about an incident where she literally changed her position from that of what would be assumed as "powerless" student to someone with authority: Shyam: So, if you have a piece of writing that may have different stylistic issues, different language issues, different sentence structure issues ... does it bother you?

Student B: Yes, it bothers me. Actually, I didn't realize that until I reviewed some conference papers last year. Until that time when I reviewed other people's papers for the conference, and I realized, okay, it's very easy to tell okay this is a native speaker's writing and this is not native speaker's writing. [laughs]

Shyam: So, it is not until you review other people's writing that you start feeling that language is important?

Student B: Because in other cases I don't have much opportunity to read drafts from others. I just read published paper that is already well-written, usually.

While Student B did not say that she was bothered by language difference in the writing of NNES writers, her responses cited above indicated her preference for native or nativelike writing style in academic journals. After I showed her the chart of four different views towards language difference, she was interested in the multilingualist view that there is no single standard: she said, "Okay, I like that idea," but a little latter, she added, "Definitely, I like this idea, but I think that it's not happening right now." It is not surprising that Student B simply conformed to prevailing views towards language difference because even the scholars who were most established and have little to risk by not doing so seem to fully buy into the same views. This means that individual members 
of the discipline are more inclined to succeed in their profession by adopting positions that facilitate that success than they are willing to take any risk by allowing language difference into their work. More generally put, when individuals are asked to assume authority they begin to change their view about power, though they may or may not appreciate such power when they lack it. And that circulation of power through institutional structure, discourse of the community, and the process of educational or professional growth of individuals gives continuity to linguistic norms and practices.

In sum, because the faculty and students believed that the elimination of language variation is a necessary condition for engineering writing, they cannot be seen as outsiders who lack the power of the norm: they are part of the dynamics of power vis-àvis language standards. As Foucault has argued, there may be no haves and have nots of power but a power dynamism where the NNES are not the default outsiders but default members alongside their NES counterparts.

\section{Being in the same boat: Multilingualism and Affective Domain}

In the two preceding sections, I discussed some of the general patterns of the participants' responses about language variation in engineering writing. As it was partly evident in how NNES faculty passed the buck of rigid monolingual standards to the system, one important issue that complicated those patterns was a sense of empathy and understanding that the participants had for NNES students or peers. I find it necessary to illustrate this dynamic because in spite of generally embracing reductive views about language and writing, the NNES faculty members can be the best resource and also best ally in any program that aims to improve the NNES students' proficiency in the language/discourse for the advanced disciplinary communication. For one thing, they are 
in the majority in the discipline, but more importantly, they are likely to possess a good deal of knowledge and experience about language and writing multilingual individuals-and even as former international students - that they can use while providing support to NNES students. If they are willing to use their multilingual abilities, they do have those abilities toward understanding and appreciating the difference in language use in their students' writing.

At a certain level, the NNES faculty seemed to feel a greater sense of responsibility toward their NNES students. Consequently, even when they espoused strong monolingual views, they justified them by arguing that they should not give the NNES students "any slack today" because the students could suffer down the road as a result. The rigid and reductive views about language that they tried to enforce did not occur to them as problematic---and that is what writing programs and courses need to promote against the grain of engineering discourse about language and writing.

The tension between being sympathetic about the struggle that NNES students had with their writing and the rejection of the English that may either be a different variety or that the students are in the process of learning seems to be caused by what I call the sense of "being in the same boat." This section illustrates how the monolingual beliefs and practices among the participants were complicated by the affective domain. It focuses on how affect influences NNES scholars' treatment of language difference in NNES writing in ways that often contradict their stated beliefs in support of monolingualism, which is shaped and influenced by the general discourse about writing and language in their disciplines. 
Even though the faculty said that they were more or less bothered by anything other than standard "technical" English, when the issue of their own language identity or the challenges that they faced in the past or present was evoked, the level of their tolerance generally increased. That is, in contrast to their strong rejection of language variation and their staunch belief that students must learn the one standard English if they want to succeed as writers and engineering professionals, the faculty members' willingness to consider language variations changed when the question, context, topic, or story involved themselves. The students' assessment of language variation similarly changed when their own struggle with language was at issue. Any moment the idea of them being in the same boat as being non-native users of English was evoked, the conversation seemed to suddenly strike a different note with both faculty members and their students, softening the harsher judgment of grammatical errors and other language variation. For example, when asked whether is bothered by different types of language differences in NNES writing, Dr. Y first emphatically stated that he is bothered by those issues.

Shyam: ... sometimes they're simply grammatically problematic, sometimes it's just awkward, sometimes it's single words and sometimes it's the sentence as a whole that's unclear--and so does it bother you when you see this kind of language difference in a student writing at the graduate level?

Dr. Y: Yes. Absolutely. Absolutely, and I have seen these not only from students but even from professors. And I am a reviewer of our own fifteenth refereed journal. And I am telling you, every ten or twenty papers that I review, there are I would say fifty percent of those papers have lots of grammar issues. 
When further asked if he would also be bothered by language issues that do not hinder his understanding of the content of a piece of writing, he insisted that he rejects professional writing that has those issues:

Shyam: But let me pose this hypothesis-- that you understand, like you are suggesting, the content, but the writing probably doesn't meet the professional standard in terms of the language. How do you respond ....?

Dr. Y: If it is a journal [article], I will reject the paper.

Shyam: Or do you--

Dr. Y: I reject based on, I mean, I can tell--typically this language is-- I don't know, seventy five or eighty percent. There [are] small technical issues. But mainly I reject the paper because of grammar. In a student, with a student, I think it is different.

However, when I raised the issue of language background and identity, his response was strikingly different:

Shyam: So let us suppose that you see Chinese, Indian, say Nepalese, Mexican, you know, different kinds of Englishes that may be completely standard in their own places, but when you come to the mainstream American academics-- How, what would your expectation be? Would you accept, would you correct, would you tolerate, would you just be okay--

Dr. Y: No, I mean obviously I need to tolerate. I am in the same boat, you know. I know that each of us have different accent. For example, in my undergraduate course on material sciences, they have around fifty students. There are always at 
least three to five students that complain about my accent. They say that I have a very strong accent. ... which kind of bothers me.

What is quite striking about this response is that whereas the anonymous writers of journal articles are viewed dispassionately, the students whose NNES identities are specified evoke empathy and understanding significantly.

Most of the participants considered difference in accent as natural and normal in spoken English, but they were not ready to recognize anything other than outright error (or insignificant spelling differences) in writing deviating from a universal standard English; some of the participants made it clear that spoken accent needs to be tolerated even though it can cause miscommunication because "I too have an accent"! For example, if we observe the above quote from Dr. C, it seems that he interpreted my question about language difference in academic writing as a question about accent, and it is possible that he saw that as the only variation of significance because it continued to affect himself. Considering that he rejected journal article submissions due to grammar errors, and also considering that accent is a language variation that is perhaps the hardest to overcome, it was evident that he---like all other participants-was willing to tolerate in others what matters most to him. None of the participants were willing to give variant forms of written expression the same status that they gave to variant accents with which the same language can be spoken. Thus, the connection to personal experience or empathy for others significantly changed the perception and treatment of language difference among the participants. 
With some of the other participants, the issue of being "in the same boat" was even more explicit. Here is, for instance, Dr. X on the subject of being tolerant about language difference:

Dr. X: Oh, how would I perceive that kind of writing ten years ago? I would have been more sympathetic to that person, because I knew ten years ago that I was not a great writer myself.

He further added that the level of tolerance would rise to a whole new level if the writer is his own friend or classmate:

Dr. X: So, I would have been more sympathetic if he was my friend or say if he was my colleague as a graduate student, and we were both writing for the same professor, and if the professor said, like "oh, you are a horrible writer," and if he came and told me, I would be like, "hey, don't worry, [friend], you know, it's not a big deal. If he's picking on you"-- and whatever.

Thus, within the same response, as he switches from past to future, or from being a student to being a teacher, he also shifts from sympathy to demand, from not worrying about language issues very much to working towards eliminating them.

Dr. X: But ten years from that time, now, if I think, I would try to tell them--like I wouldn't say that this is terrible writing. I don't say that to any student. I just say that if you cannot write then your future is not going to be all that great. You could actually make a career or break a career based on how well you write. And you tell that to your students and they seem to be very receptive of that. Because they know that they have some stake in the--then they start to work harder on 
their writing. Unless you tell them what is at stake. So, yeah, ten years ago, I would be more sympathetic than now.

Very often in the interviews, with both faculty members and students, this kind of switch leading to harshening or softening of judgment happened particularly when they brought in their own experience. Here is, for instance, an exchange with Dr. A, who was critiquing the common practice of faculty members essentially writing their students papers in response to my question about what she considered the most important quality of writing. Then I changed subject and asked where she went for her own graduate studies and whether she wrote in English:

Dr. A: Well, in my case it's just basically logic, as long as my logic is straightforward, then I'm okay.

Shyam: So, how did your writing skills transfer from that background to this [setting]? Or did you struggle at first to write a different way, or?--

Dr. A: I mean it's difficult to write in English. But you know--

Shyam: But you wrote in English back home, didn't you?

Dr. A: Not really....

In the context of students' writing, Dr. A had been asserting that she was not as concerned about grammar as she was about the thought process and clear logic of a piece of writing; here she repeated that assertion. However, my question about whether she "struggled" to write in a different way seemed to elicited empathy in such a way that the responses that followed contradicted the high demands that she had said that she made of her students only a moment earlier: 
Dr. A: [With] my international students, I am very--very — strict, because I want them to survive after they graduate. So writing something not well gives some kind of impression that the person is sloppy, although they might not be. So I am very careful.

Shyam: So, you hold them to higher standards, right?

$\mathrm{K}$ : Probably I am one of the most strict in that sense. I don't know whether it is causing a problem sometimes, because I guess it depends upon where, what kind of--I mean I am getting into very, politically not correct division.

In response, I asked her if her students' struggle with language has to do with the fact that, like her, they may have not learned writing skills in their home countries before they came to the U.S. She now switched gears and began to share her own experience about the challenges of learning English.

Shyam: Is that why the [international] students are struggling when they start writing in your discipline, in your class, when they come here?

Dr. A: I think it's much more like--I had a problem with colloquial English. The most difficult one was the idioms with prepositions. Those are difficult. I didn't get any jokes from the TV.... The prepositions are very difficult. And another thing is, you have British accent and American accent. ... It's very difficult for me to convert that to daily living or to writing this way in English. That was very difficult.

The choice to share personal experience in response to a question about international students' challenges with effective academic writing is logically relevant. But it is interesting that the choice also prompted a significant leap on the interviewee's part from 
highly demanding professor to an understanding NNES person who had and still has some challenges with the language.

The NNES students were more tolerant of language differences and sympathetic towards other NNES writers, with relatively much more sympathy towards students like themselves:

Shyam: Okay. Let's suppose that this is written by a professor who is writing this for a journal article. Would your attitude, your feeling change towards that writer? Student Y: I would think that his grammar is not that good either. [emphasis added]

The word "either" in Student Y's response indicates that she is placing herself on the side of those who make grammatical mistakes. She had been telling me that she lacked confidence in her ability to choose the right words, expressions, and grammatical structures. In fact, instead of just telling me whether her view towards the writer of an article would change if she knew that it was a professor, she now refers to her own challenge with grammar as well as refusing to make a statement of what she believes. Later on, when I showed her a few examples of errors and awkward phrasings in the anonymous sample of student writing and asked her if those issues would bother her, she not only refused to answer my question directly, she also identified herself with the NNES writers in question and contrasted "us" with native English speaking writers, or "they" who have the privilege of using their first language "naturally":

Student Y: Yeah. I think that native people can make the transition from this sentence to this sentence very naturally, but I don't think that we can do it very 
naturally. We have to think about the transition word which we want to actually use.

Student $Y$ was unwilling to judge any writing because she said that her English is not good enough to do so:

Shyam: But let us suppose that you know that this sentence is really grammatically wrong, and yet you can understand the meaning. Would that bother you when you're reading?

Student Y: No.

Shyam: No? What would you say?

Student Y: Uh, it's just a small mistake. It's like a typo to me.

In some cases, the sympathy towards fellow NNES students or scholars was expressed with strong emotional words. Thus, the participants generally bought into the deficit view of language difference in academic writing, that complicity with the prevalent discourses was significantly complicated or subverted by the evocation of the affective domain: empathy with (fellow) students, remembering one's own difficult experience or existing challenge, or the consideration of one's role as a teacher seemed to affect the monolingual disposition and complicate the dynamics of author and agency that I discussed in the previous section.

The above issue of how affect complicated the multilingual scholars' monolingual disposition is an extremely important one because it alerts us against making any generalizations from the kinds of patterns that I discussed in the previous chapters. It reminds us that there will always be an array of factors that work for and against monolingual dynamics, whether it is among the so-called monolingual scholars or their 
NNES counterparts. This also means that any intervention against monolingualism in favor of promoting a more critical view of language needs to involve an understanding of the complex factors that make the monolingual dynamics in the academy an almost selfperpetuating but highly complex mechanism.

\section{Conclusion}

Current research on NNES writing indicates that monolingual policies in the academe and the professions adversely affect NNES scholars in academic writing and publishing. Being situated squarely in the global center rather than the periphery the participants of this study seemed to be unaffected by the monolingual gatekeeping of their discipline and profession; in fact, they wanted to enforce the monolingual standards themselves. And yet, many other factors like the desire to see their students succeed within the monolingual system, empathy for the struggle that the students have, and the understanding of the inevitability of variations at least in speech complicate and often undermined the dominant monolingualism.

While the prevailing discourses, beliefs, and practices about language and writing in engineering seem to prevail among multilingual faculty and students in perhaps the same way as they do among their NES counterparts, it is also possible that multilingual faculty and students being in the majority makes the actual language and writing used in the discipline more varied, rich, and complex than the members of this discipline are willing to accept. That is, on the one hand, it seems that NNES faculty and students' being in the majority in engineering makes it more challenging to promote more nuanced and accurate understandings of language and writing in engineering; on the other hand, the fact that the discipline is linguistically very diverse and that its diverse population 
practically negotiates meaning across language varieties, cultures, and often countries also probably means that the objective of promoting more complex understanding of language and writing will be easier in this discipline. In particular, the experience, expertise, and ethos that multilingual faculty have with both standard English that students do need to learn and also for promoting more nuanced views about language could make them very effective models and teachers.

In the next two chapters, I return to both the general objective of promoting the status of writing and the particular issue of how rigid monolingualist views and practices may be addressed toward achieving that objective. 


\section{CHAPTER 4}

\section{A PRAGMATIC APPROACH TO PROMOTING WRITING IN ENGINEERING}

"I just want to use images to show what I am saying. I don't want to use words. . . The second [quality of engineering writing], I try my best to use very standard form to write a sentence. . . [and] very short sentences." - Student $\mathrm{X}$

"Some professors, probably, they do [the communication] all by themselves, they don't ask students to do that a lot. [My adviser] let me do it and she let me take a lot of responsibility in the lab. like waste management, and for that you have to communicate with a lot of people.... she takes me when she has meetings with other professors, so I watch how to communicate." - Student A

In the preceding two chapters, I discussed how multilingual faculty and students in engineering largely buy into monolingualism both in the sense of defining language and writing reductively and in the sense of considering any variety of English other than its non-existing clear, simple, and universally consistent standard as the only permissible language for scientific and technical writing. The data I analyzed in those two chapters largely came from the first and second rounds of interviews when I had focused on what the faculty and students "said" about language and writing in general, how they "reacted" to features of non-standard English in writing samples, and how they "described" their teaching and learning practices. During these interviews, a sense of awkwardness characterized my interaction with the participants, because they generally "positioned" themselves as engineers who understand and use language and writing "differently" from "you English people." While there were variations in the level of this interdisciplinary tension between me and the participants, that tension clearly showed the need for a 
different approach to interviewing and additional types of data. So, I designed a third round of interviews with faculty members ${ }^{18}$ and conducted them by assuming the role of an active participant observer. In these interviews., I also explicitly challenged the faculty to explain the paradoxes in their beliefs and responses, as well as to share my own ideas and perspectives on the issues. Consequently, this round of interviews was much more effective in helping me see past the more superficial and generalized responses like "this is how engineers think" or "it's not like English." This change in approach led me to much more engaged discussions, helped the faculty focus on the problems, discuss the issues more critically, and describe and show their best practices on their own terms. It helped me identify the contexts, purposes, and perspectives in which they valued writing and were willing to teach or promote it in other ways. Because these interviews involved more candid and in-depth discussions, and because I did not try to remain detached as a caution to not "influence the data," the interviews yielded a better view of the discourses, ideologies, practices, and priorities regarding writing among the participants. As the study developed, I also gathered emails written by students, published scholarship by the faculty members, students' writing with comments from the faculty, notes from class observation and informal discussions with the faculty and students, and so on. These materials helped me examine teaching practices more closely.

In the following pages, I first demonstrate a few striking and specific practices for teaching/facilitating students' writing among some of the faculty members which they adopted in spite of their monolingualist beliefs about language and writing. Based on the demonstration, in the second half of the chapter, I argue and propose that looking more

\footnotetext{
${ }^{18}$ I did not follow up with the students because two out of five of them had left town; my objective was best fulfilled by talking to the faculty members in more detail.
} 
closely at the actual practices of faculty even in academic disciplines like engineering can help WID scholarship and programs to start from the ground up rather than trying to confront and change the prevailing views and practices that seem to undermine writing as seen from an outside perspective. Thus, this chapter constitutes a general framework for promoting writing in engineering, highlighting some of the contexts, purposes, and perspectives in which engineering faculty considered it worth investing time and effort toward promoting their students' proficiencies in language and writing.

\section{Best Practices of Teaching Writing among the Faculty Participants}

During the course of this study, as I analyzed the data more closely, returned to conduct more rounds of interview, and collected different kinds of writing samples and engaged in informal conversation with the participants, I was not only struck by how much they shared rather problematic theories and discourses about language and writing but also by the differences among the faculty and students in terms of how they actually approached the teaching and learning of writing. A number of very effective practices among some of the faculty - in spite of their views--led me to look more closely into those practices. So, in the final interviews, I not only asked the faculty how they integrated writing into their teaching of engineering subject matters, when they started focusing on writing in the students' graduate school careers, what writing activities they assigned to their students, and what kind of support and feedback they provided on their written work. Data sources other than the interviews also showed that some of the faculty and students are also aware of their discipline's demand for increasingly complex linguistic and rhetorical skills for academic and professional communication in the long run. While they generally denied anything other than standard English a place in 
engineering writing, some of these faculty did not wait to see their students to automatically "pick up" correct English and considered that as primarily constitution writing skills: they supported the students' learning of writing as a process that involves practice, opportunity, specific contexts and purposes, and a motivation to communicate through writing. Thus, in this section, I illustrate some of those best practices that some of the faculty adopted, which I do by contrasting with what seemed to be mainstream lack of explicit teaching/learning of writing skills in engineering. When drawing the contrasts, I also highlight the contexts, purposes, and perspectives in which the faculty taught and were willing to teach promote writing. The identification of those purposes and perspectives forms the basis of the theoretical framework in the second half of this chapter.

\section{Integrating Writing into Engineering Education}

It was evident that all of the five faculty participants gave a great deal of one-onone time to their students; however, those who advised students who were relative confident and competent in writing dedicated significant amounts of that time to helping the students with their development as writers. They had an integrated view of their students' development as writers and as engineering scholars, so they gave greater priority to writing in their teaching. For instance, Dr. A and Dr. B said that their students started early, were given plenty of time and support with their writing, and the support was based on where individual students were as writers. The attention and importance that they gave to writing made a clear difference in their students' proficiency and confidence as writers. 
By contrast, the teachers of students who were relatively anxious as well as lacking in writing competence viewed and treated writing in an un-integrated manner visà-vis engineering education. These faculty also tended to see writing as separate from engineering work, as something that is best taught and learned elsewhere. Thus, they dedicated little or no time and explicit attention to writing, an issue that Dr. Y stated explicitly.

Shyam: But think about writing in general, like organizing, presenting-like how to write an abstract. Do you never spend time on such issues with your students?

Dr. Y: I don't spend formal time on doing that.

Shyam: So, you don't talk about writing at all, not just grammar.

Dr. Y: Not really. Only the technical part.

Dr. Y said that his students met him in person regularly and that they orally updated him about ongoing projects. He did not require his students to write anything substantive until it was time for them to start working on their dissertation in the third year during a four to five year program. His student, Student $Y$, described writing based on the same view that it is an independent skill from research: "the writing and the research part is separated in my opinion. I think that writing part is just summation [of research]."

The advisers of writing-anxious students also separated "good writing" from "engineering writing"; for the latter, "basic skills" in writing were sufficient (especially when it came to graduate student writing). For example, Dr. X said that writing requires a personality and aptitude that is the opposite of what engineers are normally like; he said that only the rarely "creative" and "patient" engineering scholars become good writers. According to him, the average engineering scholar or student finds writing stressful and 
does the minimum, required writing. Similarly, Dr. Z suggested that engineering writing primarily involves putting together facts and figures and only a minimal amount of verbal language in its simplest possible form. This view of writing seemed to obscure the fact that the advanced disciplinary writing that graduate engineering students need to do requires a complex set of knowledge and skills, including the mastery of not only the content but also the discourse and conventions of writing in the discipline.

\section{Treating Writing as Part of the Big Picture of Professional Development}

The advisers of the writing-confident students not only saw writing as integral to the students' graduate education, they also valued writing as part of the big picture of professional development of the students. Even as they held reductive views about language and writing, the fact that they wanted their students to develop skills for professional communication led them to better value the complexity, rhetoricity, and variability of language as used in contexts beyond the academe. Even when they said that they didn't know how engineering programs can develop sufficient professional communication skills in their students, they believed that if students do somehow and eventually develop more sophisticated language and writing skills, those skills will give them significant leverage over others for success as engineering scholars and professionals. When I asked the faculty to provide me with recommendations for teaching, curricular updates, and policy changes in favor of promoting writing in their discipline, these faculty not only recommended some very effective strategies, they also used those strategies for helping their students develop writing skills. For instance, Dr. B suggested that engineering students should be required to write frequently and also 
starting early so that by the time they graduate, they are able to fulfill writing needs in the workplace:

Dr. B: I think that if I could do it often enough ... if they are required to write often and starting early on.... to the extent that you have these courses or other opportunities or obligations where they are required to write something, that would probably be a good result.

And he went on to add students should be made aware early on that in the long run they will need to be published scholars and therefore "letting them write about something that may be out of their technical domain would be useful" even while they are in graduate school. Similarly, Dr. A recommended that graduate engineering students need to develop a wide range of professional skills including teaching skills, interviewing skills, and skills for research and publication.

In comparison, the advisers of the writing-anxious students offered recommendations that were more theoretical and tentative; their recommendations were also seldom based on their own teaching practices. For example, when asked what would need to be done to improve engineering students' writing, Dr. Z said that he would like to provide his students grammar courses, suggested that assessing what students write would lead to better writing, and then went on to add that engineering faculty are, however, not equipped to provide those supports.

Dr. Z: It takes time to really do that [assess writing] because you have to evaluate and assess the work of students on so many different levels. We don't do that. And sometimes, the people that have attempted to do that, the results are so poor, because students are just, a lot of them, just cannot [write well]. 
Even more strikingly, he suggested that academic writing in engineering could be improved by increasing the proficiency of students who are accepted into graduate school: "For example, you bring a student from [country X], and you know, he does very well technically but then at the very end, he has a very difficult time writing the dissertation. ..."

Whenever the issue of the big picture of professional development came up, all the faculty participants clearly agreed this as an important goal and purpose for improving engineering students' writing. But some of them invested clearly more time and efforts toward actually achieving that goal for their students. So, approaching the teaching of writing as a means of professional development was at least not opposed even among faculty who did nothing toward achieving that goal.

\section{Letting Students Write for Practical Purposes Beyond Academic Requirements}

The advisers of the writing-confident students gave their students various opportunities to complete small but practical writing tasks that fulfilled a variety of purposes beyond academic requirements. These writing tasks included emailing vendors, projects partners, and peers and professors to organize or lead research projects; floating agendas and taking meeting minutes during more significant meetings; preparing brief summaries and lecture notes before weekly presentations; reviewing each other's drafts; coauthoring articles with the advisor; and collaboratively developing conference papers and slide materials with their mentor or other students. These writing-mediated activities allowed the students to take the initiative to coordinate and complete the projects assigned by their advisers. Such writing also spread beyond the academic to the social sphere. For instance, Student A highlighted the importance of general communicative 
proficiency as the basis for becoming successful in academic and professional writing with the words that I quoted in the epigraph of this chapter:

Shyam: What helped you the most between the initial struggle and your current status of liking it?

Student A: ...by writing emails, or communicating with people, you feel that they are understanding you, and that's encouraging. ... My advisor, she let me do a lot of communication with other people....

Engaging students in these writing activities did not necessarily involve more time on the part of the professors. Often, the faculty who gave their students these opportunities actually saved their own time by letting the students do the work through writing.

In contrast, the teachers of the writing-anxious students almost exclusively required writing for academic purposes. Their students were not very engaged in writing to communicate in practical contexts like conducting the business of their lab by using email or carrying out writing-intensive tasks outside of class and lab. They were less motivated and did not find writing relevant and inspiring because they did not write for social and professional contexts and purposes. For these writers, writing was simply the last stage of the research process when they thought they were objectively encoding their ideas into words, rather than see writing as an opportunity to professionally develop as engineers. This view may have contributed to the idea that I discuss next, that oral communication is associated with real engineering work and technical requirements while written communication is just a small step tacked on to the end of a project. 


\section{Giving Writing its Due Place Alongside Oral and Object-Oriented Communication}

Between the two groups, there was also a clear distinction in their emphasis on oral presentation in relation to writing. The instructors who mentored the writingconfident students asked the students to write down reports and then produce slides or notes for presentation even during their regular meetings. They treated writing as involving a set of distinct skills from what oral discussion and presentation of ideas require, allowing students to start early and to gradually improve their language proficiency and understanding of writing conventions.

By contrast, the faculty of writing-anxious students let their students orally present their ideas almost exclusively, with the exception of minimal or required writing. They did not integrate writing into their daily work because they considered oral presentation a substitute for writing. For instance, when asked what he did to help his students learn writing skills, Dr. Y said: "for some reason, students that can communicate better orally are the ones that have better writing." He also added that that his students improve their "language and grammar skills" if they frequently presented their ideas orally. And here is how Student Y echoed her teacher about the place of writing in her program:

Shyam: ...But how do you document the results of your experiments without writing? ... you have to report that to your professor, right?

Student Y: I don't have to write it down. I consult with him. We talk to each other.

The professor and the student both said that they used face-to-face conversations and the student's oral presentations to be on the "same page" about ongoing projects, but 
somewhat ironically, there was little on the "page" until the student almost graduated. When I asked his student, Student Y, what might help her improve her writing, she expressed the same view as her adviser: "it would be nice if we [students] had a lot of opportunities to talk to each other" (emphasis added).

A database search of literature on oral communication in engineering indicates that there is more interest in how to enhance oral communication skills among engineering students and scholars than on how to improve their writing. Indeed, the scholarship on engineering writing suggests that the majority of engineering scholars are satisfied as long as students keep learning and presenting ideas orally, can present writing that is short and simple, and have just enough writing skills to complete degree requirements (Kranov, 2009; Leki, 2006; Braine, 2002; Belcher, 2007).

One of the reasons why oral communication is privileged in engineering is that engineers value object-oriented discourse (Winsor, 2000) which favors physical objects, space, and bodily gestures as means of communication in comparison to verbal and especially abstract language. Haas and Witte (2001) found that gestures made in oral conversations helped engineers visualize the physical realities they were discussing, which in turn facilitated them in revising their written documents. Wolfe (2005) likewise found that a group of students in a technical writing classroom "used gestures to create a conversational interaction space that they then treated like a physical text that they manipulated, wrote on, and pointed at" (298). This interaction space not only facilitated the students' in collaboratively generating ideas, but it also possibly demotivated students from engaging in the actual process of writing up the findings because "they see the written document as secondary to the primary text of the conversational space" (326). 
Being able to orally and gesturally convey their ideas gave the impression that they had already done what was necessary for writing.

The inclination to favor objects was also seen in the amount of value that engineering scholars and students accord to images, figures, and tables in their writing. In this regard, even the writing-confident students argued that in engineering images, figures, and equations were more important than the language surrounding them. For example, Student A contrasted her experience of writing as a student of ecology in her home country with that of engineering writing:

Student A: Especially in our fields, you are able to read articles if you focus on those figures and tables, the data, and then the conclusions. It is pretty clear. [In the social sciences] it's a lot of ideas. In those fields I think it's very important how you write.

While the faculty did not necessarily value images, data, and figures over words, they accepted object-focused communication as a norm in their discipline. For instance, describing an incident when his students failed to understand test questions because he did not include any images or figures but just words, Dr. Z said, "we need to do more of that, and get them used to [understanding and using words better]."

The dramatic increase in the number of NNES faculty and students in engineering could have also lowered the status of writing in relation to orality. Given that many of these faculty and students come from educational backgrounds which place little emphasis on written communication, it is possible that they exacerbate the already low priority given to writing in engineering in US universities. For instance, Dr. A (who 
came from Far East Asia) stated that in her home country English instruction was primarily limited to oral language:

S: But you wrote in English back home, didn't you?

Dr. A: Not really. We do learn English but not extensively, you know like write actual papers or something like that.

Other faculty also said that they were required to write but were never taught writing skills in college. Dr. $Z$ and his student (both of whom were from the Middle East) said that they used to pay great attention to grammatical correctness but the writing they did was by no means comparable in its quantity and quality with what they produced when they first came to the US. Dr. Y, who was from South America, also said that the rigor of research and writing was comparably weak in his home country. Dr. X said that his writing skills did not come from his academic background in India. Students from China - Student A, Student B, and Student X-said that they did write scientific reports in college, but that writing was mostly in Chinese. The findings of this study clearly showed that more research into the connection between NNES faculty and students' academic and cultural backgrounds and their views and practices of teaching/learning writing is needed.

\section{Providing Feedback on Students' Writing}

Finally, even when the advisers of the writing-anxious students helped the students with their writing, they tried to "fix the writing part" in students' work, or in some cases, do the students' writing for them. Findings on this issue have been documented comprehensively in a literature review in Jordan and Kedrowicz (2011). Because they believed engineering writing only requires minimal, simple, and easily 
learned skills, they expected their students to learn by reading and observing their teachers' corrections. The writing-anxious students accordingly exclusively focused on the content of their writing, assuming that their advisers would take care of the writing part. For example, here is how Student Y said she improves her writing:

Student Y: I think the best way is that when I finish writing the paper, the professor revises it, make changes, so I will learn from that.

It is possible that she did learn something about how to write by observing the changes made her professor on her writing; but this is arguably one of the least effective methods of doing so.

Another student, Student X found his adviser's approach of correcting his writing without explaining the corrections quite frustrating. He said that Dr. X only looked at the final product of his writing and made changes, which he found frustrating because he believed that the professor was not paying attention to his ideas and focusing unduly on the "language" (something he knew was his great weakness). Because his adviser did not provide or discuss feedback for him to improve his writing, the corrections he received neither taught nor motivated him to write better.

In a stark contrast, Dr. A and Dr. B said that they provided comments and let their students revise their writing up to ten times. Dr. A gave me a few copies of early drafts of graduate student writing from a course that she was teaching at the time. Showing me student writing in which she had used different colors to provide feedback on language and content, she said that this was a time-intensive strategy for helping students with their writing but she emphasized that the time was worth spending because she believed that writing is essential to students' development as engineering scholars. Furthermore, 
because she wanted her students to improve their writing by taking ownership of it, she even refused to provide "corrections" in the form of "track change."

Dr. A: So, what I teach is... I can actually do the tracking thing, but with tracking, they usually click--accept, click-accept. They don't really learn how to do it on their own.

As a program director, Dr. A also went to express her concern about the lack of support for students' writing among engineering faculty, a concern that aligns with what Jenkins et al. (1993) reported in their study of attitude toward writing among engineering scholars. Dr. A said that too many engineering faculty in her university do what Jenkins et al. describe with an anecdote of a faculty participant who did his students' writing:

I have both MSc and PhD students in the past that have been so [sic] poor writers that in the end, after numerous revisions, I have had to give up and essentially write the thesis myself. I could not afford to pay the students month after month on research contracts and get nothing back. (Jenkins et al., 1993; p. 62)

Dr. A said: "most of the professors simply do not have the time to do that [help their students with writing]. They just write the students' papers so they can publish." She was also critical of the underlying emphasis on just helping the students "get the degree" instead of taking the time to develop essential skills like writing.

The advisers of the writing-confident students were not only aware of the benefits of helping their students improve their writing, they also adopted relatively sophisticated approaches in their support for their students. For example, when asked to discuss a few things that he did to help his students improve their writing, Dr. B said: 
$\ldots$ it depends upon the particular student what kind of technique I might use, so if that's somebody who I think can write reasonably well, then maybe the focus should be on the technical side of it. But if it is somebody who cannot write well, then you cannot ignore the technical part and just let them express their ideas clearly in very simple terms. Then in the second and third iterations, we get into the technical stuff.

Thus, this kind of thoughtful and effective approach to teaching writing among some of the engineering faculty represents the kinds of best practice that current literature on engineering writing has not yet paid much attention to. Some of the best practices found in this study are theoretically discussed as the basis of a framework for promoting writing in engineering in the rest of this chapter.

\section{A Pragmatic Framework for Promoting Writing in Engineering}

In this brief section, I describe the central proposition of this study, a proposition that emanates from the close observation of the best practices of teaching/supporting students with their writing among the faculty participants. I argue that the promotion of writing in engineering can be most effective if universities and writing programs recognize and start by implementing and enhancing strategies that the engineering faculty and students as practical and feasible. Theoretically put, the pragmatic approach that I recommend involves the following steps:

1. Study how faculty and students in a discipline theoretically define and practically treat language and writing

2. Develop programs, resources, and collaborative mechanisms that draw on their own existing practices, especially that make practical sense to the faculty 
in the discipline as the most important stakeholders of the writing program/initiative

3. Promote writing further by fostering critical conversations about language and writing in the particular discipline

However perfect solutions proposed by writing scholars and programs may be in themselves, it is only when the faculty and students in the discipline concerned are on board that the goal of promoting writing in that discipline can be best achieved. Solutions that are developed from the perspectives of writing scholars can fail if writing programs overlook the conditions and forces that shape and influence the persisting views and ideologies about language and writing in the discipline, the curricular priorities and limitations, the institutional and professional power structures, and the mechanisms of incentives in the disciplines. Efforts for improving language and writing proficiencies in disciplines like engineering should begin by understanding what kinds of writing skills they deem relevant, from what perspectives and in what contexts they consider these skills necessary. While engineering faculty may generally embrace views about language and writing that seem problematic to writing scholars, it is by understanding their views and appreciating effective practices that academic writing can be effectively promoted in the discipline concerned.

My initial interest in how NNES scholars perceive and treat language difference in students' writing came from the desire to test some of the claims about the potential flexibility and tolerance of NNES scholars toward language variation; the NNES scholars who participated in this study not only confirmed my doubt about the claims in the scholarship but also surprised me with their views about how students learn language and 
writing in their disciplines. Thus, as the study developed, I further narrowed down my focus to the question of how the prevailing monolingualism among NNES scholars impacts the NNES graduate students' process of learning academic English, writing skills, and their academic socialization in general.

There is no doubt that academic and professional writing needs clarity and precision; and indeed one of the readily available forms of such a linguistic medium is, no doubt, what goes by the name of standard English. However, my position is that it is the standard academic English (SAE) understood as a complex and variable repertoire of linguistic resources that needs to be promoted, and not the myth that standard English is in itself a clear and simple medium, nor the idea that engineering writers do not need to pay attention to issues of language because the effectiveness of their writing comes from focusing on the content alone. And that is why I believe that it is necessary to explicitly learn and systematically teach or facilitate the learning of standard academic English. This learning will necessarily involve appreciating as well as striving to gain increasing command over the complexity of SAE. In this sense, I do not disagree with the general position held by most of my research participants that engineering writing needs to be done in SAE, which they further argued should also be more clear and objective than the language used in academic writing in the humanities and the social sciences. I only disagree with them that SAE, or "scientific" or "technical" English as they often called it, is a simple and universal medium of communication that students will learn automatically in the process of learning the content of their discipline. While it is true that if there is no alternative of explicit teaching and promotion of proficiency in SAE, then a student will learn SAE, however slowly and painfully, through exposure to the language in practice; 
by the same token, if that student has no other alternative but to learn how to write better through gradual internalization of the norms and conventions of writing, then he or she will learn to write in that manner. What is necessary to do for changing the status quo is an inquiry and application of strategies for how students learn best, what approaches and strategies help them learn more efficiently and quickly, how they gain confidence rather remaining resistant for long periods of time toward using language and writing in their scholarship. When writing programs and engineering faculty foster critical conversations about language and writing and promote the best practices for teaching them, graduate students can gain linguistic, rhetorical, and writing proficiencies quickly, efficiently, and without the frustration and failure that many of them seem to go through before they are considerably proficient.

\section{Conclusion}

In conclusion, let me highlight a few important issues that I discussed in this chapter while proposing that in order to confront the problematic views about language and writing, it is necessary to address engineering faculty and students' argument that a monolingual standard and basic writing skills are "practically" sufficient in engineering. One of the reasons why engineering faculty and students do not consider proficiency in language and writing a primary goal of engineering education is that while they agree that students with higher proficiency in language and writing can be more successful professionally down the road, they insist that complex and rhetorical language and writing skills are not necessary as part of graduate education. In fact, because the insistence that engineers do not need to strive for more than the basic language skills was a part of how the participants of this study perceived their disciplinary identity in relation 
to language, communication, and writing. The idea that "we don't do language" seemed to be a part of how they defined "engineering" and their identity as engineers. Therefore, one of the crucial steps in building writing programs or promoting writing through the engineering faculty is to counter this problematic notion that writing is pragmatically not the most important part of engineering education. Researchers have long shown that linguistic and writing skills are high on the list of demands for engineering graduates; many engineering faculty are either not aware or do not pay attention to this reality and need to do so.

The predominance of the idea that simple English is sufficient for engineers was most strikingly manifest in my interviews with writing-anxious students. Even when these students said that they did not have adequate language skills to express their ideas, they continued to disagree that they need increasingly higher levels of language and writing skills for writing successfully in their discipline. Ironically, those who lacked proficiency in language and writing believed that those skills can be replaced with a focus on logic, images, and figures. Thus, it is important disrupt such views toward making these students more aware that language is important for engineers, that standard English is not a simple and universal language, and that engineers can communicate better when they have a better understanding of language and a broader repertoire of rhetorical and writing skills in order to represent the content of their writing. The idea that language and writing skills are "not important" becomes jarring when we consider the level of proficiency at which most students start their graduate studies and lack of speed and confidence in their acquisition of those skills. On a careful analysis of the interview, this kind of insistence on the sufficiency of figures or data seems to be a manifestation of 
defensiveness about perceived lack of language proficiency. So, here is how Student X articulated his reason for downplaying of the importance of language in technical writing:

Student X: For me, in Chinese I can write a lot of things, not little. Like you say, in English I cannot write very fluently, so I just want to write the very important sentences. ... And make it shorter. Because I need to think about these sentences and how to connect them and how to use the words. I just want to some main things here.... if I use Chinese to write, I think it's better. It's much better than this one. For this one [in English], the experiment part, I just write what I did. If I use Chinese to write, I will write why I would do this and why other people do not do this. How other people do this. I will write a lot of things. But here, in English, I think it's enough. I don't want to put other things, maybe it will cost a lot of time.

The paradoxical undermining of the role and importance of language even by students who realize that they needed to acquire better language proficiency suggests that their challenges can only be addressed by first of all busting the prevailing myths about language.

Another important point that I have made in this chapter also bears highlighting. WID and WAC programs should help alleviate the challenges faced by NNES graduate students in the discipline by fostering a writing culture that is based on practical reasons for which the faculty and students are willing to foreground the learning of language and writing. The resistance to the idea that writing is a skill that is beneficial in itself doesn't seem very palatable to engineering-minded scholars. In "A new heuristic for planning WAC programs," Carson et al. (2000) argue that WAC programs should take into 
consideration the reactions of the stakeholders by asking questions such as: "How can a university broaden its base for understanding, and gain consensus and support during its planning and implementing of comprehensive programs?" (3). WAC programs are susceptible to organizational, policy, and political roadblocks. Therefore, addressing the prevalent views about language and writing in the academic discipline in favor of fostering the teaching and learning of these skills should involve outreach and promotion, support and resources, and networking and aggregation of ideas and resources. Incidentally, doing these has become easier to do with the help of new technologies. Similarly, the belief that engineering scholars only need basic language has to do with the idea that engineering is a discipline of economy and efficiency which are achieved by avoiding complexity rather than by mastering it. So, in response to this insistence on "keeping it basic"--or what may be called the ideology of "basicism"more critical views about language and writing need to be promoted as a part of helping engineering students develop as professionals who can successfully communicate increasingly complex concepts to increasingly wider audiences and in increasing number of genres of academic and professional writing and communication.

Thus, it is for universities and writing programs to ask: if engineering scholars ${ }^{19}$ do not consider it necessary and/or feasible to invest time and resources to teach or promote language and writing skills, on what basis can scholars and teachers of writing establish the significance of these skills? In this chapter, I suggested that writing scholar can make a convincing case for promoting language and writing proficiencies in disciplines like engineering by responding to the underlying view of what is practical and

\footnotetext{
19 and by implication, members of academic disciplines where language and writing skills are not considered primary components of the curriculum, teaching, and learning
} 
feasible from the perspective of the scholars of the disciplines, and not just our own. We can only justify that faculty members in the disciplines invest their time, energy, and resources if we can understand and employ their own terms and perspectives. The significance of teaching language and writing skills can be established among engineering scholars if that significance is "pragmatic" in the engineers' own frame of reference, or at least if such pragmatism can be established within the curricular context, institutional structure, and career needs for their students. 


\section{CHAPTER 5}

\section{SPECIFIC RECOMMENDATIONS AND CONCLUSION}

In the previous chapter, I illustrated some of the strategies that the faculty adopted for teaching and otherwise supporting their students to write, then proposing a framework that builds upon those best practices. The objective of this chapter is to present a number of additional recommendations for promoting writing in engineering, including recommendations for future WID research with a focus on the NNES majority in this discipline. In that sense, this chapter translates the theoretical approach discussed at the end of the previous chapter into a broader range of curricular, pedagogical, and programmatic strategies. I will conclude by briefly highlighting where current scholarship is in terms of practically addressing the need for promoting writing in engineering with a focus on the discipline's NNES student majority.

\section{Recommendations for Writing Programs}

As indicated in previous chapters, many of the participants, both faculty and students, defined language and writing "defensively" (for lack of a better term) against how they believed "English people" like me defined them. That reaction had to do with a larger interdisciplinary tension that often characterizes how engineering scholars and students view and receive the support that universities provide through their writing centers and other writing programs and resources. Thus, these programs should take into consideration how their services are perceived, trying to frame, customize, and promote them in ways that will better fit and/or appeal to the engineering faculty and students. The 
following recommendations take the interdisciplinary differences into consideration toward promoting writing in engineering.

\section{Focus on the NNES Majority and Graduate Students}

Writing programs primarily focus on undergraduate students, and this is true about support that universities provide to both NES and NNES students. But whereas the number NNES students at the undergraduate level is about two percent, graduate NNES students are about ten percent across the board (IIE, 2010) and above sixty percent in engineering (CRS, 2010). Similarly, as the faculty participants of this study asserted, NES engineering students also lack proficiency (and often interest) in writing; however, whereas NES students may lack writing proficiency in the sense of lacking writing skills, NNES students have the additional challenges of using language and basic writing conventions that their NES counterparts have learned in their social lives and in prior education in the US. Therefore, graduate engineering students clearly deserve more attention from writing programs. More writing center tutors need to be trained to deal with NNES and graduate students.

Whatever the amount (or lack thereof) and timeline of their support for their students' writing, the faculty participants in this study were aware of the greater challenges faced by their NNES students, especially new international students during their transition into the university and graduate program. While all of them stated that writing is a challenge for all engineering students, they were relatively more sensitive to international students' need to catch up with other students when they first come ineven though that sensitivity was often expressed in the form of putting more pressure on the students rather than providing support with their writing. Being the perhaps most 
significant problem that needs most urgent attention, support for academic transition to NNES students might also be the best starting point for writing programs. This need seems to elicit the greatest willingness among the faculty to invest time energy for supporting students learn to write.

\section{Point out the Limitations of Oral Communication}

Oral presentation seems to be a more important mode of communication in engineering than in most other disciplines. The fact that engineering faculty can see NNES students' struggle with oral communication also seems to prompt them to primarily focus on their oral competency. Additionally, as a result of the myth of transparency and transience, many engineering faculty do not value the distinctive functions that writing serves in relation to speaking. Another reason why oral presentation seems to replace written work in engineering is the lack of time-or more importantly, the lack of priority to writing - but if engineering faculty are shown how often and how well their students have to write for successful careers both in and outside the academy, they are more likely to deliberately teach writing and less likely to diminish the importance of "verbal" text that is put around figures and images in their writing, or to assume that oral presentations are sufficient for helping students improve writing skills.

In this study, students used oral communication to both convey their ideas and maintain rapport with their professors. But the writing-anxious students suffered communicative breakdowns because they could not represent well in writing what they did in their one-on-one meetings and oral presentations. Pointing faculty to breakdowns 
in communication due to lack of writing skills may also help dispel the myth that oral communication automatically translates into writing ability.

\section{Draw Engineering Faculty's Attention to the Complexity of their Writing}

Whatever their general belief about language and writing, the writing of engineering faculty is generally complex, not just because they are experienced writers but also because their writing requires linguistic complexity and a wide and complex range of rhetorical skills (and in fact this is largely true for their graduate students as well). Here is for example, an excerpt from an article on E-Coli written by one of the faculty members:

"PC can be, therefore, a valuable therapeutic with little side effect, unlike the currently used anti-coagulants. To reduce the cost involved in immuno purification of PC from blood plasma, single chain variable fragments (mini-Mab) are being produced by recombinant E. coli using phagemid technique."

The underlined words in the two sentences not only serve to "clearly" express her thoughts, but they also perform varied and complex rhetorical functions. For instance, "therefore" signals a move to conclusion that is also an attempt at persuasion; "unlike" indicates a contrastive argument; and "[in order] to" at the beginning of the second sentence expresses the goal of the research, apparently a major rhetorical move in the work at large. The rhetorical moves that the writer is making in the above sentences can be best described as what Wolfe, Britt and Alexander (2011) call "rhetorical sentence combining" on the basis of which the authors also recommend "rhetorical pattern practice" as a pedagogical strategy for teaching technical writing skills to students. 
Writing tutors and teachers could use samples like the above in order to help engineering students identify and practice rhetorical patterns toward improving their writing skills.

When I showed the above sample during the interviews, the faculty readily acknowledged that effective engineering writing involves expressing complex ideas using complex and precise words; they also agreed that good engineering writing involves complex and precise logical connections among the ideas being presented. The discussions that followed convinced me that foregrounding the complexity of engineering faculty's own writing would lead to recognition of that complexity and potentially help promote the explicit teaching and learning of writing for their students. At the very least, recognizing the complexity and rhetoricity of their own writing would go toward countering the prevailing belief that good writing in engineering only constitutes simple, clear, and universally consisted standard English. Promoting the understanding that advanced disciplinary writing requires a complex and wide range of linguistic and rhetorical skills could prompt the faculty to help their students embrace those qualities as inevitable and often desirable in their writing as well.

\section{Provide Support for Professional Writing}

University writing programs and writing centers typically provide engineering students support for academic writing skills. However, many writing tutors do not have the expertise in engineering discourse and discipline-specific writing skills for providing that support. Thus, writing programs may want to focus on non-academic writing such as writing email, floating meeting agendas and taking minutes, describing or reflecting on ongoing projects, and so on. Non-specialist tutors should be able to provide better support with these kinds of writing, and doing so would also have the added benefit of helping 
engineering students learn writing skills that are valued in their discipline and that also transfer more directly into the workplace. Many engineering faculty and students do not see much value in sending their students to the writing center (Dr. X, for instance said that her students often return from the writing center with their papers being worse than when they went there). The reluctance to use writing center service comes partly from their belief that the center provides basic and generic skills for academic writing; and as previous studies have shown, this belief is often based on reality. For instance, in a study of consultation provided to engineering students by writing center consultants who lacked the knowledge of the form and content of engineering writing, Mackiewicz (2004) found that the consultants "not only gave advice that was inappropriate for engineering writing but also stated that advice with certainty" (p. 316). Thus, writing centers would be able to address the perception as well as provide useful support if they focused on professionally valuable writing skills. Doing so would also encourage the faculty members to invest more time and energy in the same direction.

More generally, in order to make the promotion of writing effective and meaningful, it is necessary for universities, writing programs, and engineering departments to provide students the opportunity to learn and use writing in meaningful and practical contexts, especially as a part of a larger goal of professional development. One of the distinctive strengths of the student participants who wrote better was their approach to writing as a part of long term professional development goals as engineering scholars. These students were not just efficient writers; their writing skills hinged on better reading and research skills, their faster orientation and socialization in their program and the discipline, and their interest in implementing their academic skills for 
professional development. As these students showed, graduate engineering students need to learn not just to write but to write for purposes like presentation, publication, and professional communication.

Previous studies also show that a large proportion of engineering students enter the workforce lacking in the essential skills of professional writing. ${ }^{20}$ As a result of excessive focus on the content of the discipline, the lack of time, and the prevalence of the myths of transparency and transience about language and writing skills, a majority of them complete academic requirements without having written much and realizing the complexity and rhetoricity of writing that they will be required to do upon entry into the industry or the academe. In a longitudinal study of engineering students and professionals, Leydens (2008) found that engineering scholars only slowly began to take a rhetorical view of knowledge after they entered the professional market and become "more immersed in actual professional practice, with its own complex sets of ideologies and epistemologies" (p. 261). In this study, the distinction between students who started writing early and those who did not write until toward the end of their degrees was quite significant.

So, in general terms, writing programs can raise engineering students' awareness about the complexity, rhetoricity, and variety of purposes in engineering writing by supporting them with writing as a means for conducting professional activities, including communication, publication, presentation, and leading and coordinating projects.

\section{Incorporate Engineering Faculty's Approach to Writing Consultation}

Most engineering faculty do not share the concerns, perspectives, and priorities about improving their students' writing that writing programs do. So, it would be

\footnotetext{
${ }^{20}$ For a comprehensive review on this subject, see Jenkins et al. (1993) and Jordan and Kedrowicz (2011).
} 
effective to start from what they do want their students to learn. For instance, writing center tutoring for engineering students could be designed to help engineering students focus on simple and clear expression (for this is one, though not all, of the qualities of effective engineering writing); effective use of data, figures, and images; conventions of writing engineering genres; and so on. While the students will need more than just clear and standard English as many might believe, starting from where they are will at least appeal them toward using writing services. Accordingly, advertising writing services by using the terminology that the faculty and students use for defining effective writing would help address the kinds of resistance, and often misunderstanding, among them.

Generally speaking, engineering faculty and students might seem to espouse perspectives on writing that are outright problematic; many of their views and approaches to writing may in fact be counterproductive. But quite often, it is writing scholars, teachers, and consultants who fail to understand others' view of writing as it matters to them in their disciplines. During an interview, Dr. A told me that she has decided to no longer invite writing center consultants to give writing workshops in her class. When asked how that might have happened, she said that the writing consultants focused too much on writing jargon (or "semantics about semantics" as she called it), did not use familiar examples, and did not try to understand the context of her students' writing. Consequently, in her view, the writing consultants reinforced the stereotypical view of their work as fixing grammar; indeed, faculty who defined writing skills more reductively in terms of grammatical correctness were more likely to send their students to the writing center without supplementing that support with their own. 
Moreover, because most engineering students are NNES writers, writing programs are often guilty of automatically assuming that these students primarily need support with their language:

Dr. A: [What matters in engineering writing] is basically logic.... I'm trying to use the English students from the writing center. I have to say that it didn't work. The reason it was not useful at all-- I mean this semester I put two extra classes. ... I think that they [writing center] need to have actual [understanding of engineering writing]. It is very vague. So it's not really helpful. It is actually confusing students.... The semantics in the English department is just too much. It is not necessary that we don't need to use a lot of those words.

Whether the students are native or nonnative users of English, it remains true that engineering faculty want their students to focus primarily on engineering writing as a logical thinking process. The downplaying of language can be problematic as discussed in previous chapters, but as Dr. A suggested, the downplaying of content that can happen in conventional writing center consultations can also be equally counterproductive.

Dr. A: [Writing tutors] think that it is language, but it is not actually language.... It's about writing problems, not necessarily language. But then again these people are from foreign countries, they might think that language might be a problem; they might be exaggerating--say they fear more than what it is.

Writing consultants should avoid automatically assuming that NNES students primarily need support with language. Paradoxical as it might sound, defocusing on language in favor of focusing on the content, context, and conventions of disciplinary writing would 
be an effective starting point for writing programs to become more useful to engineering students.

\section{Make Best Practices Visible by Using Web Technologies}

Most engineering faculty are aware of the low proficiency that their students have in writing, but there is no community of discourse or practice around helping students improve their writing. As Dr. Y said, "We know [a writing course] can help, and I am sure all professors know that it would help, but [not] how to do it or how to integrate it." So, in order to inform/educate engineering faculty about how engineering writing can be promoted, the best practices among them should be made visible. And with the advent of web technologies like wikis and blogs, it is extremely easy to aggregate, provide, and promote resources built out of best practices among the engineering faculty themselves. Writing programs and consultants can solicit contribution, moderate, and promote repertoires of practical teaching tips for the faculty and writing tips for the students. Writing centers use traditional websites to provide resources to faculty and students; but by using wiki, it is possible for faculty to share ideas and resources, and blogs also make it easier for faculty to ask questions of writing consultants as well as one another. These techniques can be tremendously helpful in making best practices visible, help writing programs and services better understand the nature and needs of the engineering faculty and students, and also help promote and update existing services.

\section{Foster a More Critical Conversation about Writing}

One of the most important strategies (and in fact a significant goal) of promoting writing in engineering is to create a culture of disciplinary and campus-wide conversation about teaching and learning of writing. The participants of this study often expressed 
conflicting views about language and writing. For instance, while they were aware that engineering writing needs to be rhetorical and persuasive, they also tended to characterize that writing as "putting facts and figures together." Similarly, their argument that standard English is a simple and universally consistent code fell apart when they were asked why, then, the NNES students struggle with that language if it was so simple. Such paradoxes exist because, as some of the faculty stated, a critical conversation about language and writing does not exist in the discipline. Writing programs could promote writing among engineering students by fostering more complex and nuanced understandings of language and writing.

The attempt to raise critical awareness about language and writing skills in the academic disciplines should begin with establishing the pragmatic benefits of doing so. One of the concerns that students and faculty members in this study emphasized was the need to develop a wider range of skills among engineering students in response to the increasing challenges of the profession. I asked the participants how important language skills are in engineering writing by using a hypothetical situation where one engineering scholar is proficient in his or her language skill and the other has the same ideas but struggles with language. The participants clearly agreed that the scholar with better language skills will be more successful professionally. Complexifying the definition of language will should involve confronting the reality that in a world where the discourse community of engineers literally includes the discipline's members from around the world. 


\section{Promote Writing as a Means of Transnational Professional Communication}

In order to be successful, engineering scholars increasingly need to be aware about the big picture of higher education and the attendant complexities and challenges brought about by increasing diversification of the demographics, increasing globalization and transnational nature of their professional community, and the inevitability of language variation in their communication within their professional community. The community of engineering scholars and the audience with which they communicate through academic and professional writing even within the United States is a linguistically extremely diverse community: this community uses a great variety of Englishes in its oral communication, and similar language variations (albeit in much lower intensity) are also inevitable in their written communication; in addition, as an academic and professional community that is not limited by a national boundary, members of this community also engage in spoken and written communication across the world, through what they believe to be "standard" and "technical" English, but which is inherently variable and diverse. Therefore, success of any engineering professional today depends on the ability to communicate with an awareness and ability to navigate the linguistic diversity—no matter how strongly engineering scholars themselves deny the inevitable linguistic diversity. Seen from a certain perspective, it would be ideal if all language variations - at least in writing--could be practically eliminated at least in scientific and technical writing; but language use by diverse communities simply makes such a goal unrealistic, and therefore language variation should be accepted as a reality.

If we consider the dramatic diversification of the linguistic demographic in the discipline, the impact of globalization that increasingly connect engineering scholars in 
the US with transnational professional networks, and the increasing demand of the "market" for multilingual as well as higher standard English proficiencies in engineering graduates, it is in the pragmatic interest of the field to bust the myths of transparency and transience and embrace more complex views about language and writing. It only takes a glance at the professional journal, professional membership, or conference participation of the discipline to see that national and cultural boundaries - and therefore the boundary of the supposedly universal "technical English"—are increasingly porous and complicated. And the more aware engineering students are about these realities, the more successful they can be in their increasingly global professional community.

\section{Recommendations for engineering faculty and departments}

As with any initiative, engineering faculty's own involvement is crucial to the success and effectiveness of WID programs designed to support engineering students. As the practices of the faculty in this study showed, there are ways and reasons for them to integrate writing into engineering education as it makes sense in their own purview of academic and professional development of their students. This section describes strategies that engineering faculty can use for contributing to the promotion of writing skills among their students, including the recommendations given by the participants of this study.

\section{Make the Language and Discourse of the Discipline Explicit}

Many engineering instructors lack the time and expertise for explicitly teaching writing in their classrooms or in one-on-one advising situations, and even those who may have the time and expertise may not consider writing to be the highest priority. However, the lack of time, expertise, and priority for teaching writing also has to do with how 
engineering faculty define writing. In this study, the advisers of students who were competent and confident writers recognized writing as part of learning and using the language and discourse of the discipline. They did not view writing as a simple process of putting ideas into a language that students already knew; they recognized that students learn the language of the discipline in the process of writing. As a result, they helped their students with writing not just as a mechanical skill but as an intellectual activity, a learning process, and a means for mastering the discourse of the discipline.

An important lesson can be derived from how the faculty of the writing-confident students promoted writing, regardless of the amount of time they gave and the expertise they had with teaching writing: one of the easiest but most effective ways to promote writing in engineering is for the faculty to make explicit for students the discourses, genres, and conventions that shape engineering writing --and doing this does not require much time or expertise, just the willingness to give it greater priority. And it is important to note that engineering faculty can help students best in this regard. In this study, the advisers of the writing-confident students not only used more explicit and rigorous methods for teaching writing, they also helped their students by simply foregrounding the language of the discipline, by responding to the students' writing, and by showing them the importance of writing in their academic and professional careers. In order to save her own time, Dr. A let her.students discuss one another's writing:

Dr. A: ... I have a group meeting every week. So before the group meeting, we ask the lab manager to collect everybody's report and it is supposed to be sent out to everybody before they come in--supposed to be [laughs]. So while we are 
discussing, I do correct their explanation or why certain design is not logical, why something is not designed efficiently.

Furthermore, Dr. A and the other adviser of the writing-confident student, were aware that NNES students in particular need to learn the conventions of academic writing in the US. Dr. B said that NNES students' challenges with writing also have to do with their previous academic writing experiences - or lack thereof.

Dr. B: Part of is that you need to realize that people from different cultures have different writing styles. For instance, there are students from China who tend to write things in a very flowery way, students from Iran tend to do it in a very elaborate description of simple things-I probably shouldn't stereotype people based on different countries-

As a result, he said that he shows his students the salient features of writing in his discipline as well as writing more generally in the American university.

In short, the effort to explicate the language, norms, and conventions of engineering not only helps NNES students but is also generally helpful for all students in the discipline.

\section{Help NNES Students with Academic Orientation During Transition}

As shown in Casanave and Li's (2009) edited collection of stories on "academic enculturation" of NNES students, NNES graduate students need much more than to learn the content of their discipline: in order to be successful, they also need to gain a good grasp of the field's language including highly specialized terminology and conventions of writing and communication. But quite often, there is a glaring gap in these students' understanding of the implicit rules and expectations of graduate education in a new 
setting. In an article tellingly titled "If You Don't Tell Me, How Can I Know," Angelova and Riazantseva (1999) pointed out a striking lack of academic research and scholarship on the subject of how non-native English speaking (NNES) students adapt to the academic discourses of their disciplines, and in particular about how they learn and teach writing as expected in their disciplines. The authors observed: "we have little knowledge of the process through which these students acquire the conventions of different disciplinary discourses necessary for the successful completion of their graduate programs" (491). Their findings supported past research in WID (including Prior, 1991; Connor \& Kramer, 1995; Spack, 2004) that "writing remains problematic even for successful students at such advances levels" (Prior, 1991; 518). So, they argued that the challenges of these students could be mitigated in three ways: the needs of the students be addressed more directly, that faculty offer support as part of teaching the content of the disciplines, and institutions provide mechanisms to let students learn field-appropriate writing by starting early.

Engineering faculty could make a big difference if they invested some time and energy toward helping NNES students transition into the new academic system. In particular, NNES faculty are equipped to provide such help because, as I discussed in the previous chapter, they have been (or may even consider being) "in the same boat" with the students.

Dr. X: For example, organizing events every week where graduate students are expected to participate and talk to each other in English, and not be shy.... But those events--I don't know what they could look like...--the idea is in order to 
help NNES students [develop] into native English speaking persons, the only way is to have a lot of contact with native speakers.

This suggestion is consistent with the realization of the students who also emphasized that the opportunity to socialize and communicate in English helped them increase the proficiency in language that they needed for writing.

Some of the faculty members not only told me that there is a dire need for helping NNEs students make academic transition more quickly and successfully, they also added that their discipline needs to do more than it has been doing. In the worlds of Dr. Y, "Yeah, that's a challenge that we have. Probably, we haven't paid attention in the past." Dr. Y shared his own personal experience of making the academic transition from a country where writing and research were not integral to his prior engineering education into the university in the US where critical thinking, originality, research, and writing were at first very challenging to him.

Dr. Y: So here I was exposed to a different level of intellectual challenge, I would say. I was very challenged here; I was not challenged there. ... So you don't have to write more, you don't have to express more, you don't have to convince reviewers that your work is worth it. Here you need to do that. Engineering faculty members need to recognize their students' struggle with learning language and writing skills especially during their transitional periods. While teaching language or writing skills may not be a curricular priority to them, but the fact that a small amount of support can make a great difference in new NNES students' academic success down the road should draw the faculty's attention to the transitional period. 


\section{Engage Students in Low Stakes Writing for Practical Communication}

Contrary to what many engineering faculty believe, the best practices found in this study were not always high stakes academic writing. Some of the strategies for promoting writing in engineering would be for the faculty to integrate low stakes writing activities such as students reviewing one another's writing, using email to communicate with different kinds of audiences, preparing written reports before making oral presentations, taking minutes during meetings, writing reflections on ongoing projects, discussing writing in group settings, and seeking opportunities to write within and beyond the classroom and lab.

Whereas engineering faculty are reported in a variety of research as typically not valuing writing as an "academic skill" or a "means for critical thinking, learning, and communicating ideas," as was evident in this study, they are more likely to acknowledge the importance of writing given that engineering professionals spend up to $90 \%$ of their time at work doing some kind of writing (Conrad et al., 2009). For this reason, faculty who adopted the best practices let their students write not only for the purpose of fulfilling academic requirements but also for informal purposes within the classroom and lab, and they similarly required writing for social and professional contexts in and beyond academic settings. Because writing skills can be a pragmatic and powerful tool for professional development, as well as a means for academic success, engineering faculty should find ways to engage their students in low-stake writing activities for practical purposes.

The advisers of the confident student writers helped them professionally grow by providing opportunities to write, read, and communicate beyond the academic settings of 
the classroom and the lab. Student A highlighted the importance of general communicative proficiency as the basis for becoming successful in academic and professional writing as follows:

Shyam: So, are you suggesting that when new international students come in, only letting them do academic writing might not be the best idea?

Student A: Yes. My advisor, she let me do a lot of communication with other people, like with other professors. We collaborate with a lot of other people and she let me communicate with them. Some professors probably they do it [the communication] all by themselves, they don't ask students to do that a lot. She let me do it and she let me take a lot of responsibility in the lab, like waste management, and for that you have to communicate with a lot of people.

In the next interview, Student A also added that reading, writing, and communicating with people in both speech and writing are all interconnected and essential for international students like her, and that it is insufficient for them to try to learn academic writing in isolation, as through writing courses

When students were engaged in writing and communication in practical contexts like conducting the business of their lab by using email, they were more likely to gain both the skills and confidence more quickly than through academic writing alone. Observing the sample emails that the students sent me largely confirmed what they said about language learning and writing as well as their emotional and intellectual responses towards language and writing during the interviews. Thus, even when engineering faculty are not able or willing to spend time to teach writing in the classroom, providing opportunities or encouraging students to use writing for communicating with a variety of 
audience can help students learn and use the language, discourse, and conventions of their discipline quickly and effectively. A clear evidence of getting such opportunities was, again, Student A, who said, "I enjoy [writing]. I like languages, personally. I absorb how people speak and how people write when I listen to them or read articles. I find it fun." This kind of confidence can only come from getting opportunities to use writing and succeed doing it. Furthermore, as indicated in the voices of the writing-confident students, students are highly motivated and find writing relevant and inspiring when they frequently use it in social and professional contexts rather than limiting it as an academic practice.

\section{Let Students Read, Analyze, and Respond to Engineering Scholarship}

Whether or not they gave their students this assignment, all the faculty participants of this study said that requiring students to read engineering scholarship helped them understand engineering writing; those who advised the writing-confident students also required their students to analyze and discuss what they read. Dr. Y, for instance, said that reading relevant literature prepares students to write better.

Dr. Y: Uh, I think it also helps them a lot if graduate students in engineering read a lot of the scholarship. I think that somehow reading improves their writing skills, simply because the technical part, the research part--at least for us--is the most important part. I want my students to be able to deliver what they learn here, to be understood when they are with the experts in the field. If they have the technical concept, they can communicate effectively. It helps a lot. 
Similarly, Dr. Z said that "the most important factor in learning how to write better is to read more" and that he recommended that engineering faculty should "assign reading, a lot of reading, and summarizing published literature."

The advisers of the writing-confident students greatly emphasized to reading the scholarship, as a result of which these students were more likely to situate their own writing in that scholarship, as well as to write better by the time they embarked on their thesis or dissertation. So, while universities, writing programs, or engineering departments may not be able to make any dramatic changes against the current lack of emphasis on teaching writing, they would be able to promote reading of engineering literature. An emphasis on reading would go a long way toward improving writing, without meeting as much resistance as the teaching and learning of writing itself might.

\section{Provide Feedback and Let Students Revise/Improve their Writing}

One of the counterproductive approaches that engineering faculty tend to use for helping students improve their writing is to "correct" their writing. On the one hand, engineering instructors focus on the final product and not on the process; on the other, they expect such a high standard in the final product that they end up doing most of their students' writing for them (Braine, 2002; p. 67; also see Jenkins et al., 1993). Furthermore, because most of them believe that teaching writing is not their job, poor writing can elicit the kind of frustration that Dr. X expressed about his student's writing when I asked him to talk about the sample that Student $\mathrm{X}$ had provided me for the interview:

Dr. X: I remember him giving me something similar to this, and my head was spinning. I was like oh my god, you know, this is unbelievable.... . it was from 
annoying to complete neurotic breakdown. At one point I just threw it, okay, on my table, and just laughed.

Thus, in order to alleviate their resistance toward teaching writing, engineering faculty should first realize that their time, attention, and consistent feedback can make a great and unique difference in their students' confidence as writers and thereby their success as engineering scholars and professionals. In fact, it is they who can provide the most reliable and useful comments on their students writing because only they have a full understanding of the context, convention, and other rhetorical elements of writing in their discipline.

\section{Conclusion}

In conclusion, let me briefly highlight a few key insights from this study as well as point out some recent WID scholarship that is beginning to address the issues that I have focused on in this study. WID scholars have been highlighting the prevailing ideologies and practical challenges that undermine the status of writing in the academic disciplines; but more recently, some studies have pointed out that it is necessary to go beyond critique to developing approaches to address the challenges in ways that that will induce minimum resistance and produce maximum results. In particular, considering the "cultural gap" owing to the different ways in which most engineering faculty define writing in relation to how writing programs and faculty do the same, putting the horse of critique before the cart of practical solutions could only increase the that gap, rather than help solve the problem. For example, discussing the weaknesses of WAC/WID programs in their effort to promote writing in the disciplines, Ochsner and Fowler (2004) suggested that these programs have historically failed to appeal to faculty and students in the 
academic disciplines at large, adding that the failure largely comes from a kind of "orthodoxy" about the importance of writing: writing scholars and program administrators define writing as an inherently useful "learning tool." As a result, writing programs tend to overlook the fact that engineering faculty and students believe in different "learning styles":

As a principle of instruction, all students should learn to write--but not all students will learn best through writing. ... WAC/WID theory does attribute a special importance to writing (and perhaps reading), as if students could not learn as much or as well through other representations of ideas. ... (ibid.; p. 125). For instance, engineering faculty and students' claim that good images, figures, and equations are essential to effective writing in their discipline cannot be trumped by the language-intensive definition of writing that writing scholars tend to consider as most important. The different "learning styles" of different disciplines may be indicators of genuine disciplinary differences that the writing scholar must first of all understand, including contextually adapted and effective approaches for teaching/learning writing, different cultural backgrounds and epistemological perspectives, and different institutional and professional priorities. As Bergman (2000) pointed out in an article titled "WAC Meets the Ethos of Engineering: Process, Collaboration, and Disciplinary Practices," when the theories and general best practices of WAC and WID conflict with the disciplinary practices of "applied or technological fields like engineering," it is necessary to pause and reflect. Bergman stated that "even though there is a significant demand in engineering education for improving students' communication skills, in many local institutional situations WAC theory and practices may have little actual effect on 
the kind of writing projects that are set up or on the ways in which students actually learn to write" (4). For instance, when Student X, the mechanical engineering graduate student suggested that his primary goal of becoming an effective engineering writer involves learning how to get the best images of the nano particles from his lab tests, he was defining writing in such a way that at first surprised me; but considering the critique of WID offered by scholars like Ochsner and Fowler (2004) and Bergman 2000), there may be more to Student X's view of writing than WID scholars might see at first.

A second area of important development in recent WID scholarship is related to the need to pay attention to different perspectives and approaches about academic writing in the context of how to deal with NNES students' needs for support with writing. While the lack of strong backgrounds in academic writing and lower language proficiency among NNES students are challenges to be addressed, how those challenges are addressed is a matter of critical discussion and cautious approach. For instance, as Cox (2011) has pointed out, simply requiring or teaching NNES students to do more writing may not be as beneficial at it may appear. According to Cox, just requiring more writing, without considering how NNES students respond to or can deal with that requirement, can adversely affect their confidence and learning process. Reviewing the literatures at the intersection of second language writing and WAC/WID initiatives, Cox concludes that both these scholarships must take into considerations the special needs, challenges, and perceptions of NNES students for whom the initiatives are intended.

A third important issue that current WID scholarship has begun to highlight is that formal and curricular initiatives may not be sufficient and effective in addressing the needs (Braine, 2002; Ochnser, 2004; Vickers, 2007; Cox, 2010; Jordan \& Kedrowicz, 
2011). As Braine (2002) argues, especially at the graduate level (also see Casanave \& Hubbard, 2008), NNES students need to be taught with a broader concept of academic literacy and disciplinary discourse that underlies academic writing: "graduate students not only need to build interactive relationships with their teachers, thesis supervisors, and peers, and develop effective research strategies and good writing skills, they also need to adapt smoothly to the linguistic and social milieu of their host environment and to the culture of their academic departments and institutions" (p. 60). My own study strongly showed the importance of balancing curricular with non-curricular approaches like incentivizing, supporting, and providing resources to teachers in the disciplines toward promoting writing as and where they can integrate it into their teaching of content.

Beyond highlighting the weaknesses in the approach taken by traditional writing programs, a few recent WID scholars have also recommended practical strategies based on the critique for promoting writing in disciplines like engineering. For instance, in a well-known WID article, "Ways of Knowing, Doing, and Writing in the Disciplines," Carter (2007) proposes that writing programs promote writing in the disciplines in terms of how the disciplines define themselves in terms of "metagenres" or genres that are broadly valued as "ways of doing" rather than "ways of knowing" in their disciplines. One of the arguments Carter makes that I find particularly relevant to the framework that I am proposing is about how to bridge the gap between writing programs' understanding of writing and that of faculty members and students in academic disciplines like engineering:

The problem for WID professionals is how to bridge the gap between writing in and writing outside the disciplines, the knowing that and the knowing how. This 
is not a problem that can be solved by reference to our own discipline's understanding of the relationship between writing and knowing. Rather, we need to be able to conceptualize writing in the disciplines in a way that is grounded in the disciplines themselves, a viable alternative to an understanding of writing as universally generalizable. (387)

Similar to Carter, Halasz et al. (2008) go beyond critique of traditional WID programs and recommend that such programs solicit the views of faculty in the disciplines for developing successful writing programs. The authors explore faculty resistance through the lens of institutional, disciplinary, departmental, and personal constraints, suggesting that if we listen and respond to faculty concerns about writing among their students, what they can and cannot do to help their students, and what approaches they believe will and will not work for them, the faculty can become means to facilitate faculty engagement with and ownership of WAC initiatives. Similarly, Carson, Sipple, Yahr, Marshall, and O'Banion (2000) highlight the need to take stakeholders' views and needs about writing seriously; they call this consideration most crucial for the survival and effectiveness of any program in writing across the curriculum. Yet another critical view of WAC and WID initiatives is forwarded by other scholars who believe that these initiatives may not be sufficient in themselves, not only theoretically in terms of valuing writing as inherently useful but also practically in terms of the difficulty of aligning any broadbased initiatives with the different and complex manifestations of writing in the disciplines. Carpenter, Harrison, and Krest (2001), for instance, argue that "the problem for the teaching of discipline-specific writing is that disciplinary standards of style and form often trump writing teachers' concerns for fostering critical thinking; as a result, 
teachers overemphasize correctness and format" (n.p; web). As these and other WID scholars have warned, what is necessary is not so much valuing of "writing" as it is understood in the disciplines but a different understanding of writing in the first place, because unconditional demand for integrating more writing within disciplinary curricula can aggravate the problem instead of helping to solve it. "When no clear role is understood for writing in a science curriculum, more often than not the result is a formalistic emphasis on correctness" or a relapse into the most available conception of writing (ibid.).

The findings of this study seem to further indicate that WID initiatives need to be implemented cautiously in the particular case of NNES graduate students, because these students may not be able embrace the view about writing that generally prevails in the American university as quickly and willingly as they may be expected to by such initiatives. Most of the graduate students who participated in this study showed a clear resistance to my emphasis on writing as a means for enhancing critical thinking, learning, and communicating of their discipline's content. Their resistance seems to come from the fact that I was suggesting that they do more of what they are not good at doing. While their teachers did not seem willing to spend time teaching or facilitating their students' learning of writing skills, they clearly emphasized writing as an important skill for professional success; but the students seemed both anxious and resistant about investing more time and energy in writing. Xu's (2003) study of eleven Chinese international graduate students' transition into "the US teaching and learning system" showed that the students had difficulties not only with language but also with different expectations in terms of how their learning and writing was assessed in their courses: academic transition 
process can potentially give rise to more resistance than desire to value and learn writing in the same way as insiders of the American academy do. Current scholarship on NNES writing is also beginning to show picture of the complex linguistic, cultural, and identity transitions made by NNES students as they write across varying social, disciplinary, and rhetorical contexts. What also emerges is a map of the many opportunities available to WAC/WID professionals for advocating for NNES students. Positioned at the crossroads of teaching and learning as agents of institutional change, WAC/WID professionals are key to making our institutional landscapes, classrooms, and assessment practices more equitable for NNES students, a group that is not at the margins but at the center of US institutions of higher education.

As the data of this study also shows, it becomes all the more important to understand, take into account, and even recognize potential advantages of the diversity of language and writing in action in a discipline where the majority of faculty and students come from different academic and cultural backgrounds. As Hall (2009) argues in his article titled "WAC/WID in the Next America: Redefining Professional Identity in the Age of Multilingual Majority," WAC administrators may indeed need to prepare for a "New America" by training faculty across the disciplines to be inclusive of second language writing. This study further indicates that this training seems equally necessary for NNES engineering faculty as it may be for their NES counterparts.

This dissertation follows the recent tradition in WID research and scholarship that I mentioned in the preceding few paragraphs in that my emphasis is on first of all understanding how engineering faculty and students as stakeholders for promoting writing in their discipline perceive and treat writing, why they embrace or resist certain 
types or approaches of writing, and what their best ideas and practices are. That understanding then encouraged me to recognize and understand the different but effective teaching and learning practices among some of the participants. Observing the effective practices has convinced me that successful WID programs for engineering can be built and sustained if existing curricula, services, and resources are adapted to what the engineering faculty and students perceive to be the most important areas for support and provided in ways that serve to build interdisciplinary dialog rather than increase the resistance and misunderstanding as it often happens at present.

It seems necessary to address a seeming paradox in my key argument that while it is necessary to counter problematic views about language and writing in engineering, it is also necessary to recognize their perspectives as well as build upon the best practices. My argument and proposal is that the attempt to critique and counter the problematic views and lack of pedagogy in the discipline at large should not prevent university writing programs and professionals from understanding how and why certain disciplines cultivate and practice certain views about language and writing; nor should the problems in the discipline at large obscure existing best practices among some of the members of the discipline. Not understanding the perspectives of the primary stakeholders and not recognizing and building upon what some of them do well are both counterproductive approaches in both research/scholarship and at the level of writing programs and pedagogy. So, the motivation behind my argument and proposal is to find strategies that are acceptable to the engineering faculty and students as the most important stakeholders "before" challenging the dominant views and practices. 
Another key issue guiding this study is how NNES faculty and students-in spite of being multilingual individuals who practically navigate and negotiate meaning across languages and language variations - respond to prevailing monolingual and reductive definitions and discourses about language and writing in their discipline of engineering and how that response influences and complicates the NNES graduate students' learning of writing. Since the findings of this study showed that NNES students and faculty members generally subscribe to monolingual discourses of their discipline, NNES students' learning of language and writing could be more adversely impacted than that of their NES counterparts. Consequently, I address how the discourse of the discipline, institutional dynamics and professional incentives, and the fact that the participants were driven by the same motivations toward monolingual norms and practices (regardless of their language identity). Toward the middle of the dissertation, NNES-specific concerns necessarily became a less prominent issue in relation to the larger issues about how language and writing are treated in engineering at large. However, in each of the chapters, I have more or less directly focused on how the dynamics may make greater impacts on NNES students' learning and their NNES instructors' teaching of writing.

The faculty participants of this study generally emphasized that their students' struggle with writing have little do with their being NNES users of English; but this denial is actually the consequence of the same problematic views about language writing that create the pedagogical/educational gap in the first place. That is, if the language and writing that engineering students and scholars need are basic, simple, and transparent, then the NNES students with lower language proficiency face the same kinds and amounts of challenges as their NES counterparts. But, again, there was more to this claim 
than it first appeared. When the participants were asked to provide writing samples, describe the approaches and activities that they adopted for teaching/learning writing, and were engaged in broader and more open discussions about writing in their discipline and also the engineering profession at large, they went past the discourse of defining language and writing reductively. Some of them described and provided evidence of highly effective teaching and learning practices. This development in the study helped me go beyond understanding the problematic views about language writing into actual practices of teaching and writing, some of which significantly contradicted the participants' beliefs and arguments on the subject.

While describing the existing best practices of teaching and learning writing among the participants, I continued to adopt the dual focus by discussing issues about writing with and without reference to how were relevant to the NNES students and faculty. At first the discourses, ideologies, and practices about writing in engineering seemed to be disciplinary phenomena that have the same effect on both NNES and NES faculty and students; but they do have different meanings and impacts for the NNES students and faculty. For instance, when NNES students strive for clarity and diminish the importance of rhetoricity and complexity, they can quickly end up with simplicity, ignoring the real problems that they do have with learning rhetorical skills for using a language with which they normally lag behind the NES counterparts.

This study had a limited number of participants. Studies with larger numbers of participants would yield more useful results. Future studies on this subject could also use a wider variety of data. In this study, while the interview data was rich and extensive, less space and priority were given to the writing samples (in particular the emails seemed 
promising as research materials). In some cases, language barrier affected the response of students during the interview; some students either did not have or were unwilling to provide writing samples (which affected the consistency of the method among participants). But in spite of the limitations of time and space in this study as a dissertation, it has hopefully identified some important issues and practices that deserve to be further studied. It has highlighted the need to understand not only monolingual ideologies in academic disciplines like engineering but also how those ideologies function even through multilingual scholars and how they do so vis-à-vis specific institutional, disciplinary, and professional contexts; it has showed the presence of effective teaching and learning practices in spite of the general tendency to undermine writing; and it has emphasized the importance of building upon existing practices of teaching writing in a particular discipline.

Perhaps the most important insight that this study has offered is that monolingualism needs to be seen in disciplinary and professional contexts, particularly in light of the dynamic of roles and responsibilities, power and authority of the individuals within those contexts, rather than as an issue of sociolinguistic identity or experience of language. Future studies should look into the issue of monolingualism in engineering more extensively. In light of the fact that NNES faculty and students are increasing in proportion, further research could investigate how NNES faculty and students do engage in multilingual negotiation of meaning in spite of monolingual discourses and beliefs among them, in the same way as this study found a number of significant best practices for teaching writing in spite of beliefs to the contrary (that language is transparent and writing is learned automatically). Such research could find ways to promote more 
complex and critical views about language and writing, including how to deal with language variation, since engineering is an extremely diverse discipline whose members not only practically use many different varieties of English but are also part of transnational and cross-cultural professional communities. Not only writing scholars and programs but also engineering faculty and students will greatly benefit from better understanding the paradox of monolingualism in engineering as a multilingual-dominated discipline. 


\section{REFERENCES}

Ammon, U. (2007). Global scientific communication: Open questions and policy suggestions. AlLA Review, 20, 1, 123-133.

Angelova, M., \& Riazantseva, A. (1999). "If you don't tell me, how can I know?": A case study of four international students learning to write the U.S. way. Written Communication, 16, 4, 491-525.

Barber, E. G., \& Morgan, R. P. (1987). The impact of foreign graduate students on engineering education in the United States. Science 236, 4797, 33-37.

Belcher, D. D. (2007). Seeking acceptance in an English-only research world. Journal of Second Language Writing, 16, 1, 1-22.

Belcher, D. D., \& Braine, G. (1994). Academic writing in a second language: Essays on research and pedagogy. Norwood, NJ: Ablex.

Bergmann, Linda S. (2000). WAC meets the ethos of engineering: Process, collaboration, and disciplinary practices. Language and Learning across the Disciplines, 4, 1, 4-15.

Braine, G. (2002). Academic literacy and the nonnative speaker graduate student. Journal of English for Academic Purposes, 1, 1, 59-68.

Brandt, C. (2009). The case for reflexivity in developing ESL students' academic communication skills. International Journal of Arts and Sciences, 3, 5, 1-18.

Burbules, N. C. (1986). A theory of power in education. Educational Theory, 36, 2, 95-114. 
Burnett, R. E. (1996). Some people weren't able to contribute anything but their technical knowledge: The anatomy of a dysfunctional team. In Duin, A. H. \& Hansen, C. J. (Eds.), Nonacademic writing. (pp. 123-56). Mahwah, NJ: Lawrence Erlbaum.

Canagarajah, A. S. (1999). Interrogating "native speaker fallacy": Non-linguistic roots, non-pedagogical results. In Braine, G. (Ed.). Non-native educators in English language teaching. 77-92. Mahwah, NJ: Lawrence Erlbrum, ---. (2002). A geopolitics of academic writing. Pittsburgh Series in Composition, Literacy, and Culture. Pittsburgh: U of Pittsburgh.

---. (2006a). Toward a writing pedagogy of shuttling between languages: Learning from multilingual writers. College English, 68, 6, 589-604.

-.-. (2006b). The place of World Englishes in composition: Pluralization continued. College Composition and Communication, 57, 4, 586-619.

--. (2007). Lingua franca English, multilingual communities, and language acquisition. The Modern Language Journal, 91, 923-939.

---. (2009). Multilingual negotiation strategies in working English. Journal of Academic Communication. 29, 17-48.

Carpenter, J. Harrison; Margie Krest. (2001). It's about the science: Students writing and thinking about data in a scientific writing course. Language and Learning Across the Disciplines, 5, 2, 1-20.

Carson, J., Sipple, W., Yahr, M., Marshall, T., \& O’Banion, J. (2000). A new heuristic for planning WAC programs: Ensuring successful collaboration from all stakeholders. Language and Learning Across the Disciplines, 3, 3, 3-35. 
Carter, M., Ferzli, M., \& Wiebe, E. (2007). Writing to learn by learning to write in the disciplines. Journal of Business and Technical Communication, 21, 3, 278-302.

Carter, M., Vouk, M., Gannod, G. C., Burge, J. E., Anderson, P. V., \& Hoffman, M. E. (2011). Communication genres: Integrating communication into the software engineering curriculum. 2011 24th IEEE-CS Conference on Software Engineering Education and Training (CSEET), 21-30.

Casanave, C. P., \& Li, X. M. (2008). Learning the literacy practices of graduate school: Insiders' reflections on academic enculturation. Ann Arbor: University of Michigan Press.

Casanave, C., \& Hubbard, P. (1992). The writing assignments and writing problems of doctoral students: Faculty perceptions, pedagogical issues, and needed research. English for Specific Purposes, 11, 33-49.

Congressional Research Service Report (CRSR, 2010). Foreign science and engineering presence in U.S. institutions and the labor force (A report prepared by Matthews, C. M.) Congressional Research Service.

Connor, U., \& Kramer, M. (1995). Learning from sources: Case studies of graduate students in business management. In D. Belcher \& G Braine (Eds.), Academic writing in a second language. Norwood, NJ: Ablex. 155-182

Conrad, S., Dusicka, P., Pfeiffer, T., Evans, R. (2009). Work in progress - A new approach for understanding student and workplace writing in engineering. Proceedings of Frontiers in Education Conference.

Cox, Michelle. (2010). WAC-WID and second language writers, WPA-CompPile Research Bibliographies, No. 8. Retrieved January 7, 2012 from http://comppile.org/wpa/bibliographies/Bib8/Cox.pdf. 
---. (2011). WAC: Closing doors or opening doors for second language writers? Across the Disciplines, 8, 4. Retrieved January 8, 2012, from http://wac.colostate.edu/atd/ell/cox.cfm.

Dennett, J. T. (2000). Going beyond the native speaker in technical communication. IEEE Transactions on Professional Communication, 43, 327-330.

Flowerdew, J. (1999). Problems in writing foe scholarly publication in English: The case of Hong Kong. Journal of Second Language Writing, 8, 3, 243-264.

---. (2000). Discourse community, legitimate peripheral participation, and the nonnativeEnglish-speaking scholar. TESOL Quarterly, 34, 1, 127-150.

---. (2001). Attitudes of journal editors to nonnative speaker contributions. TESOL Quarterly, 35, 1, 121-150.

--.. (2008). The non-Anglophone scholar on the periphery of scholarly publication. AILA Review, 20, 14-27.

Giddens, Anthony. (1979). Central problems with social theory: Action, structure and contradiction in social analysis. Berkeley: University of California Press.

Haas, C. and Witte, S. P. (2001). Writing as an embodied practice: The case of engineering students. Journal of Business and Technical Communication, 15, 4. 413-457

Halasz, Judith, Brinckner, Maria, Gambs, Deborah, Geraci, Denise, Queeley, Andrea, \& Solovyova, Sophie. (2006, August 24). Making it your own: Writing fellows reevaluate faculty "resistance". Across the Disciplines, 3. Retrieved January 9, 2012, from http://wac.colostate.edu/atd/articles/halasz2006.cfm

Hall, Jonathan. (2009). WAC/WID in the next America: Redefining professional identity in the age of the multilingual majority. WAC Journal, 20, 33-49. 
Herrington, A. J. (1985). Writing in academic settings: A study of the contexts for writing in two college chemical engineering courses. Research in the Teaching of English, 19, 331-361.

Homer, B. (2001). “Students' Right,” English Only, and Re-Imagining the Politics of Language. College English, 63, 6, 741-758.

Horner, B, and Lu, M-Z. (2007). Resisting monolinguialism in "English": Reading and writing the politics of language. In Ellis, V., Fox, C., and Street, B. V. (Eds.) Rethinking English in Schools: Towards a New and Constructive Stage. Continuum studies in education. (141-57). London: Continuum.

Horner, B. and Lu, M. (2011). Translingual Literacy and Matters of Agency. Conference paper presented at the $22^{\text {nd }}$ Pennsylvania State University Conference on Rhetoric and Composition, July 2011 (reference copy provided by the authors).

Horner, B., NeCamp, S., \& Donahue, C. (2011). Toward a multilingual composition scholarship: From English only to a translingual norm. College Composition and Communication, 63, 2, 269-300.

Horner, B., and Trimbur, J. (2002). English only and U.S. college composition. College Composition and Communication. 53, 4, 594-630.

Hu, J. (2009). Discovering emerging research in a qualitative study of ESL academic writing. Qualitative Report, 14, 4, 629-664.

Institute of International Education (IIE, 2011)). Open Door report 2010-2011. Retrieved January 12, 2011 from http://www.iie.org/en/Who-We-Are/News-andEvents/Press-Center/Press-Releases/2010/2010-11-15-Open-Doors-InternationalStudents-In-The-US. 
Jenkins, S. J., Kaye, M. \& Weiland, P O. (1993). The role of writing in graduate engineering education: A survey of faculty beliefs and practices. English for Specific Purposes, 12, 1, 51-67.

Jordan, J. \& Kedrowicz, A. (2011). Attitudes about graduate L.2 writing in engineering: Possibilities for more integrated Instruction. Across the Disciplines, 8, 4. Retrieved January 8, 2012, from http:/wac.colostate.edu/atd/ell/jordan-kedrowicz.cfm Kranov, Ashley A. (2009). "It's not my job to teach them how to write": Facilitating the disciplinary rhetorical socialization of international ESL graduate assistants in the sciences and engineering. Proceedings of ASEE Annual Conference and Exposition, Conference. Austin, TX.

Krase, Ethan. (2007). "Maybe the communication between us was not enough": Inside a dysfunctional advisor/L2 advisee relationship. Journal of English for Academic Purposes, 6, 1, 55-70.

Lave, Jean; Wenger, Etienne (1991), Situated learning: Legitimate peripheral participation. Cambridge, UK: Cambridge University Press.

Lax, Joanne. (2002). Academic writing for international graduate students. In Frontiers in Education, 2002. FIE 2002. 32nd Annual, 2, F3H-8-F3H-12. Proceedings of Frontiers in Education conference.

Leki, Ilona. (2006). "You cannot ignore": L2 graduate students' response to disciplinebased written feedback. In Feedback in second language writing: Contexts and issues Cambridge, UK: Cambridge University Press. 266-286.

Leung, C., Harris, R., \& Rampton, B. (1997). The idealised native speaker, reified ethnicities, and classroom realities. TESOL Quarterly, 31, 3, 543. 
Leydens, J. A. (2008). Novice and insider perspectives on academic and workplace writing: Toward a continuum of rhetorical awareness. IEEE Transactions on Professional Communication, 51, 3, 242-263.

Lillis, T., \& Curry, M. (2006). Professional academic writing by multilingual scholars. Written Communication, 23, 1, 3-35.

--- (2010). Academic Writing in a global context: The politics and practices of publishing in English. Routledge.

Lu, M.-Z. (1994). Professing multiculturalism: The Politics of style in the contact zone. College Composition and Communication, 45, 4, 442-458.

Mackiewicz, J. (2004). The effects of tutor expertise in engineering writing: A linguistic analysis of writing tutors' comments. IEEE Transactions on Professional Communication, $47,4,316-328$.

MacLure, Maggie. (2007). Clarity bordering on stupidity: Where's the quality in systematic review?. In B. Somekh and T. A. Schwandt. (Eds.). Knowledge production: research work in interesting times. (393-416). London: Routledge.

Morita, N. (2002). Negotiating participation in second language academic communities. TESOL Quarterly. 38, 4, 573-603.

Ochsner, R., \& Fowler, J. (2004). Playing devil's advocate: Evaluating the literature of the WAC/WID movement. Review of Educational Research, 74, 2, 117-140.

Pearson, S. (1983). The challenge of Mai Chung: Teaching technical writing to the foreign-born professional in industry. TESOL Quarterly, 17, 3. 383-99.

Prior, P. (1991). Contextualizing writing and response in a graduate seminar. Written Communication, 8, 267-311. 
Reave, L. (2004). Technical communication instruction in engineering schools: A survey of top-ranked U.S. and Canadian programs. Journal of Business and Technical Communication, 18, 4, 452-490.

Roberts, F., \& Cimasko, T. (2008). Evaluating ESL: Making sense of university professors' responses to second language writing. Journal of Second Language Writing, 17, 3, 125-143.

Rose, M. (1985). The language of exclusion: Writing instruction at the university. College English, 47, 4, 341-59.

Rude, C. (1992). The rhetoric of scientific inquiry. (review) Professional Communication, 35, 2, 88-90.

Russell, D. (1989). Composition for the culture of professionalism: Notes on the history of technical writing instruction. Proceedings of Professional Communication Conference, 39-41.

---. (1995). Activity theory and writing instruction. In Petraglia, Joseph (E.). Reconceiving writing, rethinking writing instruction. (51-78). Mahwah, NJ: Lawrence Erlbaum.

--- (2007). Writing in the academic disciplines: A curricular history. Carbondale, IL: Southern Illinois Univ. Press.

---. 1991. Writing in the Academic Disciplines, 1870-1990: A Curricular History. Carbondale: Southern Illinois University Press.

Santos, T. (1988). Professors' reactions to the academic writing of nonnative-speaking students. TESOL Quarterly, 22, 1, 69-90. 
Soklaridis, S. (2009). The process of conducting qualitative grounded theory research for a doctoral thesis: Experiences and reflections. Qualitative Report, 14, 4, 719-734.

Spack, R. (2004). The acquisition of academic literacy in second language: A longitudinal case study. In Zamel, V and Spack, R. (Eds.). Crossing the Curriculum: Multilingual Learners in College Classrooms. (19-46). New York, NY: Routledge/Taylor \& Francis.

Strauss, A. L., \& Corbin, J. M. (1990). Basics of qualitative research: Grounded theory procedures and techniques. Newbury Park, Calif: Sage Publications.

Thaiss, C. and Zawacki, T. (2002). Questioning alterative discourses: Reports from across the disciplines. In Schroeder, C., Fox, H., and Bizzell, P. (Eds.) AL.T/DIS: Alternative Discourses and the Academy. (80-96). Portsmouth, NH: Boynton/Cook.

Trice, A.G. (2001) Faculty perceptions of graduate international students: The benefits and challenges. Higher Education, 7, 4, 379-403.

Turner, J. (1999) Academic Literacy and the Discourse of Transparency' In Jones, C. Turner, J. \& Street, B. (Eds) Students Writing in the University: Cultural and epistemological issues. (pp. 149-160). London: John Benjamins.

Vickers, C. H. (2007). Second Language socialization through team interaction among electrical and computer engineering students. The Modern Language Journal, 91, 4, 621-640.

Wenger, E. (1998). Communities of practice: Learning, meaning, and identity. Cambridge, U.K: Cambridge University Press.

Wiener, H. S. (1985). Multicultural literacy for faculty: Accommodating non-native speakers of English in content courses. Rhetoric Review, 4, 1, 100-107. 
Winsor, D. A. (1990). Engineering writing/Writing engineering. College Composition and Communication, 41, 1, 58-70.

--- (1996). Writing like an engineer: A rhetorical education. Mahwah, N.J: Lawrence Erlbaum.

--- (2003). Writing power: Communicating in an engineering center. Albany, New York: SUNY.

Wolfe, J. (2005). Gesture and collaborative planning. Written Communication, 22, 3, 298-332.

Wolfe, J., Britt, C., \& Alexander, K. P. (2011). Teaching the IMRaD genre: Sentence combining and pattern practice revisited. Journal of Business and Technical Communication, 25, 2, 119-158.

Xu, J. (2003) Chinese students' adaptation to learning in an American university: A multiple case study. Dissertation Abstracts International, 63, 7-A, 243.

Zamel, V. (1995). Strangers in academia: The experiences of faculty and ESL students across the curriculum. College Composition and Communication, 46, 4, 506-521.

Zhu, W. (2004). Faculty views on the importance of writing, the nature of academic writing, and teaching and responding to writing in the disciplines. Journal of Second Language Writing, 13, 1, 29-48. 


\section{APPENDIX}

\section{Appendix A}

\section{Questions for the first round of interviews (faculty and students)}

1. Just to start the conversation - and this is not a trick question or anything-what would you consider one most important thing, or skill, or feature, or strength that you emphasize or want to see in successful student writing in your discipline?

Opening questions: based on writing sample

2. [pick a sample that has grammatical, syntactic, and relatively local issues] Let us talk about one of these two pieces of writing by your student (or you).

a. What do you find well done in this sample and what is less effective in terms of writing?

b. [point to a specific example style difference]. Is this acceptable to you? Why? What impression does this give you of the writer? What impression do you think other readers in your field will draw of this writer based on this writing?

c. [point to an issue of organizational difference]. Is this common in your field? If not, how important is it that the writer change this? Why? What impression does this difference give you of the writer? What impression will other readers in your field draw of the writer?

d. [point to an issue of grammar difference]. What do you think about features such as this? How important is it to eliminate this kind of difference in this kind of writing? Why? What impression does this give you of the writer? What impression will other readers in your field draw of the writer?

3. [pick the sample that has lexical, organizational, and relatively global issues] How do you think this sample compares with the first one?

e. [point to a difference in word choice]. What do you think about this difference? [Ask interviewee to compare the two samples if appropriate.]

f. Is there anything about the writing style of this paper-how it starts, ends, or is organized, etc. - that is typical about writing in your discipline? [Ask interviewee to compare the two samples if appropriate.]

g. Would you have a different assessment of these language issues differently if this was a different kind of writing? [Ask to compare the two samples.]

h. How would your assessment of this writing change if this was written by a native English speaking student? [Ask interviewee to compare the two samples if appropriate.]

i. What if this was written by an established scholar in the discipline who works outside of the US? [Ask interviewee to compare the two samples if appropriate.] 
Questions related to eradicationist view (if not addressed in responses above)

4. How important is it for your students to write in "proper English" in the courses that you teach? How do you define "proper English?"

a. How much importance do you attach to grammatical and other linguistic features in this type of writing? Which types of differences as we saw in these two samples would you ask the writer to change/eliminate?

b. To what extent do you care about correct and precise use of words in writing like these? Would you care more about those issues in one of these writings than in the other?

c. What impressions do language errors give you of students whose written work you are assessing?

d. More generally, do you think that successful learners and effective writers are, or should be, also able to eliminate language difference - for instance, difference in sentence structure or word choice-in their writing?

Questions related to second language and accommodationist views

5. What kind of role do you think proper academic English play in students' writing in your courses?

a. How much does deviation from standard English bother you when you are reading or assessing your students' writing? [give an example from one of the samples]

b. Do you become more or less lenient about those problems when the student is non-native user of English? Can you point to an example in these writings about which you would be more tolerant? Why would you be more tolerant of "error" in one than in the other?

c. What percentage of credit do you think you generally give to elements of clear and correct language in your students' writing in graduate level courses?

Questions related to multilingual view

6. How do you deal with the writing of a student who does not seem to be using standard academic English but you know that he or she is using a different variety of English, which may be standard academic English in a different part of the world?

a. Do you tell the student to revise the work to make it consistent with the American standard or do you focus on the content instead as long as you understand it? Did you ask the writer of these samples to improve the language? If so, which one and why?

b. Is there an acceptance of language difference among non-native English users in your discipline or your department in this university? For example, how do you think this sample [relatively less polished] would be assessed by faculty members in your discipline?

c. Do you think that native English speaking faculty in your field treat non-native English speaking students' work differently because of their language difference? How do you think non-native English speaking faculty like you would generally assess these texts? 


\section{SECONDARY QUESTIONS: DEMOGRAPHIC/BACKGROUND ISSUES}

[faculty members]

7. How many years have you taught in the US?

a. How has that experience influenced the way you view, integrate, or judge writing in your courses?

b. What is your specialization within your discipline?

c. How does your level of experience, status in the department, or your expertise in the subject affect your confidence with writing in a language that is not your first language?

d. Have you ever felt that the attitude towards you by your students', colleagues, or other people in your field was problematic because you are not a native user of English?

[graduate students]

a. Do you teach in your department? [if the answer is yes] Does teaching involve developing assignments or just grading them for your professors?

b. How much importance do you give to "good writing" when you assess your students' work?

c. Have you ever felt that you were at a disadvantage because you are a non-native user of English - as in writing for publication or integrating writing in your teaching?

d. Have you ever felt that you are an advantage as a user of multiple languages?

[both faculty members and students]

e. Tell me about the how writing was done by university students in the educational system/culture where you studied and/or taught before you came to the US.

f. What was different about how writing was done back home as opposed to how writing is done in your discipline here in the US?

g. What, if anything, is better about academic writing here in US higher education in any way in your opinion?

h. What, if anything, did you like more about writing practices back home instead?

ENDING QUESTIONS: THEORIES OF LINGUISTIC DIFFERENCE

8. Non-native English speaking students from different backgrounds also write differently; in a sense their writing may have an "accent" like their speech. Can you imagine those accents or linguistic differences being as a positive resource?

9. [in a one page handout, present the four types of attitude: eradicationist, second language, accommodationist, multilingual, etc]. What would be your personal reaction to this view of language difference?

10. Generally, in what kinds of situations--for example coursework versus publication or oral versus written work-do you consider language difference acceptable? When is language difference less or not acceptable?

Wrap Up Questions

11. To ask you a little more about the question that we began with — what you care most as a feature of effective or successful writing in your field now that we've discussed writing in your field in more detail, would you mind telling me, or maybe jotting down a few things (say 4 or 5 things) that you consider are most important for students to learn to be able to write effectively in your discipline? 


\section{Appendix B}

Questions for the second/follow up interviews with the students. [using writing samples]

1. Tell me a little about your writing experience when you first came to the US.

2. Let us talk about the two samples here. Why did you choose this sample as an example of writing that you struggled with?

3. Why did you choose this one as a piece of good writing, or writing you are more satisfied with?

4. Do you like to write? What is your typical response when you have an assignment or project that has much writing to do?

5. Give me a few examples of particular sentence, grammar, or other linguistic issues where you tend to make most mistakes? For example, I sometimes make mistakes with articles and I tend to use sentence structures with too many prepositions.

6. Imagine that your department provides you a free and private English language tutor for one month in order to help you brush up on your English language. What would be a few things that you would ask the tutor to help you improve?

7. Imagine that the graduate director or chair of your department asks you and other nonnative English speaking students to give him or her suggestions for helping you all with both language and writing skills. What would be one strategy or program you would suggest?

8. In the process of gaining writing skills, what has been the most useful strategy, situation, or person that facilitated your learning?

9. How does your supervisor/mentor help you with your writing skills? Give me an example of how he or she teaches or facilitates your learning of language and writing skills?

10. Finally, I have found that most engineering students and scholars demand correct, standard English that is clear, simple, and universally understandable which is in one sense a perfectly reasonable and practical demand, because that is a necessary quality for scientific and technical writing. But in reality, you know that engineering scholars in different parts of the world and even those within the US will write differently because their writing is not only consists universal scientific words but also words that differ in usage in different societies and cultures. Please help me explain the puzzle as to why these engineering scholars who speak quite different varieties of English all want to make writing completely universal. Do you demand a universal standard of language in technical writing, and if you do, what is your explanation for that demand? 


\section{CURRICULUM VITAE}

\section{Ghanashyam Sharma}

Website/profile: www.shyamsharma.net

\section{EDUCATION}

Ph.D. in Rhetoric and Composition, University of Louisville, Louisville, Kentucky, 2012

Dissertation: Ideological Tensions, Pedagogical Gaps: Multilingual Engineering Scholars' Response to Language Variations in Academic Writing

Committee: Joanna Wolfe (Director), Bruce Horner, Min-Zhan Lu, Beth Boehm, Tatjana Soldat-Jaffe

M. A. in English (Rhetoric and Composition), University of Louisville, Louisville, Kentucky, August 2008

Thesis: "Epistemological Agency in Literacy Narrative as a Cultural Function"

Committee: Beth Boehm (Director), Carol Mattingly, Tatjana Soldat-Jaffe

M. A. in English (Literature), Tribhuvan University, Kathmandu, Nepal, 2000

Thesis: "The Language of Silence in Harold Pinter's The Homecoming"

Supervisor: Anita Dhungel

B. Ed. in English (ELT), Tribhuvan University. Kathmandu, Nepal, 2004

B. A. in English, Butwal College, Tribhuvan University, Butwal, Nepal, 1997

\section{PUBLICATIONS}

- "The Importance of Professional Development in Graduate Education." Coauthored with Beth A. Boehm. Pedagogy.

- "Global Popular Culture and Literacy Practices of Nepalese Youth Online." Co-authored with Bal K. Sharma. New Media Literacies and Participatory Popular Culture Across Borders. Eds. Bronwyn Williams and Amy Zenger (Routledge)

- "The Third Eye: An Exhibit of Literacy Narratives from Nepal." Stories that Speak to Us. Eds. Cynthia Selfe et al. (forthcoming, Utah State University Digital Press)

- "Criticalizing the pedagogy of English studies." Bodhi: An Interdisciplinary Journal (Kathmandu). 4.1 (2011): 111-35.

- "Rethinking Language and Writing in Composition." JAC. 29 (1\&2): 2009. 251-55. 


\section{ACADEMIC AWARDS, HONORS}

- K. Patricia Cross Future Leaders Award (2012), Association of American Colleges and Universities

- Barbara Plattus Award for Excellence in Graduate Student Teaching (2011), University of Louisville English Department

- Maddox Prize for best research paper (2010), University of Louisville Department of Women and Gender Studies

- University of Louisville Doctoral Fellowship (2008-2012)

- Alice Barns Award for Outstanding Achievement in MA (2008), University of Louisville Graduate School

- Dean's List and Dean's Citation awards for MA in English (2008), University of Louisville

- "Mahendra Bidya Bhusan" (2000, national academic excellence award and gold medal, as first-class-first in MA in English), Narayanhiti Royal Palace, Kathmandu, Nepal

- Central Bank of Nepal scholarship (1995, based on a national essay writing contest), Kathmandu, Nepal

- Diligence scholarships (1995, 1996, 1998, 1999, based on academic merit during BA and MA), Tribhuvan University, Kathmandu, Nepal

\section{TEACHING EXPERIENCE}

ENGLISH COMPOSITION AND LITERATURE

\section{University of Louisville, 2007-2011}

Business Writing (Engl 306), Summer 2008, Summer 2009-II \& III, Spring 2011.

Advanced Composition (Engl 105), Fall 2010.

British Literature (Engl 302), Summer 2010.

Intermediate College Composition (Engl 102), Spring 2008.

Introduction to College Composition (Engl 101), Fall 2007.

ENGLISH LITERATURE, LINGUISTICS, AND LITERARY THEORY

Tribhuvan University (Central Department of English and Campion College), Kathmandu, Nepal, 2000-2006

Survey of British and American Poetry (graduate course), 2001-06.

Linguistics and Stylistics (graduate course), 2000-06.

Literary Criticism and Theory (graduate course), 2002-06.

Critical and Creative Thinking (upper division course), 2002-06.

Business English (Bachelor of Business Administration courses, lower division courses), 2004-06. 
Foundation of English Literature (lower division course, 2002-06).

ENGLISH LANGUAGE TEACHING IN GRADE SCHOOLS

GEMS (high school), Lalitpur, Kathmandu, Nepal, 1998-2000.

New Pinewood School (elementary and middle school), Butwal, Nepal, 1994-97.

\section{CONFERENCE PRESENTATIONS}

- "Beyond the Greco-Roman View of Rhetoric: The Use of Nyaya Sutra Argument in a Writing Classroom." Rhetoric Society of America Conference, Philadelphia, PA, May 24-28, 2012.

- "Does Language Matter? Non-Native English Speaking Scholars' Perceptions of Language Difference in Academic Writing in the Disciplines," (proposal accepted) Conference on College Composition and Communication, St. Louis, Missouri, Apr., 2012.

- "Epistemological Crossroads: Writing Practices of Multilingual Scholars in the Academic Disciplines," The 22nd Pennsylvania State University Conference on Rhetoric and Composition, State College, Pennsylvania, July 11, 2011.

- "Global Popular Culture and Literacy Practices of Nepalese Youth Online," Conference on College Composition and Communication, Atlanta, GA, Apr. 8, 2011.

- "Implications of the Politics of Language involving International Teaching Assistants for Composition Studies," Thomas R. Watson Conference, University of Louisville, Louisville, KY, Oct. 15, 2010.

- "Fear of the Un-American University: Popular Sentiments and Public Debates about Higher Education in Nineteenth Century America." Rhetoric Society of America Conference, Minneapolis, MN, May 30, 2010.

- "Navigating Epistemological Worldviews: Nepalese Graduate Students in Rhetoric and Composition Programs in the US," Conference on College Composition and Communication, Louisville, KY, March 18, 2010.

- "Using Wiki for Enhancing Collaborative Learning in the Writing Classroom," a multimodal poster at "Digital Media and Learning in a Social World" Pre-

Conference Workshop, Conference on College Composition and Communication, Louisville, KY, Mar. 17, 2010.

- "Politics of Technology in Education: The Dangers of Celebration and Resistance." Kentucky Philological Association Conference, Richmond, KY, Mar. 9, 2010.

- "Marilyn Nelson's The Cachoeira Tales as Transcultural 'World' Literature." The Louisville Conference on Literature and Culture since 1900, Louisville, KY, Feb. $19,2010$.

- "At the Table with the Enemy: Engaging the Public with the Rhetoric of Diplomacy," Annual Graduate and Undergraduate Student Conference on 
Literature, Composition and Rhetoric, University of Chatanooga, Chatanooga, TN, Oct. 17, 2009

- "Neither Resistance nor Zeal: A Critical View of Technology in Research Writing." Thomas R. Watson Conference, U of Louisville, Louisville, KY, Oct. 16,2008

- "The Politics of Global English: Pedagogical Response to a Double Bind." Kentucky Philological Association Conference, Louisville, KY, Mar. 9, 2008

- "Perceptions and Perspectives: The Journey of Knowledge in Abhi Subedi's Fire in the Monastery." Conference of the Literary Association of Nepal, Kathmandu, Nepal, Mar. 2, 2005

- “Teaching Speaking: Designing Activities for Large Classes." International Conference of the Nepal English Language Teachers Association (NELTA), Kathmandu, Feb.26, 2001.

- "Teaching Listening: Developing Student-Centered Activities." International Conference of the Nepal English Language Teachers Association (NELTA), Kathmandu, Feb. 24, 2000

\section{ADMINISTRATIVE EXPERIENCE}

Graduate Research Assistant to the Dean of the Graduate School, University of Louisville, 2009-2011.

- Conducted research, helped develop programs, and assisted with the establishment of the PLAN initiative for graduate students' professional development

- Worked with students, faculty, and administrators from across the university, learning how to pool expertise and resources, creating opportunities for professional development of graduate students

- Developed content and assisted with design and maintenance of the PLAN initiative website

- Gathered and documented program data, analyzed and presented results, produced and documented annual project reports and promotional materials

- Developed, organized and led the presentation of three PLAN workshops along with other students from different disciplines

- Assisted the Dean with various other day to day activities for the PLAN initiative

Assistant Director, Composition Program (Consultant for College of Business),

University of Louisville, 2009-10.

- Consulted with student and faculty writers

- Presented writing skill workshops in the classroom upon faculty members' request

- Collaborated with some of the faculty members for integrating and teaching writing skills into their courses 
- Developed and provided resources for student writers on the consultant's website

- Added group consultation at flexible hours by using Skype conferencing and synchronously editable web documents

- Digitized existing resources and documented my service as resource for future assistant directors in this position

Assistant Director, University Writing Center, U of Louisville, Louisville, KY, Aug. 2007- 2008.

- Developed resources for writers and also made them available on the WC website

- Consulted with clients in the Writing Center, with a focus on multilingual writers

- Consulted in and helped further develop the Virtual Writing Center (VWC)

- Gave classroom presentations for students and workshops for faculty and staff

- Created and maintained the Writing Center website

- Set up a mechanism for clients to make their own appointments using TutorTrac

- Wrote administrative manuals for future graduate assistants

- Mentored and participated in the training of new consultants, developed resources for the VWC, and assisted the Director with the promotion of WC services and with other day to day activities

Consultant, University Writing Center, U of Louisville, Louisville, KY, Aug. 2006 Aug. 2007.

- Consulted with WC clients including students, faculty members, and university staff

- Supported the Director by adding and updating resources for writers

- Conducted research on consultation session using peer observation, closed vertical transcription, and theoretical scholarship on significant issues of consultation

- Added and updated useful handouts for writers/clients

Consultant and Translator, Family Health International, Kathmandu, 2005 - 2006.

- Translated documents between English and Nepali

\section{PROFESSIONAL MEMBERSHIP}

College Composition and Communication (NCTE), 2009-

Rhetoric Society of America, 2009-

Nepal English Language Teachers Association, Kathmandu, Nepal, 1998-

Literary Association of Nepal, Kathmandu, Nepal, 2003- 
SERVICE TO THE PROFESSION

EDITORIAL ROLE

Editor, Journal of NELTA (Nepal English Language Teachers' Association), Nepal, 2009, ' $10, ' 11$

ORGANIZATIONAL LEADERSHIP

Leader, Connected Community initiative, Conference on College Composition and Communication, 2010-

Information Chair (executive member), Graduate Student Council, University of Louisville, 2010-11

Executive Member, English Graduate Organization (EGO), University of Louisville, 2007-08, 2008-09

MENTORSHIP AND OTHER SERVICE

Member of Planning Committee, "Celebration of Teaching and Learning" (2012), Delphi Center for Teaching and Learning, University of Louisville, 2011-12

Graduate Student Ambassador, School of Interdisciplinary and Graduate Studies (Graduate School), University of Louisville, 2011-12

Mentor to new graduate students in the English Department, University of Louisville, 2009, 2010, 2011

Member of Search Committee for the Joint Program Manager position for the School of Interdisciplinary and Graduate Studies and Delphi Center for Teaching and Learning, May-August 2011

Student Representative, Strategic Technology Executive Committee (STEC), University of Louisville, 2011 